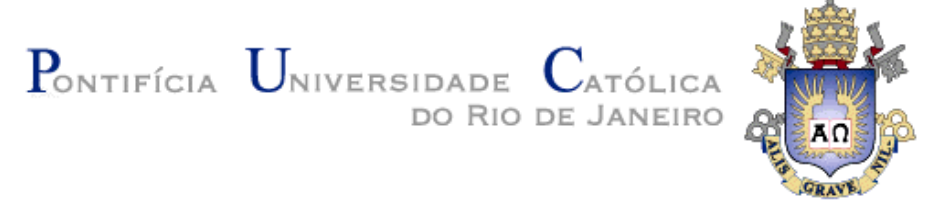

Rodrigo Rangel Ribeiro Bezerra

\title{
Problema de Roteirização de Veículos com Probabilidade de Roubo de Carga: resolução com Simulated Annealing
}

Dissertação de Mestrado

Dissertação apresentada ao Programa de Pós-Graduação em Engenharia de Produção da PUC-Rio como requisito parcial para obtenção do grau de Mestre em Engenharia de Produção.

Orientador: Prof. Hugo Miguel Varela Repolho

Rio de Janeiro

Julho de 2015 


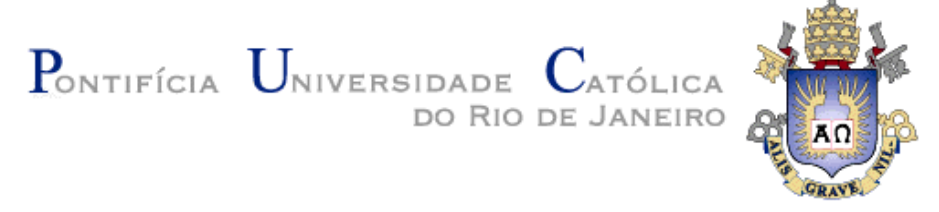

Rodrigo Rangel Ribeiro Bezerra

\title{
Problema de Roteirização de Veículos com Probabilidade de Roubo de Carga: resolução com Simulated Annealing
}

\begin{abstract}
Dissertação apresentada como requisito parcial para obtenção do grau de Mestre pelo Programa de Pós-Graduação em Engenharia de Produção da PUC-Rio. Aprovada pela Comissão Examinadora abaixo assinada.
\end{abstract}

\author{
Prof. Hugo Miguel Varela Repolho \\ Orientador \\ Departamento de Engenharia Industrial - PUC-Rio \\ Prof. José Eugênio Leal \\ Departamento de Engenharia Industrial - PUC-Rio \\ Prof. Silvio Hamacher \\ Departamento de Engenharia Industrial - PUC-Rio
}

Prof. José Eugênio Leal

Coordenador (a) Setorial do Centro Técnico Científico - PUC-Rio 
Todos os direitos reservados. É proibida a reprodução total ou parcial do trabalho sem autorização do autor, do orientador e da universidade.

Rodrigo Rangel Ribeiro Bezerra

Graduou-se em Engenharia de Produção pela Universidade do Estado do Pará - UEPA em 2013.

Ficha Catalográfica

Bezerra, Rodrigo Rangel Ribeiro

Problema de Roteirização de Veículos com Probabilidade de Roubo de Carga: resolução com Simulated Annealing / Rodrigo Rangel Ribeiro Bezerra; orientador: Hugo Miguel Varela Repolho. Rio de Janeiro: PUC, Departamento de Engenharia Industrial - 2015.

$$
101 \mathrm{f} \text { : : il. (color.) ; } 30 \mathrm{~cm}
$$

Dissertação (mestrado) - Pontifícia Universidade Católica do Rio de Janeiro, Departamento de Engenharia Industrial, 2015.

Inclui bibliografia

1. Engenharia Industrial - Teses. 2. Logística. 3. Roteirização de Veículos. 4. Roubo de Carga. 5. Programação Linear Inteira Mista. 5. Simulated Annealing. I. Repolho, Hugo Miguel Varela. II. Pontifícia Universidade Católica do Rio de Janeiro. Departamento de Engenharia Industrial. III. Título. 


\section{Agradecimentos}

Agradeço aos meus pais que com muita dedicação puderam me fornecer uma boa educação, sempre me estimulando a traçar uma Meta.

Agradeço aos meus professores que participaram da minha formação do conhecimento, que estavam sempre dispostos a ajudar. Em especial ao professor Hugo Repolho pela contribuição, sabedoria e paciência no desenvolvimento desta Dissertação.

Agradeço aos amigos estiveram presente nessa etapa da minha vida e que contribuíram para o meu desenvolvimento como pessoa e também profissional. Agradeço a Janaina Marchesi pela ajuda nos trabalhos desenvolvidos.

Ao CNPq, à PUC-Rio, pelos auxílios concedidos, sem os quais o desenvolvimento desse trabalho não seria possível. 


\section{Resumo}

Bezerra, Rodrigo Rangel Ribeiro; Repolho, Hugo Miguel Varela (Orientador). Problema de Roteirização de Veículos com Probabilidade de Roubo de Carga: resolução com Simulated Annealing. Rio de Janeiro, 2015. 101p. Dissertação de Mestrado - Departamento de Engenharia Industrial, Pontifícia Universidade Católica do Rio de Janeiro.

O Problema de Roteirização de Veículos (Vehicle Routing Problem - VRP) é um problema clássico combinatório bem conhecido. Este trabalho apresenta um novo fator no modelo de otimização matemática de otimização do VRP, considerando restrições que abordam a probabilidade de roubo de cargas nas regiões visitadas, além das restrições tradicionais, tais como o número de veículos, janelas de tempo, a capacidade do veículo e tempo de ciclo dos veículos. O modelo desenvolvido é testado em um estudo de caso real, considerando uma empresa de distribuição de produtos farmacêuticos do Rio de Janeiro. As soluções de rota com e sem risco de roubo de carga são comparadas. O modelo é resolvido usando o software AIMMS, para análises com instância pequenas, e resolvidas executando a Metaheurística Simulated Annealing, para o estudo de caso, onde se utiliza de duas instâncias.

\section{Palavras-chave}

Logística; Roteirização de Veículos; Roubo de Carga; Programação Linear Inteira Mista; Simulated Annealing. 


\section{Abstract}

Bezerra, Rodrigo Rangel Ribeiro; Repolho, Hugo Miguel Varela (Advisor). Vehicle Routing Problem with Cargo Theft Probability: Resolution with Simulated Annealing. Rio de Janeiro, 2015. 101p. MSc. Dissertation Departamento de Engenharia Industrial, Pontifícia Universidade Católica do Rio de Janeiro.

The Vehicle Routing Problem (VRP) is a classic well-known combinatorial problem. This paper introduces a new factor in the VRP mathematical optimization model, considering restrictions that address the probability of cargo theft in the regions visited, beyond the traditional constraints such as the number of vehicles, time windows, the capacity of the vehicle and the vehicle's cycle time. The paper proposes a mixed integer linear model that minimizes total transportation costs and cargo theft costs. The model is tested in a real-life case study, a company that distributes pharmaceutical products in Rio de Janeiro. The route solutions with and without cargo theft risk are compared. The model is solved using AIMMS software for analysis with small instance, and resolved by running the Simulated Annealing Metaheuristic, for the case study, which uses two instances.

\section{Keywords}

Logistics; Vehicle Routing; Cargo Theft; Linear Mixed Integer Programming; Simulated Annealing. 


\section{Sumário}

1 Introdução 12

1.1 Considerações Iniciais 12

1.2 Justificativa 14

$\begin{array}{lll}1.3 & \text { Objetivos } & 15\end{array}$

$\begin{array}{lll}\text { 1.3.1 Objetivo geral } & 15\end{array}$

$\begin{array}{ll}\text { 1.3.2 Objetivos específicos } & 15\end{array}$

$\begin{array}{ll}1.4 \text { Hipótese } & 16\end{array}$

$\begin{array}{ll}1.5 \text { Metodologia da Pesquisa } & 16\end{array}$

$\begin{array}{ll}\text { 1.5.1 Caracterização e delineamento da pesquisa } & 16\end{array}$

$\begin{array}{ll}\text { 1.5.2 Etapas de concepção do estudo } & 16\end{array}$

$\begin{array}{ll}1.6 & \text { Organização do Trabalho } \\ \end{array}$

2 Referencial Teórico $r$

$\begin{array}{ll}2.1 & \text { Logística Empresarial } \\ & 18\end{array}$

$\begin{array}{ll}2.2 \text { Distribuição Física } & 19\end{array}$

2.3 Gerenciamento de Riscos 20

2.4 Roubo de Cargas $\quad 21$

2.4.1 Roubo de cargas no modal rodoviário brasileiro 22

2.4.2 Roubo de cargas no modal rodoviário no Rio de Janeiro 23

2.5 O Probema de Roteirização de Veículos 25

2.5.1 Problemas Clássicos de Roteirização de Veículos 27

2.6 Formulação do Problema de Roteirização de Veículos, VRP 35

2.7 Formulação do Problema de Roteirização de Veículos com

Janelas de Tempo, VRPTW 38

2.8 Formulação do Problema de Roteirização de Veículos com

Frota Heterogênea Fixa e Restrições de Janelas de Tempo, HFVRPTW 41

2.9 Complexidade Computacional dos Problemas de Roteirização de Veículos 43

3 Modelo de Roteirização de Veículos com Probabilidade de Roubo de Carga, VRPCTP

3.1 Caracterização do Problema 45

3.2 Formulação do Problema 45

$\begin{array}{ll}3.3 \text { Validação do Modelo } & 50\end{array}$

3.4 Análise do Modelo 57

3.5 Estratégia de Solução 59 
3.5.1 Simulated Annealing 60

3.5.1.1 Geração de solução inicial $\quad 61$

3.5.1.2 Estrutura de vizinhança 62

4 Estudo de Caso 66

4.1 Apresentação da Empresa 66

4.2 Coleta e Tratamento dos Dados 67

4.3 Apresentação e Análise dos Resultados Obtidos 72

4.3.1 Instância de 151 nós 73

4.3.2 Instância de 465 nós 81

5 Considerações Finais $\quad 91$

5.1 Considerações Sobre os Resultados Alcançados 91

5.2 Proposta de Estudos Futuros 92

6 Referências $\quad 94$ 


\section{Lista de Figuras}

Figura 1 Evolução do roubo de cargas no Brasil em milhões de reais 22

Figura 2 Proporção de roubo de cargas por região 23

Figura 3 Risco Global de Roubo de Carga: Avaliação da Ameaça 23

Figura 4 Brasil - Mapa de risco $\quad 24$

Figura 5 Grafo do Problema Hamiltoniano $\quad 29$

Figura 6 Estratégias para solução do VRP 36

Figura 7 (a) Roteiro Teste 5 e (b) com mudança do dado de probabilidade $\quad 57$

Figura 8 Quantidade de veículos por valor de carga 59

Figura 9 Heurística de distribuição 62

Figura 10 Movimento Reordenar rota 63

Figura 11 Movimento Realocar ponto $\quad 64$

Figura 12 Movimento Trocar ponto $\quad 64$

Figura 13 Pseudocódigo do Simulated Annealing implementado 65

Figura 14 Localização das farmácias - 151 nós 75

Figura 15 Rotas 41 e $37-465$ nós 84

Figura 16 Localização das farmácias - 465 nós 84 


\section{Lista de Tabelas}

Tabela 1 Características dos problemas de roteirização 26

Tabela 2 Classificação dos principais problemas de roteirização de veículos 34

Tabela 3 Conjuntos e Índices $\quad 47$

Tabela 4 Parâmetros $\quad 47$

$\begin{array}{ll}\text { Tabela } 5 \text { Variáveis } & 48\end{array}$

$\begin{array}{ll}\text { Tabela } 6 \text { Demanda por cliente } & 50\end{array}$

Tabela 7 Matriz O/D assimétrica utilizada para testes 51

Tabela 8 Resultado - Teste 1

Tabela 9 Probabilidade de roubo de carga - Teste $2 \quad 53$

Tabela 10 Resultado - Teste 2

Tabela 11 Resultado - Teste $3 \quad 55$

Tabela 12 Resultado - Teste $4 \quad 56$

Tabela 13 Comparação com probabilidade de 25\% no cliente 4

Tabela 14 Comparação com probabilidade de $20 \%$ no cliente $4 \quad 58$

$\begin{array}{ll}\text { Tabela } 15 \text { Caracterização dos veículos } & 67\end{array}$

Tabela 16 Demanda 464 famácias - Problema Real 68

$\begin{array}{ll}\text { Tabela } 17 \text { Probabilidade de roubo de carga } & 70\end{array}$

Tabela 18 Resumo da solução obtida pelo Simulated Annealing -

$\alpha=3 \%-151$ nós 73

Tabela 19 Melhor solução obtida pelo Simulated Annealing -

$\alpha=3 \%-151$ nós

Tabela 20 Resumo da solução obtida pelo Simulated Annealing -

$\alpha=0 \%-151$ nós

Tabela 21 Melhor solução obtida pelo Simulated Annealing -

$\alpha=0 \%-151$ nós

Tabela 22 Resumo da solução obtida pelo Simulated Annealing $\alpha=3 \%$ e restrição (4.1) - 151 nós

Tabela 23 Melhor solução obtida pelo Simulated Annealing $\alpha=3 \%$ e restrição (4.1) - 151 nós

Tabela 24 Resumo da solução obtida pelo Simulated Annealing -

$\alpha=100 \%-151$ nós

Tabela 25 Melhor solução obtida pelo Simulated Annealing $\alpha=100 \%-151$ nós

Tabela 26 Resumo da solução obtida pelo Simulated Annealing - 
$\alpha=3 \%-465$ nós

Tabela 27 Melhor solução obtida pelo Simulated Annealing -

$\alpha=3 \%-465$ nós

Tabela 28 Resumo da solução obtida pelo Simulated Annealing -

$\alpha=0 \%-465$ nós

Tabela 29 Melhor solução obtida pelo Simulated Annealing -

$\alpha=0 \%-465$ nós

85

Tabela 30 Resumo da solução obtida pelo Simulated Annealing $\alpha=100 \%-465$ nós

Tabela 31 Melhor solução obtida pelo Simulated Annealing -

$\alpha=100 \%-465$ nós 


\section{1 \\ Introdução}

Esta dissertação apresenta uma nova variante do Problema de Roteirização de Veículos (Vehicle Routing Problem - VRP) com Frota Heterogênea e restrições de Janela de Tempo, que rastreia a quantidade de carga que sai de cada nó e leva em consideração o impacto da Probabilidade de Roubo de Carga na mudança do roteiro. O problema é uma combinação do Problema de Roteirização de Veículos com Frota Heterogênea (Heterogeneous Fleet Vehicle Routing Problem - HFVRP), e com o Problema de Roteirização de Veículos com Janelas de Tempo (Vehicle Routing Problem with Time Windows VRPTW), ao qual se junta o problema da probabilidade de roubo de carga. $O$ autor desta dissertação desconhece a existência de qualquer abordagem do mesmo gênero na literatura. O problema foi designado como Problema de Roteirização de Veículos com Probabilidade de Roubo de Carga no Nó (Vehicle Routing Problem with Cargo Theft Probability - VRPCTP).

O primeiro capítulo expõe algumas considerações iniciais sobre o problema de roteirização de veículos. Nos tópicos seguintes, é externado à justificativa, seguido pelos objetivos da pesquisa, hipótese, metodologia utilizada e a organização do trabalho.

\section{1}

\section{Considerações Iniciais}

Nos últimos anos, fatores como ampliação da linha de produtos, mudança na filosofia de estoque, aumento no custo de transporte, entre outros, tem alterado a abordagem na gestão de atividades logísticas sob a perspectiva do Supply Chain Management (SCM) (Bowersox \& Closs, 2001). Assim, ao utilizar como referência os modernos conceitos do SCM, verifica-se que as atividades logísticas conquistaram uma visão estratégica diferenciada, auxiliando significativamente para obtenção de novos mercados, para o aumento da competitividade além do aumento do market share das empresas inseridas na cadeia de suprimentos (Novaes, 2007). Até então, as organizações vinham concentrando esforços em tomar decisões efetivas apenas na logística interna. 
No novo contexto, as empresas devem integrar e gerir de maneira eficiente e eficaz a logística inbound, interna e outbound de forma a otimizar globalmente o sistema por meio da minimização de custos e maximização do nível de serviço. Relativamente na logística outbound o desempenho da Distribuição Física dos Produtos é de extrema importância, dado que, entre outros fatores, a redução dos custos de transporte, bem como a eficiência na prestação do serviço, assegura uma melhor competitividade. Segundo Lambert et al. (1998), o transporte é um dos ramos mais importantes no gerenciamento da logística, em virtude do seu impacto na estrutura de custos da empresa e nos níveis de serviço ao cliente.

De acordo com uma pesquisa realizada pelo Instituto de Logística e Supply Chain - ILOS (ILOS apud Durão, 2013), os custos logísticos representaram $11,5 \%$ do Produto Interno Bruto (PIB) Brasileiro em 2012, R $\$ 507$ bilhões, sendo o transporte responsável pelo maior aumento, alcançando $7,1 \%$ do PIB (R $\$$ 312,4 bilhões). Segundo a mesma fonte, o frete rodoviário alcançou o valor de $\mathrm{R} \$ 259$ por mil toneladas quilômetros útil (TKU), mas apesar do alto custo desse modal comparado a outros mais competitivos (ferroviário - $R \$ 43$ por mil TKU, dutoviário - $R \$ 49$ por mil TKU e hidroviário - $R \$ 59$ por mil TKU), a fatia de cargas transportadas por rodovias aumentou cerca de 1,8\% de $2010(65,6 \%)$ à $2012(67,4 \%)$. Dado o peso dos transportes nos custos logísticos totais (entre um e dois terços segundo Ballou, 2001) é de extrema importância definir estratégias de distribuição que reduzam ao máximo os custos logísticos garantindo os níveis de serviço.

No contexto da América Latina existe um fator adicional de importância crescente a se ter em conta na definição das estratégias de distribuição, o problema de roubo de carga. A atualidade do problema é visível desde logo pelo crescente número de empresas de distribuição que recorrem a escoltas armadas para assegurar a segurança da mercadoria. Esta constatação revela a existência de um novo tópico de estudo ligado aos problemas de transportes, i.e., o problema de roubo de carga.

As ações violentas de roubo de carga causam muito prejuízo ao Brasil. De acordo com a Associação Nacional dos Transportadores de Carga \& Logística NTC \& Logística (2014), estima-se que o valor de roubos de carga chegou a $R \$$ 1 bilhão em 2013 em todo o país. O Instituto de Segurança Pública - ISP (2014) mostra que houve um crescimento de mais de 84,4\% em outubro de 2014 em relação ao mesmo período do ano anterior. Ao relacionar o local de ocorrência percebe-se que $70 \%$ dos roubos de acontecem em áreas urbanas e a maior 
parte destes são realizadas no período da manhã (70\%), e os outros $30 \%$ são realizados em rodovias onde as incidências são maiores no turno da noite (60\%) (Associação Brasileira de Transporte de Carga - ABTC, 2010). De acordo com a Polícia Federal (PF), a região sudeste do Brasil concentra a maior parte das ocorrências porque tem uma intensa produção industrial e grande malha viária, além de uma grande quantidade de comércio de varejistas que adquirem as mercadorias, sendo que o Rio de Janeiro concentra $20 \%$ dos casos de roubos de carga do país (PF apud ABTC, 2010). Os reflexos desses roubos de carga na cadeia logística vão além das perdas relativas às cargas, pois causam transtornos como a não entrega da mercadoria no local e na data prevista, afetando os custos e o nível de serviço oferecido ao cliente.

A partir da visão geral mostrada acima se pode realizar a seguinte pergunta:

Quais os impactos causados nos roteiros gerados nos Problemas de Roteirização de Veículos quando são considerados as probabilidades de roubo de carga em cada região onde se localizam os clientes a serem atendidos?

\section{2 Justificativa}

Os modelos de roteirização de veículos são uma importante área de pesquisa em logística à qual se dedica uma comunidade científica numerosa. A inovação nesta área de pesquisa advém da proposição de métodos de resolução mais rápidos e eficientes ou da formulação de novas variações para o problema de roteirização de veículos, VRP, clássico. Alguns exemplos de métodos de resolução são: algoritmo de colônia de formigas (Balseiro et al., 2011), algoritmo memético (Cattaruza, 2014), algoritmo híbrido (Subramanian et al., 2013) e redes neurais (Torki et al., 1997). Alguns exemplos de variações do VRP são: VRP com janela de tempo (Yu et al., 2011), VRP com janela de tempo flexível (Tas et al., 2014), VRP com frota heterogênea (Choi \& Tcha, 2007) e VRP com frota heterogênea e janela de tempo (Jiang et al., 2014). Apesar da extensa literatura no tema é do desconhecimento do autor a existência de qualquer modelo de VRP que inclua o problema do roubo de carga.

O roubo de carga é uma realidade com peso expressivo na operação diária das empresas distribuidoras de carga Brasileiras. Identificada esta lacuna na literatura, é do interesse do autor desenvolver um modelo de roteirização 
adequado à realidade Brasileira que inclua o problema do roubo de carga na definição das rotas de entregas de produtos.

A motivação para a realização deste trabalho prende-se desta forma com a possibilidade de contribuir para acrescentar à literatura uma nova abordagem ao problema de VRP e ao mesmo tempo contribuir para a resolução de um problema que tanto prejuízo inflige às empresas de transportes que operam no Brasil.

\section{3}

\section{Objetivos}

Os objetivos desta dissertação de mestrado estão divididos em dois níveis. O primeiro deles contém o objetivo geral. No segundo nível são apontados os objetivos específicos.

\subsection{1 \\ Objetivo geral}

O presente trabalho tem como objetivo principal a proposição de um modelo matemático para a roteirização de veículos na distribuição física de mercadorias por uma frota de veículos a partir de um centro de distribuição, considerando a minimização de custos de transporte e o possível custo de perda de carga por roubo, desempenhando uma relação de trade-off entre a distância percorrida e a probabilidade de roubo de carga.

\subsection{2}

Objetivos específicos

Para o alcance desse objetivo principal, os seguintes objetivos específicos serão considerados no desenvolvimento desse trabalho:

- Adaptar a Metaheurística Simulated Annealing para o modelo proposto.

- Resolver o modelo proposto em um caso real de uma empresa que distribui produtos farmacêuticos no estado do Rio de Janeiro, tendo como estratégia de solução a execução da Metaheurística Simulated Annealing. 


\section{4 \\ Hipótese}

A proposição do modelo para a resolução do Problema de Roteirização de Veículos considerando a Probabilidade de Roubo de Carga baseia-se na seguinte hipótese:

A alteração da ordem e número de clientes incluídos na rota de cada veículo seguindo um modelo de roteirização que tenha em conta as perdas potenciais decorrentes de roubo de carga permite reduzir significativamente os custos estimados da empresa.

\section{5 Metodologia da Pesquisa}

A estruturação da metodologia realizada nesta dissertação de mestrado se fundamenta nos conceitos apresentados em Silva Menezes (2001), dividindo nos seguintes tópicos para melhor esclarecimento: Caracterização e Delineamento da Pesquisa e Etapas de Concepção do Estudo.

\subsection{1}

\section{Caracterização e delineamento da pesquisa}

A natureza da pesquisa que será realizada se enquadra no tipo de pesquisa Aplicada, por ter como objetivo aplicar praticamente o conhecimento existente visando utilidade social e econômica dirigida à solução de problemas. A forma de abordagem do problema é Quantitativa, pois considera que tudo pode ser quantificado. Nesta dissertação, a probabilidade de roubo de carga vista pela empresa do estudo de caso como um parâmetro qualitativo, será quantificada de maneira a incluir no modelo matemático. Do ponto de vista dos objetivos, o trabalho se classifica como uma pesquisa de caráter Exploratório, devido assumir a forma de pesquisa bibliográfica e estudo de caso. Com relação aos procedimentos técnicos é classificada como Bibliográfica, Experimental, Estudo de caso e Participante.

\section{5 .2}

\section{Etapas de concepção do estudo}

Para o desenvolvimento desta dissertação de mestrado foi adotado um método de estudo composto das seguintes etapas: 
- Definição, elaboração e apresentação do projeto de dissertação;

- Revisão da literatura compreendendo os modelos matemáticos de resolução de Problemas de Roteirização de Veículos e suas variações;

- Desenvolvimento do modelo matemático de Problema de Roteirização de Veículos considerando a Probabilidade de Roubo de Carga;

- Implementação e resolução do modelo em pequena escala, para análise e validação;

- Adaptação da Metaheurística Simulated Annealing ao modelo proposto.

- Aplicação do modelo proposto através da realização de um estudo de caso com recurso à Metaheurística Simulated Annealing, seguido de uma análise dos resultados obtidos;

- Por último, elaboração das conclusões e da proposta para trabalhos futuros.

\section{6}

\section{Organização do Trabalho}

Além do presente capítulo, de caráter introdutório, esta dissertação é composta por mais 4 capítulos.

O capítulo 2 aborda o desenvolvimento do trabalho, com o referencial teórico sobre os temas considerados importantes que auxiliam à sua composição: uma visão sobre Logística Empresarial, a questão do Roubo de Carga na distribuição física de produtos, o Problema de Roteirização de Veículos e suas variações e mostrando a complexidade computacional desses problemas.

O capítulo 3 apresenta o modelo proposto, sendo realizada a validação e análise do modelo. Neste mesmo capítulo é apresentada a estratégia de solução a ser utilizada.

O capítulo 4 trata da aplicação do modelo proposto em um estudo de caso, e a seguir, uma análise dos resultados obtidos.

Por último no capítulo 5 são apresentadas as considerações finais e as propostas de trabalhos futuros. 


\section{2 \\ Referencial Teórico}

Neste capítulo, serão abordados os principais conceitos que fundamentam ou se relacionam ao tema da presente dissertação. Os assuntos estudados auxiliam na compreensão do problema e no conhecimento da complexidade de resolução para o problema de roteirização de veículos abordado neste trabalho.

\section{1}

\section{Logística Empresarial}

A logística é considerada um fator chave na estratégia competitiva das empresas. Inicialmente era apenas relacionada a transporte e a armazenagem de produtos, mas com a evolução viu-se a necessidade de uma integração na cadeia produtiva, buscando atuar de acordo com o conceito de Supply Chain Management (SCM). Apesar desta evolução conceitual, a logística pode ser definida segundo o Council of Logistics Management - CLM (Ballou, 2006, p. 27) como:

Logística é o processo de planejamento, implementação e controle de fluxo eficiente e eficaz de mercadorias, e das informações relativas desde o ponto de origem até o ponto de consumo, com o propósito de atender às exigências dos clientes.

Para Bowersox et al. (2007), a logística é um subconjunto mais estruturado e amplo da Supply Chain e a gestão desta cadeia de suprimentos pode ser entendida como o gerenciamento integrado de processos de negócios, por meio de um enfoque sistêmico de maneira que o cliente final perceba a criação de valor ao longo da cadeia produtiva.

Conforme Novaes (2004), a logística busca definir prazos e cumpri-los integralmente ao longo de toda a cadeia de suprimento. Além de integrar de maneira efetiva e sistêmica os setores da empresa, as parcerias com fornecedores e clientes. Desta maneira tende a otimizar globalmente os processos visando a redução dos custos na cadeia de suprimentos e no final conseguindo a satisfação do cliente pelo serviço adequado realizado.

A logística empresarial constitui a integração da distribuição física com a administração dos materiais. O primeiro diz respeito ao canal de distribuição, 
enquanto o segundo está ligado ao gerenciamento de materiais nos armazéns (Ballou, 2006).

A principal meta das empresas é desenvolver uma Supply Chain eficaz e eficiente, onde atrasos, bem como a entrega antes do programado, podem se combinar e aumentar ou mesmo reduzir o tempo necessário para completar um ciclo de atividades. Assim tanto a antecipação quanto o atraso são indesejáveis e inaceitáveis do ponto de vista operacional (Bowersox et al., 2007).

O tema central desta dissertação tem correlação com o processo de distribuição física, desta maneira no tópico a seguir é dado ênfase a este conceito.

\section{2 \\ Distribuição Física}

A distribuição física de produtos, ou apenas distribuição física, tem a competência de levar os produtos acabados ou semiacabados do local produzido ou centro de distribuição até o ponto de venda ou consumo. Martins \& Laugeni (1999), conceituam as funções da distribuição física de produtos a contratação de fretes, a seleção do modal de transporte e rotas, assim como os serviços ofertados e sua qualidade.

O objetivo principal da distribuição física é levar os produtos certos, ao lugar correto, no momento exato e com o nível de serviço desejado pelo consumidor, com o mínimo de custo possível. Para alcançar estes objetivos estão presentes no sistema de distribuição: instalações físicas (centros de distribuição, armazéns), estoque de produtos, veículos, informações diversas, hardware e software diversos, custos e pessoal (Novaes, 2004).

Bowersox \& Closs (2001) afirmam que a distribuição física é a que efetua o vínculo entre a empresa e seus clientes. Neste contexto, Ballou (2006) ressalta que as principais tarefas logísticas ligadas à distribuição física estão relacionadas à manutenção de estoque, processamento de pedidos, programação de produtos, embalagem, armazenamento, controle de materiais, manutenção de informações e transporte.

A atividade de transporte confunde-se com distribuição física, sendo a atividade mais onerosa dentro da distribuição. Esta dissertação foca um problema específico da atividade de transporte, o problema de roteirização de veículos sujeitos a probabilidade de roubo de carga. A seguir o problema de roubo de carga é conceituado e contextualizado na realidade Brasileira. 


\section{3}

\section{Gerenciamento de Riscos}

O gerenciamento de riscos envolve a identificação dos riscos a que a distribuição está exposta, os valores e a frequência dos roubos e atuar preventivamente a fim de minimizar os danos gerados.

Rosa (2007) afirma que para a minimização dos danos, é importante que a empresa utilize medidas visando assegurar a reparação financeira dos danos, caso esse venha a ocorrer. Tais medidas compreendem:

- Retenção de perdas, i.e., resuprir mercadoria roubada, utilizando os próprios recursos.

- Transferência de perdas, i.e, utilização de seguros para a cobertura do roubo.

- Prevenção de riscos, i.e, utilizando medidas de gerenciamento, como, rastreamento e escolta armada.

- Redução de riscos, i.e, adotar equipamentos que aumentem a segurança na distribuição.

Segundo Rosa (2007, apud CNT, 2004), o índice de roubos só não é maior em virtude do alto grau de investimento realizado pelas empresas em gerenciamento, inclusive com monitores via satélite. Após o investimento em tecnologia os índices de roubos reduzem aproximadamente $99 \%$, mas os custos se elevam consideravelmente.

Devido a grande necessidade do gerenciamento de riscos, há a necessidade de ter um único setor que gerencie as frotas, sendo responsáveis por mobilizar pessoal de segurança e recursos tecnológicos avançados, como o rastreamento de veículos por satélites e escolta armada (Rosa, 2007).

Os custos relacionados se dividem em dois:

- Custos de gestão de riscos de acidentes e avarias (Frete-Valor)

- Custos de gerenciamento de riscos de roubos (GRIS)

O Frete-Valor não se limita aos custos relacionados ao seguro. Têm-se os seguintes itens: prêmios, administração de seguros, indenização por extravios, perdas, danos e riscos não cobertos pelo seguro, segurança interna, seguros de instalações e outros seguros. 
O GRIS ou Custos de Gerenciamento de Riscos podem ser classificados como: seguros facultativos de desvios de cargas, salários, monitores de equipamentos de rastreamento, segurança e monitoramento, reposição de equipamentos, custos operacionais de gerenciamento de riscos, taxas de blindagem e etc.

\section{4}

\section{Roubo de Cargas}

No Brasil, onde a fragilidade dos modais de transporte tem sido responsável pelos elevados custos logísticos, o modal rodoviário é o mais utilizado na distribuição de mercadorias, servindo todo o país, embora apresente sérios problemas estruturais (Bordin, 2008). Entre eles destacam-se os problemas de insegurança nas vias brasileiras, sendo marcadas por assaltos às transportadoras de cargas.

Segundo Bezerra (2006), a insegurança que assola as empresas em todo o território nacional obteve maior atenção a partir da década de 1980, em virtude do notável número de registros de roubos de cargas, provocando um aumento evidente nos custos logísticos.

Para Caixeta Filho \& Gameiro (2002), mercadorias com elevado valor agregado, de fácil venda e com difícil rastreamento, são as mais visadas por criminosos. Nesta categoria se encontram os produtos alimentícios, têxteis, eletroeletrônicos, calçados, itens de higiene e limpeza, cosméticos, bebidas, plásticos, borrachas, combustíveis, além de pneus e autopeças. Nesta listagem existem dois artigos que merecem destaque, os medicamentos e os cigarros, pois sempre esteveram no topo da lista das mercadorias mais roubadas. Tal realidade levou algumas seguradoras a se recusarem a cobrir essas cargas.

Os produtos roubados destinam-se ao mercado informal, ou até mesmo ao mercado formal, sendo neste caso necessária a falsificação de documentos. Os empresários tentam se organizar de maneira a tomar ações preventivas de modo a ficarem menos vulneráveis e reduzir esses prejuízos, e para isso realizam mapeamento de pontos onde há ocorrência de roubos, monitoramento das rotas dos veículos e das entregas, da utilização de escoltas e de mecanismos de bloqueio automático, além da contratação de seguros para suas cargas (ABTC, 2010). 


\subsection{1}

\section{Roubo de cargas no modal rodoviário brasileiro}

De acordo com Associação Nacional dos Transportadores de Carga \& Logística - NTC \& Logística (2014), o número de ocorrências de roubo de cargas em 2013 aumentou 5,5\% em relação ao ano anterior, registrando 15,2 mil casos e um prejuízo de $\mathrm{R} \$ 1$ bilhão para o setor. Sendo o maior número já registrado nos últimos dezesseis anos.

A Figura 1 informa a evolução do roubo de cargas no Brasil, onde em 2007 houve um prejuízo de 735 milhões de reais e em 2013 houve prejuízo de 1 bilhão de reais.

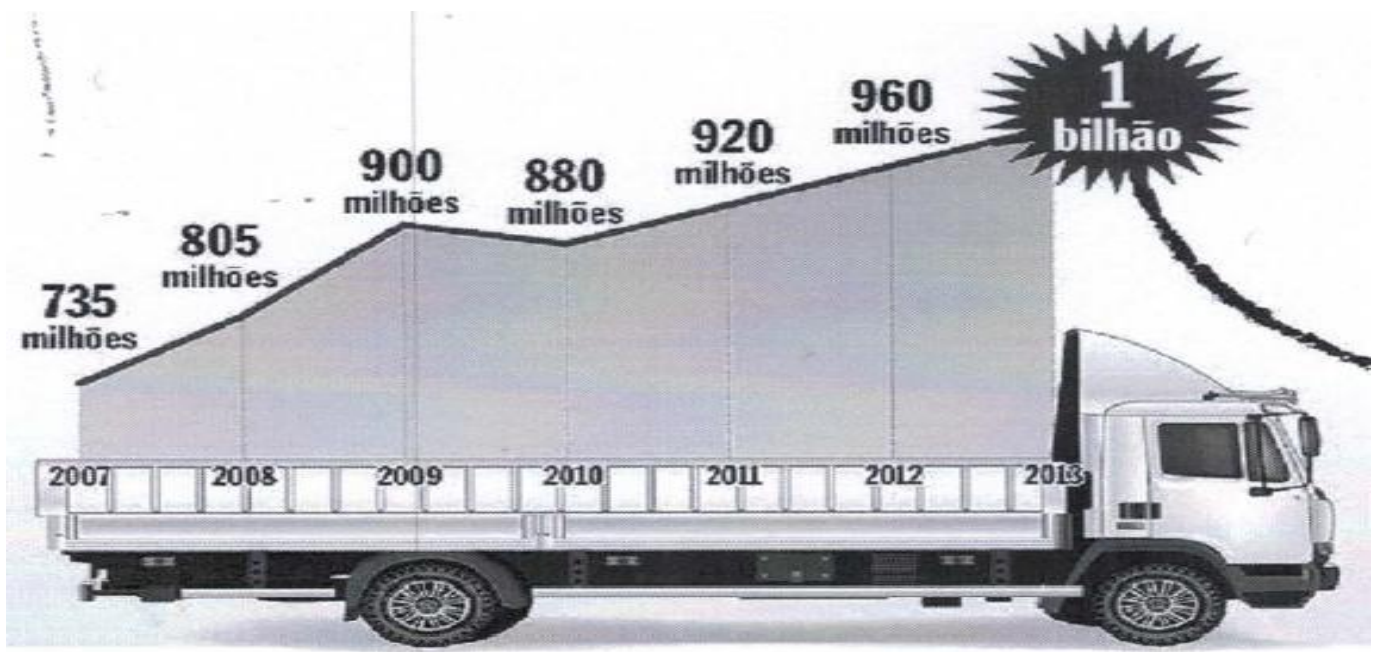

Figura 1: Evolução do roubo de cargas no Brasil em milhões de reais. Fonte: Leitão, 2014.

Segundo a NTC \& Logística (2013), a maioria das cargas tem como origem ou destino o Sudeste do país, por isso a região concentra $83,64 \%$ das ocorrências. De acordo com os dados da maior consultoria especializada nesse tipo de crime (roubo de carga), FreightWatch International - FI (2013), a média dos roubos totais de carga faz com que São Paulo e Rio de Janeiro sejam os mais favoráveis para a prática deste crime no país, com um combinado de $84 \%$.

Segundo NTC \& Logística (2012, apud FI, 2013) os alvos preferenciais são produtos alimentício / bebidas, cigarros, eletroeletrônicos e remédios devido a sua facilidade de venda, e em última análise tem como destino o mercado ilícito ou mercado negro. Pode-se verificar na Figura 2 a porcentagem por região. 


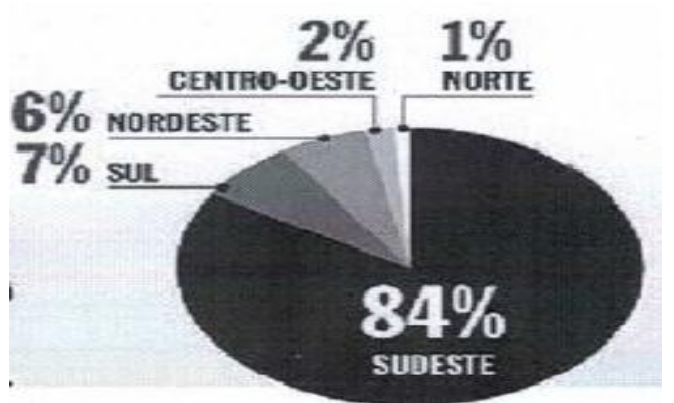

Figura 2: Proporção de roubo de cargas por região.

Fonte: Leitão, 2014.

Segundo a FI (2013), Brasil em 2012 manteve a sua posição como um dos países mais violentos do mundo no que diz respeito ao crime de carga, seguido, de longe, por México, África do Sul, assinalando esses três países com a cor preta, designado com altíssimo risco. Ver Figura 3.

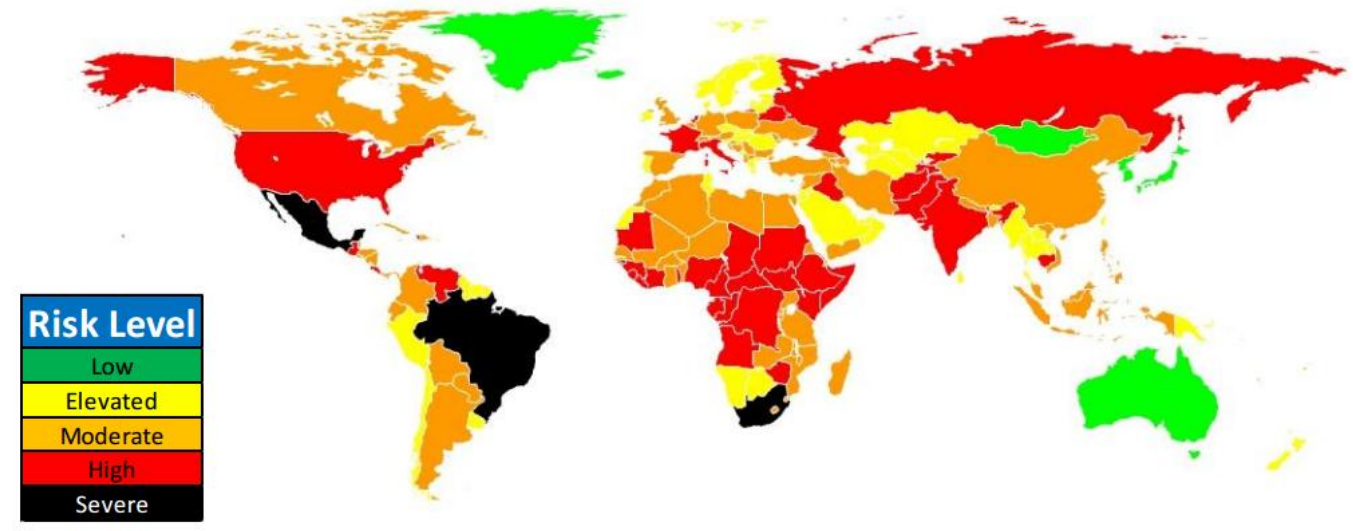

Figura 3: Risco Global de Roubo de Carga: Avaliação da Ameaça.

Fonte: FI, 2013.

\subsection{2}

\section{Roubo de cargas no modal rodoviário no Rio de Janeiro}

A região sudeste apresenta o maior índice de roubo de carga, e é simultaneamente onde se localiza o corredor rodoviário mais congestionado do país, sendo São Paulo e Rio de Janeiro os estados com maiores índices. Segundo NTC \& Logística (2014), o estado de São Paulo tem uma representatividade de $52,5 \%$ e o Estado do Rio de Janeiro $23,3 \%$ de incidências. O estado de São Paulo lidera o ranking, mas o estado do Rio de Janeiro vive situação mais crítica pelo avanço das ocorrências. No primeiro semestre de 2012 o roubo de carga no Estado do Rio de Janeiro aumentou 30\% (NTC \& Logística, 2012). 
A Figura 4 mostra o mapeamento de risco realizado no Brasil por estado pela FI.

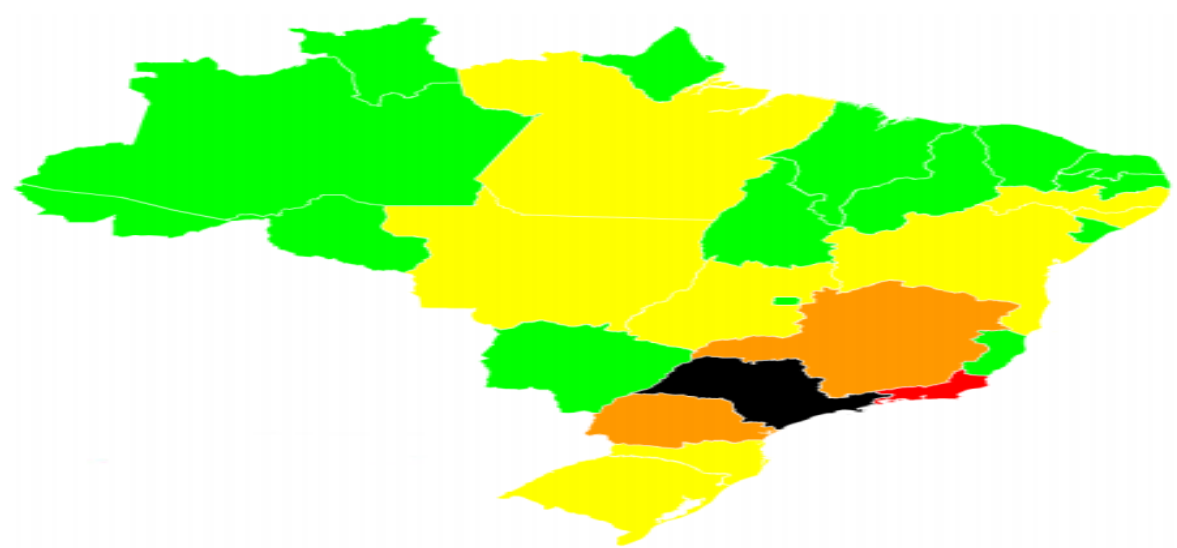

Figura 4: Brasil - Mapa de risco. Fonte: $\mathrm{FI}, 2013$.

Segundo o Instituto de Segurança Pública - ISP (2014, apud G1, 2014), de janeiro a outubro de 2014, o índice de roubos de carga no Rio de Janeiro aumentou $154 \%$ em relação ao mesmo período do ano anterior.

Estas ações resultam em um considerável impacto nos custos logísticos das empresas brasileiras, pois as mesmas são obrigadas a contratar escolta armada, investir em equipamentos de vigilância, como, câmeras e sistemas de rastreamento de veículos de carga, além do grande aumento do preço dos seguros que em alguns casos devido ao elevado índice não são mais oferecidos pelas seguradoras, além de em muitos casos as empresas serem obrigadas a trabalharem sem a capacidade máxima de seus veículos, ou seja, ociosos, em virtude de que caso sejam roubados não seja levada uma carga elevada e reduza esse prejuízo. Portanto, para minimizar essas ações de roubo de carga, as empresas estão escolhendo roteiros que fogem daqueles que são alvos dos ladrões, fazendo uma rota mais longa em nome da segurança da carga (NTC \& Logítica, 2013).

Conforme a NTC \& Logística (2014), o custo operacional do transporte tem um aumento médio de $7,7 \%$ quando não há escolta. Do contrário, o valor cresce cerca de $12,5 \%$.

Segundo o Resumo mensal do mês de novembro de 2014 do Instituto de Segurança Pública do Rio de Janeiro, entre os delitos que registraram o maior aumento percentual, no trimestre de setembro, outubro e novembro de 2014 em relação ao mesmo período do ano anterior, encontras-se, roubo de carga como primeiro, sendo $83,6 \%$ ou 741 casos. 
Esses dados ressaltam a importância do tema e incentivam os pesquisadores a ajudar a melhorar essa situação, como é o caso desta dissertação. No tópico 2.4 será abordado o problema de roteirização de veículos.

\section{5}

\section{O Problema de Roteirização de Veículos}

Tarantilis (2005) afirma que o Problema de Roteirização de Veículos (Vehicle Routing Problem - VRP) é um problema focal de gestão de distribuição dentro da área de serviço de gestão de operações e logística.

Segundo Cordeau et al. (2002), o VRP foi introduzido por Dantzig e Ramser em 1959 e tornou-se um dos problemas mais estudados em otimização combinatória, de acordo com o mesmo autor, o VRP é um problema de otimização combinatorial difícil e somente pode ser resolvido de maneira ótima em problemas de instancias relativamente pequena, desta maneira as heurísticas são comumente utilizadas na prática.

Já conforme Eksioglu et al. (2009), o primeiro registro de VRP na literatura foi realizado por Dantizig et al. (1954), em um estudo que propôs um método de solução para o TSP em escala relativamente grande. Segundo o mesmo autor, Clarke \& Wright (1964) foram os primeiros a considerar mais de um veículo na formulação do problema e, assim, pode ser considerado como sendo o primeiro estudo de VRP como é conhecido atualmente.

No que diz respeito aos objetivos do VRP, estes são variados, dependendo de cada aplicação. Eles podem considerar a minimização dos custos de viagem, do número de veículos utilizados, do tempo de viagem, das penalidades por atraso ou maximizar o número de clientes atendidos, ou ainda, uma abordagem pode ser feita utilizando-se múltiplos objetivos (Batistus, 2009).

De acordo com Christofides et al. (1981), o VRP básico é um problema onde se encontra um conjunto de clientes dispersos geograficamente com demandas conhecidas e devem ser atendidos por uma frota de veículos a partir de um centro de distribuição, minimizando a soma das distâncias percorridas na distribuição, assumindo que todas as rotas de veículos devem começar e terminar no depósito. Quando a definição das rotas envolve aspectos temporais, como restrições de horários de atendimento nos pontos a serem visitados, estes problemas são conhecidos como problemas de roteirização e programação de veículos (Cunha, 2000). 
O problema básico de roteirização de veículos desconsidera uma extensa e diversa quantidade de restrições adicionais e extensões, que fazem parte do dia-a-dia operacional. Segundo Christofides (1985, apud Belfiore, 2006), as restrições mais usuais do problema estão relacionadas às capacidades dos veículos.

O VRP pode ser classificado em variadas categorias e tipos. Para tal concorre o grande número de situações práticas do dia-a-dia. Entre outros fatores, o VRP pode ser diferenciado de acordo com os tipos de operações, de carga, de frota, de localização dos clientes, tipo de restrições e função objetivo (Belfiore, 2006).

$\mathrm{Na}$ Tabela 1 são apresentadas algumas extensões do problema básico de roteirização de veículo, com os parâmetros mais relevantes e comuns. Estes parâmetros foram obtidos por meio do trabalho de Belfiore (2006), que realizou uma taxonomia do problema utilizando como base os trabalhos desenvolvidos por Christofides (1985), Bodin \& Golden (1981), Bodin et al. (1983), Assad (1988), Ronen (1988) e Brejon (1998). Os parâmetros são classificados em quatro categorias: função objetivo, restrições, variáveis de decisão e hipótese/recursos e características do problema.

Tabela 1: Características dos problemas de roteirização

\begin{tabular}{|c|c|}
\hline Categorias & Possibilidades \\
\hline Função objetivo & $\begin{array}{l}\text { Minimizar os custos totais de distribuição (custos fixos mais variáveis); } \\
\text { Minimizar a distância total percorrida; } \\
\text { Minimizar a duração das rotas; } \\
\text { Minimizar o número de veículos; } \\
\text { Maximizar a função utilidade pelo cliente. }\end{array}$ \\
\hline $\begin{array}{l}\text { Restrições dos } \\
\text { veículos }\end{array}$ & $\begin{array}{l}\text { Limite de capacidade dos veículos; } \\
\text { Limite com relação ao tipo de carga dos veículos; } \\
\text { Operação de carga e descarga dos veículos; } \\
\text { Número e tipo de veículos disponíveis. }\end{array}$ \\
\hline $\begin{array}{l}\text { Restrições junto } \\
\text { aos clientes }\end{array}$ & $\begin{array}{l}\text { Janelas de tempo dos clientes (intervalo de atendimento de cada cliente); } \\
\text { Atendimento total ou parcial das demandas; } \\
\text { Prioridade no atendimento de clientes; } \\
\text { Tempo máximo permitido para carga e descarga; } \\
\text { Necessidade ou restrição de serviço em algum dia específico da semana. }\end{array}$ \\
\hline $\begin{array}{l}\text { Restrições das } \\
\text { rotas }\end{array}$ & $\begin{array}{l}\text { Horários de início e término das viagens; } \\
\text { Tempo máximo de viagem de um veículo; } \\
\text { Distância máxima percorrida; } \\
\text { Locais de paradas fixas, etc. }\end{array}$ \\
\hline $\begin{array}{l}\text { Variáveis de } \\
\text { decisão }\end{array}$ & $\begin{array}{l}\text { Roteiro a ser percorrido por cada veículo; } \\
\text { Qual veículo é designado por cada cliente; } \\
\text { Qual a quantidade de carga transportada para cada cliente da rota; } \\
\text { Tempo de início de atendimento do primeiro cliente da rota. }\end{array}$ \\
\hline
\end{tabular}




\begin{tabular}{|c|c|}
\hline $\begin{array}{l}\text { Tipo de } \\
\text { operação }\end{array}$ & $\begin{array}{l}\text { Coleta; } \\
\text { Entrega; } \\
\text { Coleta e entrega simultaneamente; } \\
\text { Coleta (ou entrega) com carga de retorno. }\end{array}$ \\
\hline Tipo de carga & $\begin{array}{l}\text { Única ou carga de lotação; } \\
\text { Múltiplas cargas ou cargas fracionadas. }\end{array}$ \\
\hline $\begin{array}{l}\text { Tipo de } \\
\text { demanda }\end{array}$ & $\begin{array}{l}\text { Determinística; } \\
\text { Estocástica. }\end{array}$ \\
\hline $\begin{array}{l}\text { Localização da } \\
\text { demanda }\end{array}$ & $\begin{array}{l}\text { Demanda localizada somente em arcos; } \\
\text { Demanda localizada somente em nós; } \\
\text { Demanda localizada em arcos e nós. }\end{array}$ \\
\hline $\begin{array}{l}\text { Tamanho da } \\
\text { frota }\end{array}$ & $\begin{array}{l}\text { Limitada; } \\
\text { \|limitada. }\end{array}$ \\
\hline Tipo de frota & $\begin{array}{l}\text { Homogênea; } \\
\text { Heterogênea. }\end{array}$ \\
\hline $\begin{array}{l}\text { Depósitos e } \\
\text { localização de } \\
\text { veículos }\end{array}$ & $\begin{array}{l}\text { Um único depósito; } \\
\text { Vários depósitos; } \\
\text { Quantidade de produtos disponíveis no depósito central para entrega aos clientes; } \\
\text { Número de bases de origem e destino dos veículos. }\end{array}$ \\
\hline $\begin{array}{l}\text { Jornada de } \\
\text { trabalho }\end{array}$ & $\begin{array}{l}\text { Duração; } \\
\text { Horário de almoço e outras interrupções; } \\
\text { Permissão para viagens com mais de um dia de duração; } \\
\text { Número de tripulantes por veículos. }\end{array}$ \\
\hline $\begin{array}{l}\text { Pagamento dos } \\
\text { tripulantes }\end{array}$ & $\begin{array}{l}\text { Por jornada de trabalho; } \\
\text { Por produtividade; } \\
\text { Jornada e horas extras. }\end{array}$ \\
\hline $\begin{array}{l}\text { Estrutura da } \\
\text { rede }\end{array}$ & $\begin{array}{l}\text { Direcionada; } \\
\text { Não direcionada; } \\
\text { Mista; } \\
\text { Euclidiana. }\end{array}$ \\
\hline $\begin{array}{l}\text { Horizonte de } \\
\text { planejamento }\end{array}$ & $\begin{array}{l}\text { Curto prazo; } \\
\text { Longo prazo. }\end{array}$ \\
\hline $\begin{array}{l}\text { Outras } \\
\text { hipóteses }\end{array}$ & $\begin{array}{l}\text { Cada veículo pode visitar um cliente uma única vez durante a rota; } \\
\text { Um cliente pertence a uma única rota; } \\
\text { Um cliente pode pertencer a mais de uma rota. }\end{array}$ \\
\hline
\end{tabular}

Fonte: Adaptado de Belfiori (2006).

\subsection{1}

Problemas Clássicos de Roteirização de Veículos

O primeiro problema clássico de roteirização a ser estudado, de acordo com Cunha (2000), foi o TSP, o qual tinha como objetivo definir uma rota de cidades a serem visitadas por um caixeiro viajante exatamente uma vez, de maneira que a distância total seja minimizada. 
O problema clássico de encontrar uma rota ótima para um único veículo em uma rede é um problema combinatório muito difícil pertencente à classe NPhard (Karp, 1972).

A maioria dos problemas de roteirização de veículos e programação de interesse são NP-hard, i.e., o esforço necessário para resolver tais problemas aumenta exponencialmente com seu tamanho (Bodin et al, 1983). O VRP pode ser resolvido por métodos exatos ou heurísticos. Os métodos exatos de solução são limitados já que só são capazes de resolver os casos com cerca de 100 clientes e com taxas de sucesso variável. Já os métodos heurísticos resolvem o problema de maneira mais rápida, mas não garantem o ótimo global (Baldacci et al., 2008).

De acordo com Laporte (1992), os algoritmos exatos podem ser classificados em três categorias: métodos de busca direta em árvore, programação dinâmica e programação linear inteira. Já os métodos heurísticos mais conhecidos são: algoritmo de Clarke \& Wright, método da varredura, o algoritmo de duas fases de Christofides-Mingozzi-Toth, o algoritmo de busca tabu e a colônia de formigas.

O problema de roteirização pode ser classificado, segundo Bodin et al. (1983), como node routing problem, arc routing problems, ou general routing problem. Bodin (1975) e Bodin \& Golden (1981), proporcionaram uma taxonomia conveniente para estes problemas. O problema de visitar todos os nós em uma rede, em uma quantidade de tempo mínimo (node routing) é o clássico problema do caixeiro viajante (Traveling Salesman Probem - TSP). O problema de cobertura de todos os arcos de uma rede, minimizando a distância total percorrida (arc routing) é o problema do carteiro chinês (Chinese Postman Problem - CPP). O General Routing Problem (GRP) em rede $\mathrm{G}=(\mathrm{N}, \mathrm{A})$ (N é o conjunto de todos os nós, A o conjunto de todos os arcos) é uma generalização que inclui o TSP e o CPP como casos especiais.

Segundo Held \& Karp (1971), o TSP é um problema de otimização que escolhe caminhos denominados hamiltonianos. Esse nome advém do autor William Rowan Hamilton que desenvolveu o jogo na década de 1800, este jogo consiste em encontrar uma rota através dos vértices de um decaedro de tal maneira que a rota se inicie e termine no mesmo vértice, sem nunca repetir uma visita.

O grafo do problema está apresentado na Figura 5. 


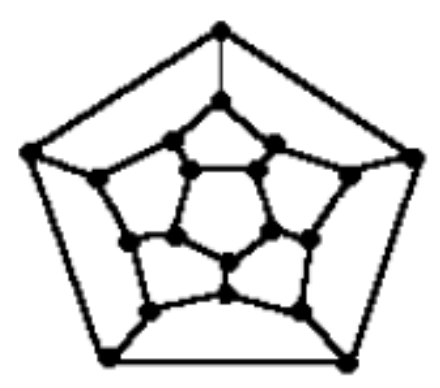

Figura 5: Grafo do Problema Hamiltoniano.

Fonte: Goldbarg \& Luna (2000, apud Belfiore, 2006).

A formulação do TSP foi realizada por Dantzig et al. (1954), como um problema de programação binária sobre um grafo $G=(N, A)$ da seguinte maneira:

Função Objetivo (F.O.) Minimizar

$$
Z=\sum_{j=1}^{n} \sum_{i=1}^{n} c_{i j} x_{i j}
$$

Sujeito a

$$
\sum_{i=1}^{n} x_{i j}=1, \forall j \in N
$$

$\sum_{j=1}^{n} x_{i j}=1, \forall i \in N$

$\sum_{i, j \in S}^{n} x_{i j} \leq|S|-1, \forall S \subset N$

$x_{i j} \in\{0,1\}, \forall i, j \in N$

A variável $x_{i j}$ pode assumir valores iguais a 1 ou 0 , o primeiro se 0 arco $(i, j) \in A$ for escolhido para integrar a solução, e o segundo caso contrário. Já $c_{i j}$ é o custo correspondente ao uso do arco $(i, j)$, e $S$ é um subgrafo $G$ em que $|S|$ significa o número de vértices desse subgrafo. As restrições (2.2) e (2.3) garantem que cada vértice seja visitado uma única vez. Já a restrição (2.4) impede que haja a criação de subciclos (subtours).

Conforme Solomon \& Desrosiers (1988), o CPP é um problema relevante dentro do assunto de roteirização, o mesmo pode ser considerado como uma variação do TSP, porém, o seguinte problema trabalha com arcos, ao invés de nós. De acordo com Dror (2000, apud Summerfield et al., 2015), o CPP remonta a 1962, o qual consiste em determinar um circuito de custo mínimo no qual o 
carteiro chinês (veículo) deve sair de um único depósito e retornar ao mesmo ao final da conclusão do circuito passando por todos os arcos (clientes) do grafo apenas uma vez. Neste problema clássico, também não há restrições de capacidade de veículos e a demanda é determinística.

O TSP e o CPP são dois problemas bem conhecidos, mas além destes existem outros problemas clássicos que também fazem parte de problemas básicos de roteirização e programação de veículos.

O Problema Clássico de Roteirização de Veículos (Vehicle Routing Problem - VRP) é uma generalização do TSP e tem como objetivo obter um conjunto de rotas com o menor custo possível, iniciando e terminando em um depósito, atendendo todos os clientes com restrições de capacidade de veículos e em alguns problemas são apresentados restrições de tempo máximo de ciclo do veículo.

A partir do VRP surgem outros problemas que se tornaram também clássicos, como:

- Problema de Roteirização de Veículos com Múltiplos Depósitos (Multi-Depot Vehicle Routing Problem - MDVRP): derivação do VRP clássico, com a diferença de ter mais de um depósito. O veículo sai de um depósito, realiza as entregas e no final retorna para qualquer depósito existente. Um trabalho de grande relevância com grande número de citações é o de Cordeau et al. (1997), no qual além de considerar múltiplos depósitos também é periódico;

- Problema de Roteirização de Veículos com Demanda em Arcos (Capacitated Arc Routing Problem - CARP): generalização do problema do carteiro chinês, com restrição de capacidade de veículos, e é uma derivação do VRP clássico, em virtude de ter os clientes localizados em arcos ao invés de nós. Um trabalho de relevância é Eiselt et al. (1995);

- Problema de Roteirização de Veículos com Demanda Estocástica (Stochastic Vehicle Routing Problem - SVRP): problema gerado a partir do VRP clássico, mas diferentemente dos demais problemas que utilizam uma demanda determinística, este modelo sugere a utilização de uma demanda estocástica, Gendreau et al. (1996) realizaram um trabalho com o objetivo de fornecer uma revisão da literatura sobre o assunto em questão; 
- Problema de Roteirização de Veículos com Entregas Fracionadas (Vehicle Routing Problem with Split Deliveries - VRPSD): cada ponto de demanda pode ser servido por mais de um veículo. $O$ trabalho realizado por Dror et al. (1994) apresenta a primeira formulação como uma programação linear inteira;

- Problema de Dimensionamento e Roteirização de uma Frota Homogênea de Veículos (Fleet Size and Vehicle Routing Problem FSVRP): determina a quantidade de veículos necessários, frota ilimitada e homogênea, além da realização das rotas minimizando os custos fixos dos veículos e variáveis das distâncias percorridas;

- Problema de Roteirização de Veículos com Frota Heterogênea Fixa (Heterogeneous Fixed Fleet Vehicle Routing Problem - HFFVRP): derivação do VRP clássico em que a frota de veículos é heterogênea e fixa. Tarantilis et al. (2004) apresentam uma nova metaheurística para resolver o HFFVRP;

- Problema de Dimensionamento e Roteirização de uma Frota Heterogênea de Veículos (Fleet Size and Mix Vehicle Routing Problem - FSMVRP): generalização do FSVRP em que a frota é heterogênea e ilimitada. O objetivo do problema consiste em determinar, roteiros e a quantidade ideal dos veículos em termos de tamanho, a composição da frota, além de minimizar os custos totais, Golden et al. (1984) descrevem vários procedimentos de soluções heurísticas, bem como técnicas de geração de um limite inferior e uma subestimativa da solução ótima;

- Problema de Roteirização de Veículos Multi-Período ou Periódico (Periodic Vehicle Routing Problem - PVRP): extensão do problema clássico do VRP em que, o horizonte de tempo passa a ter $N$ dias ao invés de ser diário. Hemmelmayr et al. (2009) propuseram uma nova heurística para o PVRP, utilizando como método o Variable Neighborhood Search (VNS);

- Problema de Roteirização de Veículos com Tempo Dependente (Time Dependent Vehicle Routing Problem - TDVRP): neste modelo a velocidade e os tempos de viagem dependem do tempo de viagem no planejamento das rotas. Yiyo (2010) faz uso do TDVRP para resolver um problema de redução de carbono na atmosfera e recorre ao algoritmo Simulated Annealing (SA); 
- Problema de Roteirização (e Programação) de Veículos com Janelas de Tempo (Vehicle Routing (and scheduling) Problem with Time Windows - VRSPTW ou VRPTW): extensão do problema clássico,com as restrições de janelas de tempo. O trabalho de Solomon (1987) é considerado uma referência nesta área. O mesmo realizou projetos e análises computacionais extensivos de vários algoritmos para a resolução de um conjunto de problemas;

- Problema de Roteirização (e Programação) de Veículos com Janela de Tempo Flexível (Vehicle Routing (and Scheduling) Problem with "Soft" Time Windows - VRSPSTW ou VRPSTW): neste problema as janelas de tempo podem ser violadas, mas em contrapartida há uma penalização. Balakrishnan (1993) descreve três heurísticas de resolução do modelo e mostra os resultados computacionais em um conjunto de problemas benchmark;

- Problema de Coleta e Entrega (Pickup and Delivery Problems PDP) e Dial-a-ride Problem (DARP): o PDP é o problema onde há transporte de cargas de origens para destinos sem transbordo em pontos intermediários. Savelsbergh (1995) discute as características do modelo e faz um levantamento dos tipos de problema e métodos de solução encontrados na literatura. O DARP tem como diferença a carga transportada que nesse caso são pessoas, ver Mauri (2006).

A Tabela 2 sintetiza uma classificação dos principais problemas de roteirização de veículos. Apesar de a função objetivo ser um elemento fundamental, o mesmo não foi incluído na Tabela 2, pois pode haver diversas variações para um mesmo tipo de problema. As características como número de depósitos, restrições adicionais, etc, foram alteradas e adicionadas ao clássico VRP resultando em variações e extensões. A Tabela 2 não esgota todas as variantes do VRP existentes.

O problema estudado nesta dissertação é uma combinação do problema de roteirização de veículos com frota heterogênea fixa (HFVRP) com o problema de roteirização de veículos com janela de tempo (VRPTW), ao qual se junta à probabilidade de roubo de carga no local onde se encontram os clientes. Sendo assim, é um Problema de Roteirização de Veículos com Frota Heterogênea Fixa, com Janelas de Tempo e com Probabilidade de Roubo de Carga nos Nós, podendo ser denominado apenas como: Problema de Roteirização de Veículos 
com Probabilidade de Roubo de Carga (Vehicle Routing Problem with Cargo Theft Probability - VRPCTP).

Dada a relevância do VRP, do VRPTW e do HFVRPTW para o estudo desenvolvido nesta dissertação, as Seções 2.5, 2.6 e 2.7 apresentam, respectivamente, cada um desses modelos de forma mais detalhada. 
Tabela 2: Classificação dos principais problemas de roteirização de veículos

\begin{tabular}{|c|c|c|c|c|c|c|c|c|c|c|}
\hline & $\begin{array}{l}\text { Número } \\
\text { roteiros }\end{array}$ & $\begin{array}{l}\text { Localiz. } \\
\text { clientes }\end{array}$ & $\begin{array}{l}\text { № } \\
\text { depósitos }\end{array}$ & Tipo demanda & Restrições & $\begin{array}{l}\text { № Entregas } \\
\text { por cliente }\end{array}$ & Variáveis de decisão & Período & Tipo de frota & $\begin{array}{l}\text { Número de } \\
\text { Veículos }\end{array}$ \\
\hline TSP & 1 & nós & 1 & determinística & & 1 & roteiros de entrega & $1 \mathrm{dia}$ & 1 veículo & limitado \\
\hline CPP & 1 & $\operatorname{arcos}$ & 1 & determinística & & 1 & roteiros de entrega & 1 dia & 1 veículo & limitado \\
\hline VRP & múltiplos & nós & 1 & determinística & capacidade do veículo & 1 & roteiros de entrega & $1 \mathrm{dia}$ & homogênea & limitado \\
\hline MDVRP & múltiplos & nós & múltiplos & determinística & capacidade do veículo & 1 & roteiros de entrega & 1 dia & homogênea & limitado \\
\hline CARP & múltiplos & $\operatorname{arcos}$ & 1 & determinística & capacidade do veículo & 1 & roteiros de entrega & $1 \mathrm{dia}$ & homogênea & limitado \\
\hline SVRP & múltiplos & nós & 1 & estocástica & capacidade do veículo & 1 & $\begin{array}{l}\text { roteiros de entrega } \\
\text { roteiros de entrega }\end{array}$ & 1 dia & homogênea & limitado \\
\hline VRPSD & múltiplos & nós & 1 & determinística & capacidade do veículo & $>=1$ & $\begin{array}{l}\text { Quantidade entregue a } \\
\text { cada cliente }\end{array}$ & 1 dia & homogênea & limitado \\
\hline FSVRP & múltiplos & nós & 1 & determinística & capacidade do veículo & 1 & roteiros de entrega & $1 \mathrm{dia}$ & homogênea & ilimitado \\
\hline HFFVRP & múltiplos & nós & 1 & determinística & capacidade do veículo & 1 & roteiros de entrega & $1 \mathrm{dia}$ & heterogênea & limitado \\
\hline FSMVRP & múltiplos & nós & 1 & determinística & capacidade do veículo & 1 & roteiros de entrega & 1 dia & heterogênea & ilimitado \\
\hline PVRP & múltiplos & nós & 1 & determinística & capacidade do veículo & 1 & roteiros de entrega & $M$ dia & homogênea & limitado \\
\hline TDVRP & múltiplos & nós & 1 & determinística & $\begin{array}{l}\text { capacidade do veículo } \\
\text { tempo dependente }\end{array}$ & 1 & roteiros de entrega & 1 dia & homogênea & limitado \\
\hline VRPTW & múltiplos & nós & 1 & determinística & $\begin{array}{l}\text { capacidade do veículo } \\
\text { janela de tempo }\end{array}$ & 1 & roteiros de entrega & $1 \mathrm{dia}$ & homogênea & limitado \\
\hline VRPSTW & múltiplos & nós & 1 & determinística & $\begin{array}{l}\text { capacidade do veículo } \\
\text { janela de tempo flexível }\end{array}$ & 1 & roteiros de entrega & $1 \mathrm{dia}$ & homogênea & limitado \\
\hline $\begin{array}{l}\text { PDP } \\
\text { Dial-a-ride }\end{array}$ & múltiplos & nós & 1 & determinística & $\begin{array}{l}\text { capacidade do veículo } \\
\text { precedência entre tarefas }\end{array}$ & 1 & roteiros de entrega & 1 dia & homogênea & limitado \\
\hline
\end{tabular}

Fonte: Adaptado de Belfiori (2006). 


\section{6 Formulação do Problema de Roteirização de Veículos, VRP}

Segundo Laporte (2007), o VRP clássico é representado em um grafo direcionado $G=(V, A)$ sendo $V=\{0,1, \ldots, n\}$ o conjunto de vértices e $A=\{(i, j): i, j$ $\epsilon \mathrm{V}, \mathrm{i} \neq \mathrm{j}\}$ o conjunto de arcos. $\mathrm{O}$ Vértice 0 representa um depósito ao qual é alocado no máximo $k$ veículos de capacidade $B_{k}$. Cada cliente i $\epsilon \bigvee\{0\}$ é associado a uma demanda não negativa $a_{i} \leq B_{k}$. $A$ matriz de custo $c_{i j}$ (simétrica, $c_{i j}=c_{j i}$ para todo $\left.i, j\right)$ é definida no conjunto de arco A. Pode-se também definir o problema num grafo não direcionado $G=(V, E)$, sendo $E=\{(i, j): i, j \in V, i<j\}$ o conjunto de arestas. Assim o problema consiste em determinar um conjunto de rotas de veículo que começam e terminam no mesmo ponto de maneira a minimizar o custo total. Cada cliente é visitado exatamente uma vez e a demanda total de cada rota não pode exceder a capacidade $B_{k}$ do veículo.

Apresenta-se abaixo a notação e em seguida a formulação de programação inteira do VRP.

Parâmetros:

$\mathrm{K}=$ número de veículos.

$\mathrm{N}$ = número de clientes que a entrega deve ser feita. Clientes são indexados de 1 até $\mathrm{n}$ e $\mathrm{o}$ índice 0 denota o depósito central.

$B_{K}=$ capacidade (peso ou volume) do veículo $K$.

$a_{i}=$ tamanho da entrega para o cliente $\mathrm{i}$.

$c_{i j}=$ custo da viagem direta do cliente i para o cliente $j$.

Variáveis:

$Y_{i k}=1$, se o pedido do cliente $\mathrm{i}$ é entregue pelo veículo $\mathrm{K}$. 0 , Caso contrário.

$X_{\mathrm{ijk}}=1$, se o veículo $\mathrm{K}$ viaja diretamente do cliente i para o cliente j. 0 , caso contrário.

A formulação matemática do VRP clássico proposta por Fisher \& Jaikumar (1979), pode ser verificada da seguinte maneira:

$$
\min \sum_{\mathrm{ijk}} c_{\mathrm{ij}} \mathrm{X}_{\mathrm{ijk}}
$$

Sujeito a

$\sum_{\mathrm{i}} \mathrm{a}_{\mathrm{i}} \mathrm{Y}_{\mathrm{ik}} \leq \mathrm{B}_{\mathrm{k}}, k=1, \ldots, K$

$\sum_{k} Y_{i k}=K, i=0$ 


$$
\begin{aligned}
& \sum_{k} Y_{i k}=1, i=1, \ldots, n \\
& \sum_{i} X_{i j k}=Y_{j k}, j=0, \ldots, n ; k=1, \ldots, K \\
& \sum_{j} X_{i j k}=Y_{i k}, i=0, \ldots, n ; k=1, \ldots, K \\
& \sum_{i j \in S \times S} X_{i j k} \leq|S|-1, S \subseteq\{1, \ldots, n\} ; 2 \leq|S| \leq n-1 ; k=1, \ldots, K \\
& Y_{i k}=0 \text { ou } 1, i=0, \ldots, n ; k=1, \ldots, K \\
& X_{i j k}=0 \text { ou } 1, i=0, \ldots, n ; j=0, \ldots, n ; k=1, \ldots, K
\end{aligned}
$$

$\mathrm{Na}$ formulação apresentada, a função objetivo (2.6) busca minimizar o custo total de distribuição. As restrições (2.7) a (2.9) são as restrições de um problema de atribuição generalizada e garante que cada percurso comece e termine em um depósito (cliente 0), que cada cliente é atendido por algum veículo, e que a carga atribuída a um veículo está dentro da capacidade do mesmo. Se $Y_{i k}$ são fixados para satisfazer (2.7) à (2.9), em seguida, para um dado $\mathrm{K}$, as restrições (2.10) à (2.12) definem o TSP sobre os clientes atribuídos ao veículo $k$. As restrições (2.13) e (2.14) garantem que as variáveis sejam binárias.

A Figura 6, abaixo, mostra como foram desenvolvidas as estratégias para tratamento de problemas de roteirização.

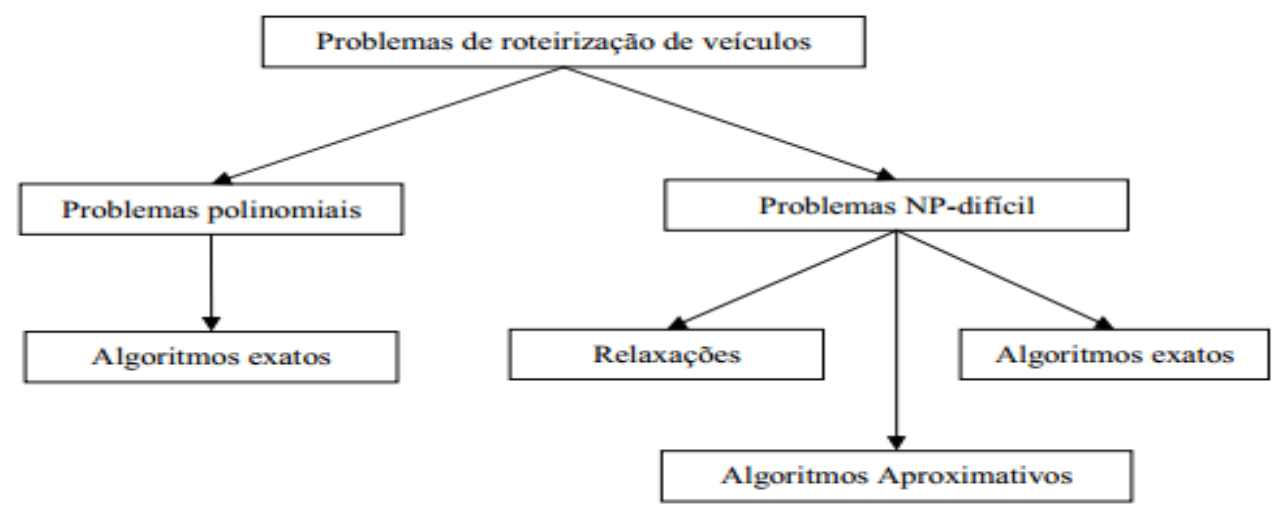

Figura 6: Estratégias para solução do VRP.

Fonte: Goldbarg \& Luna (2000, apud Miura, 2008).

Laporte \& Nobert (1987) realizaram um estudo sobre os algoritmos exatos para o VRP, enfatizando os resultados apresentados pelas pesquisas além de 
evitar a duplicação de trabalhos anteriores, no que diz respeito à resolução do VRP por métodos exatos.

Dentro dessa pesquisa pode ser encontrado o trabalho realizado por Christofides et al. (1981), o qual foi implementado algoritmo exato para o VRP clássico com frota homogênea, utilizando de relaxação lagrangeana $e$ programação dinâmica relaxada dos problemas da árvore de cobertura mínima e do caminho mínimo. Consideraram as limitações de capacidade de veículos e também restrição de tempo máximo de jornada de trabalho. Segundo os mesmos autores, o algoritmo final inclui reduções do problema e testes de dominância e pode ser resolvido problemas, de maneira ótima, com até 25 clientes.

Achuthan et al. (2003, apud Belfiori, 2006) elaboraram novos algoritmos de plano de corte, que foram executados em um algoritmo branch and cut, para revolver o VRP. O método foi aplicado para resolução de problemas de 15-100 clientes e os resultados foram comparados com outros encontrados na literatura e, segundo os autores, obtiveram resultados significativos.

Devido a essa difícil resolução por métodos exatos, a maioria das estratégias de solução utilizam métodos heurísticos e métodos emergentes (metaheurísticas) (Belfiori et al., 2006).

As heurísticas clássicas do VRP podem ser divididas em construtivas e de melhoria. Exemplos de heurística clássica para resolução do VRP são o Algoritmo do Vizinho mais Próximo e o Algoritmo de Clarke e Wright.

O algoritmo do vizinho mais próximo, segundo Solomon (1987), começa na criação do percurso com base nas distâncias entre os pontos, no qual o ponto mais próximo do depósito é adicionado primeiro na rota e os demais pontos são adicionados em seguida. Esses pontos são inseridos com base na ideia de proximidade em relação ao último cliente posto na rota.

O método dos savings de Clarke \& Wright (1964) foi um dos primeiros criados para a solução do VRP. Neste método, primeiramente é criada uma solução inicial enviando-se um veículo para cada cliente possível. Então, são calculadas economias, ou savings, obtidas ao se juntar duas rotas, ou seja, um veículo que antes visitava um cliente passaria e visitar dois. Os savings obtidos são ordenados de maneira decrescente.

A partir deste ponto, conforme Christofides et al. (1981), o algoritmo pode seguir duas abordagens distintas com base na lista de savings:

Sequencial: uma rota é escolhida aleatoriamente, e, com base na lista, o melhor saving factível é escolhido para se juntar dois clientes em uma rota só. $\mathrm{O}$ 
processo é repetido para a mesma rota até que já não seja mais possível adicionar clientes e manter a rota factível. Neste ponto o algoritmo repete o processo para uma rota diferente, até que já não existam rotas para otimizar.

Paralelo: Começando pelos melhores savings factíveis da lista em diante, o algoritmo vai unindo um dado número de rotas paralelamente, enquanto permanecerem factíveis, até o momento em que não existam savings factíveis ou rotas a serem consideradas.

Outra técnica é o método de inserção do ponto mais distante, que é apropriado para situações onde a área de distribuição está definida e existem poucos clientes. O método consiste em definir o ponto de origem do roteiro e, depois, verificar qual é o ponto mais distante desse ponto de origem, traçando uma reta. O próximo passo é buscar o ponto mais distante da reta já traçada, e assim sucessivamente, buscando sempre o ponto mais distante das retas traçadas e que ainda não foram incluídas no roteiro (Novaes, 2004).

\section{7 \\ Formulação do Problema de Roteirização de Veículos com Janelas de Tempo, VRPTW}

O problema de roteirização de veículos com janelas de tempo (Vehicle Routing Problem with Time Windows - VRPTW) é uma generalização do VRP com restrições adicionais, as chamadas janelas de tempo, onde o serviço de entrega para qualquer cliente inicia dentro de um dado intervalo de tempo. Assim tem-se o que chamam de janelas de tempo rígida (hard), mas caso essa janela possa ser violada, ou seja, caso o atendimento inicie depois do intervalo, sob a imposição de penalidades, tem-se o problema com janelas de tempo flexíveis (soft), assim como no VRP a duração de qualquer rota (tempo de serviço mais o tempo de viagem) não pode exceder o tempo limite de duração da rota, que é pré-determinado (Kallehauge, 2006).

A formulação matemática para o VRPTW, encontrada em Kallehauge (2006), envolve variáveis binárias $X_{i j k}$, bem como variáveis inteiras $S_{i k}$. Para um dado veículo $\mathrm{k} \epsilon \mathrm{K}$ a variável binária de arco $\mathrm{X}_{\mathrm{ijk}}$ para cada arco (i,j) $\epsilon \mathrm{A}$ são definidos como se segue. $X_{i \mathrm{ijk}}=1(\mathrm{i}, \mathrm{j}) \in \mathrm{A}$ é usado pelos $\mathrm{k}$ veículos no caminho $\mathrm{m}$, 0 , caso contrário. As variáveis de decisão $S_{i k}$ são definidas para cada nó i $\epsilon N$, cada veículo $\mathrm{k} \epsilon \mathrm{K}$ e representam o tempo que o veículo $\mathrm{k}$ começa o serviço ao cliente i. No caso, dado um veículo $k$ não atender o cliente $i, S_{i k}$ não quer dizer nada. O VRPTW é formulada como o seguinte programa linear inteiro: 
$\min \sum_{k \in K} \sum_{(i, j) \in A} c_{\mathrm{ij}} \mathrm{X}_{\mathrm{ijk}}$

Sujeito a

$$
\begin{aligned}
& \sum_{k \in K} \sum_{j \in V} \mathrm{X}_{\mathrm{ijk}}=1, \forall i \in N \\
& \sum_{j \in V} X_{0 j v}=1, \forall k \in K \\
& \sum_{i \in V} X_{i h k}-\sum_{j \in V} X_{h j k}=0, \forall h \in N, \forall h \in K \\
& \sum_{i \in V} X_{i, n+1, k}=1, \forall k \in K \\
& \sum_{i \in N} d_{i} \sum_{i \in N} X_{i j k} \leq q, \forall k \in K \\
& s_{i k}+t_{i j}-L_{i j}\left(1-X_{i j k}\right) \leq s_{j k}, \forall i, j \in N, \forall k \in K \\
& a_{i} \leq s_{i k} \leq b_{i}, \forall i \in N, \forall k \in K \\
& X_{i j k} \in\{0,1\}, \forall i, j \in A, \forall k \in K \\
& s_{i k} \in \mathbb{Z}_{+}, \forall i \in N, \forall k \in K
\end{aligned}
$$

Onde $L_{i j}=b_{i}-a_{j}$ e $\mathbb{Z}_{+}$denota que o conjunto de inteiros não negativos.

A função objetivo (2.15) expressa o custo total. Igualdades (2.16) são restrições de atribuição exigindo que cada cliente deve ser servido exatamente por um veículo. Restrições (2.17) à (2.19) são os que garantem que cada veículo inicie a sua rota no depósito, equilíbrio de fluxo e por fim a restrição que obriga que todo veículo volte para o depósito no final do roteiro. As restrições (2.20) representam a limitação de capacidade. As desigualdades (2.21) e (2.22) são utilizadas para modelar as restrições de janela de tempo. As duas últimas são as restrições binárias e inteiras.

Solomon (1987) realizou um problema de roteirização de veículos com janelas de tempo que se tornou referência e tem sido comumente adotado para analisar e equiparar novos algoritmos. A dificuldade de resolução é alta, em virtude disso o problema de Solomon que apresentava 100 clientes, só foi possível a resolução para uma instância de 56.

Baker (1982, apud Belfiore, 2006), usou o método do branch and bound com algoritmo de etiquetagem para resolver um problema de roteirização com restrição de janela de tempo, um único veículo e capacidade do veículo, tendo como objetivo minimizar o tempo total dos caminhos percorridos. 
Kolen et al. (1987), também utilizaram um algoritmo branch and bound em um VRPTW. Os clientes são atendidos por uma frota de veículos de capacidade homogênea, determinando um conjunto de trajetos viáveis, de maneira a minimizar a distância total percorrida pelos veículos, atendendo as restrições de janelas de tempo e a capacidade dos veículos.

Desrochers et al. (1992) executaram o procedimento de geração de colunas para resolver o problema de roteirização e programação de veículos com janelas de tempo (VRPTW) e frota homogênea. Segundo os mesmos autores, foi assumido que a quantidade de veículos seria ilimitada, de maneira a definir o tamanho da frota ao mesmo tempo dos roteiros. O objetivo do modelo é minimizar a distância percorrida. Foi aplicado o método de solução aos problemas apresentados por Solomon (1987), solucionando os problemas dos conjuntos R1, C1 e RC1. Esses conjuntos possuem problemas com 25, 50 e 100 consumidores. Esses conjuntos apresentam restrições mais apertadas, com demanda de carga mais próxima ao limite dos veículos e as janelas de tempo menores. Foi alcançada a solução de alguns problemas primários, mas o maior problema resolvido incluía 18 veículos e 100 clientes. Equiparando-se com o maior problema resolvido por métodos exatos até o momento, essa pesquisa desempenhou uma significativa contribuição na pesquisa de métodos exatos de resolução de problemas de roteirização e programação com janelas de tempo.

Devido alta complexidade de resolução do VRPTW, métodos de solução, em geral, utilizam de heurísticas e/ou metaheurísticas.

Solomon (1987) elaborou sete heurísticas construtivas para o VRPTW, sendo, heurística de economia, heurística de economia com limite de tempo de espera, heurística do vizinho mais próximo com orientação temporal, heurística de inserção I1, com critério que minimiza o acréscimo de tempo e distância total da rota, heurística de inserção 13 e heurística da varredura com orientação temporal. De acordo com o autor, alterações nos algoritmos originais produziram métodos mais robustos e flexíveis, capazes de incorporar restrições de janelas de tempo, concluindo que a heurística de inserção 11 apresentou o melhor resultado, seguido da heurística 12.

Silva Júnior (2013) apresentou diversos algoritmos para resolver as versões estática e dinâmica de roteirização de veículos com janelas de tempo. Estes problemas tiveram como objetivo determinar rotas de custo mínimo para uma frota homogênea, atendendo a demanda de um conjunto de clientes dentro de intervalos de tempo, chamados de janelas de tempos. Além disto, na versão dinâmica no problema, novos clientes podem ser atendidos durante a execução 
das rotas pelos veículos. Para a versão estática do problema propôs-se um algoritmo híbrido utilizando otimização por colônias de formigas e o método de descida em vizinhança variável aleatória. Para a versão dinâmica do problema foram propostos seis algoritmos, baseados em métodos de inserção, de otimização por colônia de formigas e das versões sequencial e aleatória do método de busca em vizinhança variável. Os resultados computacionais mostram que a maior parte dos algoritmos propostos é competitiva com os algoritmos propostos na literatura.

Li \& Lim (2003) apresentaram uma metaheurística com objetivo de minimizar o custo total de deslocamento e a quantidade de veículos utilizados, com restrições de janelas de tempo e capacidade de veículos. O algoritmo teve duas fases, a primeira corresponde achar uma solução inicial para o VRPTW usando uma heurística e na segunda fase se inicia uma busca local a partir da solução inicial gerada, utilizando do Simulated Annealing com Busca Tabu Embutida - TSA com a estratégia K-restart.

Ainda sobre a utilização do Simulated Annealing, Kim et al. (2006) trataram um problema de roteirização de veículos de coleta de resíduo comercial com janelas de tempo (VRPTW) em um estudo de caso real, adotando múltiplas viagens de descarga e as paradas para almoço. O objetivo do problema, além do comum encontrado na literatura que é a minimização do deslocamento e a utilização de veículos, foi considerado a compactação da rota e o equilíbrio da carga de trabalho. $O$ algoritmo de inserção de Solomon foi estendido para o problema. $\mathrm{O}$ algoritmo elaborado foi executado em uma situação real.

\section{8}

\section{Formulação do Problema de Roteirização de Veículos com Frota Heterogênea Fixa e Restrições de Janelas de Tempo, HFVRPTW}

De acordo com Koç et al. (2014), O Problema de Roteirização de Veículos com Frota Heterogênea Fixa e Restrições de janelas de Tempo (Heterogeneous Fleet Vehicle Routing Problems with Time Windows - HFVRPTW), considera que a frota de veículos tem várias capacidades e custos relacionados diferentes, assim como um conjunto de clientes com a demanda determinística e janelas de tempo. Vale ressaltar que os números de veículos são limitados, ou seja, fixo. Este problema consiste em determinar um conjunto de rotas, onde cada cliente é visitado apenas uma vez por um único veículo dentro de uma janela de tempo, todo veículo inicia e termina sua rota no depósito e a carga de cada veículo não 
pode exceder a capacidade do mesmo. O objetivo principal é minimizar os custos de transporte.

A formulação matemática para o HFVRPTW inclui as seguintes variáveis:

a) o tempo de chegada em cada cliente i, é denotado por $s_{i v}$;

b) a sequência com que cada veículo realiza o seu roteiro, $x_{i j}^{v}$;

c) a indicação de utilização do veículo, $y_{v}$

Dada as definições acima o HFVRPTW pode formular-se utilizando as equações 2.25 - 2.37, onde (2.25) a (2.31) são equações tradicionais encontradas em Arenales et al. (2007, apud Araujo, 2008), (2.32) e (2.33) equações tradicionais de roteirização de veículos com janelas de tempo, podendo ser encontradas, por exemplo em, Kohl et al. (1999), e a restrição (2.34) pode ser encontrada em Kallehauge (2008).

$\min \sum_{k \in K} \sum_{(i, j) \epsilon A} \mathrm{C}_{\mathrm{ij}} x_{i j}^{v}$

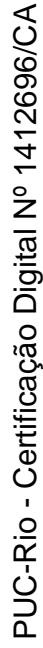

Sujeito a

$\sum_{v=1}^{V} \sum_{j=1}^{N+1} x_{i j}^{v}=1, \forall i \in C$

$\sum_{j=1}^{N+1} x_{0 j}^{v}=y_{v}, \forall v \in V$

$\sum_{i=0}^{N} x_{i N+1}^{v}=y_{v}, \forall v \in V$

$\sum_{i=0}^{N} x_{i h}^{v}-\sum_{j=1}^{N+1} x_{h j}^{v}=0, \forall h \in C, \forall v \in V$

$\sum_{i=0}^{N} \sum_{j=1}^{N+1}\left(T D_{i j}+T A_{i}\right) x_{i j}^{v} \leq T C_{v} y_{v}, \forall v \in V$

$\sum_{i=1}^{N} \sum_{j=1}^{N+1} R_{i} x_{i j}^{v} \leq Q_{v} y_{v}, \forall v \in V$

$A_{i} \leq s_{i v}, \forall i \in C, \forall v \in V$

$s_{i v} \leq B_{i}, \forall i \in C, \forall v \in V$

$s_{i v}-s_{j v}+\left(B_{i}+\left(T D_{i j}\right)-A_{j}\right) x_{i j}^{v} \leq B_{i}-A_{j}, \forall i, j \in C, i \neq j, \forall v \in V$

$s_{i v} \in R_{+}, \forall i \in C, \forall v \in V$

$x_{i j}^{v} \in\{0,1\}, \forall i, j \in N, \forall v \in V$

$y_{v} \in\{0,1\}, \forall v \in V$ 
A função objetivo (2.25) visa minimizar o custo de transporte. A restrição (2.26) estabelece que cada cliente é visitado uma única vez e por um só veículo. A restrição (2.27) e (2.28) garantem que todo veículo deve sair e chegar ao depósito. A restrição (2.29) é a equação de conservação de fluxo que assegura a continuidade de cada veículo na rota. A restrição (2.30) impõe que o tempo de ciclo do veículo não seja excedido. A Restrição (2.31) garante que a capacidade do veículo não seja excedida. Restrições (2.32) e (2.33) certificam que as janelas de tempo sejam respeitadas. Restrição (2.34) assegura a eliminação de subrotas, uma vez que define a relação entre horário de partida do veículo de um cliente, o tempo de deslocamento até o seu sucessor imediato e consequentemente a hora de chegada ao mesmo. Finalmente, Restrições (2.35) faz cumprir a não negatividade da variável, (2.36) e (2.37) certificam a integralidade das respectivas variáveis.

Paraskevopoulos et al. (2007) apresentou uma metodologia de resolução bem sucedida para o HFVRPTW baseada em Tabu Search. O objetivo é minimizar os custos totais de distribuição. Tal problema usando uma estrutura de solução de duas fases, com base em Tabu Search híbrido, dentro da Reactive Variable Neighborhood Tabu Search (ReVNTS). A performance do ReVNTS foi avaliada em múltiplos experimentos computacionais publicado por Solomon (1987), que inicialmente foi proposto para o VRPTW. Segundo os mesmo autores, o ReVNTS produziu soluções de alta qualidade para o HFVRPTW. Notavelmente, o desempenho ReVNTS em conjuntos de dados da subclasse a e todos as subclasses de $R 2, C 2$ e $R C 2$, conseguiu uma notável redução de custos totais de distribuição.

\section{9 Complexidade Computacional dos Problemas de Roteirização de Veículos}

A complexidade computacional pode ser interpretada como a quantidade de tempo ou esforço necessário para que um algoritmo encontre uma solução ótima para um determinado problema. Tal esforço tende a variar conforme o tamanho do problema, sendo este calculado pelo número de entradas necessárias para descrever o problema (Garey et al., 1976).

Diferentes algoritmos podem solucionar o mesmo problema em tempos computacionais diferentes, portanto variam distintamente de acordo com o número de entradas. Dessa forma, Garey et al. (1976) afirmam que cada 
algoritmo possui uma função de complexidade computacional, que determina a variação do tempo computacional necessário para solucionar o problema de acordo com o número de entradas.

Para se definir um algoritmo como eficiente ou ineficiente, distingue-se o tipo de função de complexidade computacional, existindo dois tipos: i) os algoritmos polinomiais, cuja função de complexidade cresce de forma polinomial, sendo considerados os mais eficientes para a solução de problemas; ii) os algoritmos exponenciais, cuja função de complexidade computacional cresce de forma exponencial, tornando-os ineficientes para problemas grandes demais (Garey et al., 1976).

O problema $\mathrm{P}$ versus NP (Nondeterministic Polynomial time) é um dos principais problemas sem solução na matemática, fazendo parte dos 7 Problemas Prêmio do Milênio do Instituto Clay de Matemática (agora são 6, pois um foi resolvido), que oferece recompensa de 1 milhão de dólares para a resolução de um (CMI, 2000).

A Classe $\mathrm{P}$ é a classe de problemas de decisão resolvida por algum algoritmo em tempo computacional polinomial, a Classe NP, pode ser definida como aqueles problemas em que se pode checar, em tempo polinomial, se uma solução fornecida é ótima ou não, mas são apenas conhecidos algoritmos exponenciais para sua resolução (Cook, 1992)

Desta maneira, entende-se que o esforço computacional para a resolução de problemas cresce exponencialmente com o tamanho do problema, dado pelo número de pontos a serem atendidos. Assim para estes problemas difíceis e complexos, a otimização utiliza de técnicas para alcançar soluções próximas da ótima, como as heurísticas. Os problemas do VRP podem ser classificados como Problemas NP. 


\section{3 \\ Modelo de Roteirização de Veículos com Probabilidade de Roubo de Carga, VRPCTP}

O objetivo deste capítulo é apresentar e detalhar o modelo matemático que foi desenvolvido. A seção 3.1 é dedicada à caracterização do problema em análise. As seções 3.2, 3.3 e 3.4 descrevem, respectivamente, a formulação do problema, a validação do modelo e uma análise do modelo. A seção 3.5 detalha a heurística de Simulated Annealing utilizada para resolver o modelo.

\section{1}

\section{Caracterização do Problema}

De maneira geral, o objetivo do Problema de Roteirização de Veículos VRP, da presente pesquisa, tem, em sua essência, a mesma ideia central de um VRP clássico, cujo objetivo é entregar as mercadorias e atender as demandas, conhecidas, dos clientes que estão geograficamente dispersos, alocando veículos a roteiros que irão ser percorridos de acordo com uma sequência de atendimento e considerando a janela de tempo. A diferença entre ambos os problemas reside na escolha de quem atender primeiro, considerando a probabilidade de roubo de carga do local e assim ponderando com a distância de deslocamento. Em outras palavras, o modelo de otimização matemática de VRP proposto aborda a questão da probabilidade de roubo de carga no nó, sugerindo soluções de roteirização cujas entregas das mercadorias ocorram primeiramente em regiões probabilisticamente mais seguras, evitando o roubo de carga consolidada caso o roteiro começasse pela região mais perigosa, ponderando com o custo de deslocamento. Como solução visa-se obter um conjunto de rotas com o objetivo de minimizar os custos de deslocamento e o risco de roubo de carga.

\section{2}

\section{Formulação do Problema}

O problema descrito nesta dissertação se configura como um Problema de Roteirização de Veículos com Janela de Tempo e frota heterogênea, 
acrescentando a Probabilidade de Roubo de Carga no Nó (Vehicle Routing Problem with Cargo Theft Probability - VRPCTP). O modelo aqui apresentado pode ser adaptado a qualquer formulação derivada. $O$ problema pode ser definido como segue: dado um conjunto de veículos disponíveis $(V$ ) com capacidades diferentes e conhecidas $\left(Q_{v}\right)$, encontrar um conjunto de rotas para servir um dado número de clientes $|C| \subset|N|$, de modo a minimizar os custos. $|N|$ é um conjunto de nós que inclui clientes e o Centro de Distribuição (CD), os índices $i, j$ e $h$ referem-se aos clientes quando assumem valores entre 1 a $n$, e para o CD quando $i=0$ e $j=n+1$ representam o depósito, ou seja, $N=C \cup\{0$, $n+1\}$. Um índice adicional $v$ é atribuído aos veículos $(v=1, \ldots, \mid \eta)$. Os veículos são inicialmente localizados no CD. Cada cliente $i$ demanda $R_{i}$ Stock Keeping Units (SKUs) do CD e deve ser servido por exatamente um veículo dentro de uma janela de tempo $\left[A_{i}, B_{i}\right]$, onde $B_{i}>A_{i}$. O tempo de atendimento para cada cliente $i$ é $T A_{i}$. Cada cliente $i$ é associado a um valor de probabilidade de roubo de carga, $P_{i}$. A distância e o tempo de viagem entre o nó $i$ e $j$ são, respectivamente, $D_{i j}$ e $T D_{i j}$, onde o último é medido em função do anterior e de uma velocidade média de viagem. $C T_{v}$ é o custo de transporte por $\mathrm{km}$ percorrido para cada tipo de veículo $v$. Os parâmetros adicionais incluem o tempo de ciclo máximo permitido para cada veículo, $T C_{v}$, o início e o fim do expediente no $C D$ (IE e $F E$ ), o valor de carga $L$ e um fator de calibragem, a, que representa uma porcentagem paga pelo $C D$ em virtude do prejuízo pelo roubo da carga, também conhecido como "prêmio" ou "franquia" e consequentemente a seguradora paga 1- a do prejuízo em virtude do roubo, ou seja, se o a for igual a $3 \%$ e o valor da carga roubada for de 1 milhão, então o CD irá apenas 3\% desse valor e a seguro $97 \%$.

Cada veículo inicia e termina a rota no centro de distribuição e deve satisfazer as seguintes premissas: (1) a quantidade de demanda atendida por cada rota não deve exceder a capacidade do veículo; (2) o tempo de percurso de cada rota não deve ultrapassar o tempo de ciclo do veículo; (3) o veículo não pode iniciar o atendimento no cliente $i$ antes de $A_{i}$ e depois de $B_{i}$, entretanto o veículo pode chegar antes de $A_{i}$ e esperar para iniciar o serviço; (4) todo cliente deve ser atendido uma vez por um veículo; (5) todo veículo deve chegar e sair de cada cliente. Além disso, deve-se atualizar a quantidade de carga que sai de cada nó, pois será um dos fatores de decisão para a escolha do melhor roteiro, sendo ponderada pelo valor da carga e probabilidade de roubo de carga.

O problema em questão inclui as seguintes variáveis de decisão: 
a) O tempo de chegada em cada cliente $i$ pelo veículo $v$, é denotado por $s_{i v}, \mathbb{R}_{+}$.

b) A sequência com que cada veículo realiza o seu roteiro, $x_{i j}^{v}$, 1 se o cliente $j$ é atendido após o cliente $i$ pelo veículo $v, 0$ caso contrário.

c) A indicação de utilização do veículo $v, y_{v}, 1$ se o veículo $v$ é utilizado, 0 caso contrário.

d) O carregamento de carga no veículo $v$ após deixar o nó $i$ quando se move para o nó $j$ é $z_{i j}^{v}, \mathbb{Z}_{+}$.

Por uma questão de clareza, os elementos que compõem o modelo matemático estão apresentados nas Tabelas 3,4 e 5 que representam os conjuntos e índices, os parâmetros e as variáveis do problema, respectivamente.

Tabela 3: Conjuntos e Índices

\begin{tabular}{ll}
\hline Conjuntos & Índices \\
\hline Veículos $(\boldsymbol{V})$ & $v$ \\
Nós $(\boldsymbol{N})$ & $i, j$ \\
Clientes $(\boldsymbol{C})$ & $i, j, h$ \\
\hline
\end{tabular}

Fonte: Autor, 2015.

Tabela 4: Parâmetros

\begin{tabular}{|c|c|c|}
\hline Parâmetros & Descrição & Unidade \\
\hline $\mathrm{V}$ & Quantidade de veículos disponíveis & - \\
\hline$Q_{v}$ & Capacidade do tipo de veículo $v$ & SKUs \\
\hline$R_{i}$ & Demanda do cliente $i$ & SKUs \\
\hline$T A_{i}$ & Tempo de Atendimento no cliente $i$ & Hora \\
\hline$A_{i}$ & Tempo mais cedo para o início de atendimento em $i$ & Hora \\
\hline$B_{i}$ & Tempo mais tarde para o início de atendimento em $i$ & Hora \\
\hline$C T_{v}$ & Custo de Transporte por cada tipo de veículo $v$ & $\mathrm{R} \$ / \mathrm{km}$ \\
\hline$D_{i i}$ & Distância entre os nós $i, j$ & $\mathrm{~km}$ \\
\hline$T D_{i i}$ & Tempo de Deslocamento entre os nós $i, j$ & Hora \\
\hline$T C_{v}$ & Tempo de Ciclo de cada tipo de veículo $v$ & Hora \\
\hline$P_{i}$ & Probabilidade de roubo de carga no cliente $i$ & - \\
\hline M & Valor muito grande & - \\
\hline IE & Início do Expediente no CD & Hora \\
\hline FE & Fim do Expediente no CD & Hora \\
\hline$\alpha$ & Porcentagem do valor de carga roubada paga pelo $C D$ & - \\
\hline L & Valor médio de mercadoria & $\mathrm{R} \$ \mathrm{SKUS}$ \\
\hline
\end{tabular}

Fonte: Autor, 2015. 
Tabela 5: Variáveis

\begin{tabular}{llll}
\hline Variaveís & Descrição & Unidade & Domínio \\
\hline$s_{i v}$ & Instante de tempo em que se inicia o serviço no cliente i pelo veículo v & Hora & $R_{+}$ \\
$x_{i j}^{v}$ & Decisão se o cliente $j$ é atendido após o cliente $i$ pelo veículo v & - & $\{0,1\}$ \\
$y_{v}$ & Indicação se o veículo v é utilizado & - & $\{0,1\}$ \\
$z_{i j}^{v}$ & Quantidade de carga que vai do nó $i$ ao nó $j$ no veículo v & SKU & $Z_{+}$ \\
\hline
\end{tabular}

Com base na notação acima o VRPCTP pode ser formulado da seguinte forma:

Função Objetivo Minimizar

$E=\sum_{i=0}^{N} \sum_{j=1}^{N+1} \sum_{v=1}^{V} C T_{v} D_{i j} x_{i j}^{v}+\sum_{i=0}^{N} \sum_{j=1}^{N} \sum_{v=1}^{V} P_{j} L z_{i j}^{v} \alpha$

Sujeito a

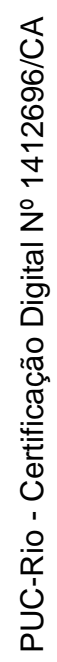

$\sum_{v=1}^{V} \sum_{j=1}^{N+1} x_{i j}^{v}=1, \forall i \in C$

$\sum_{j=1}^{N+1} x_{0 j}^{v}=y_{v}, \forall v \in V$

$\sum_{i=0}^{N} x_{i N+1}^{v}=y_{v}, \forall v \in V$

$\sum_{i=0}^{N} x_{i h}^{v}-\sum_{j=1}^{N+1} x_{h j}^{v}=0, \forall h \in C, \forall v \in V$

$\sum_{i=0}^{N} \sum_{j=1}^{N+1}\left(T D_{i j}+T A_{i}\right) x_{i j}^{v} \leq T C_{v} y_{v}, \forall v \in V$

$\sum_{i=1}^{N} \sum_{j=1}^{N+1} R_{i} x_{i j}^{v} \leq Q_{v} y_{v}, \forall v \in V$

$y_{v} A_{i} \leq s_{i v}, \forall i, j \in C, \forall v \in V$

$s_{i v} \leq B_{i} y_{v}, \forall i \in C, \forall v \in V$

$s_{i v}-s_{j v}+\left(B_{i}+\left(T D_{i j}+T A_{i}\right)-A_{j}\right) x_{i j}^{v} \leq B_{i}-A_{j}, \forall i, j \in C, i \neq j, \forall v \in V$

$I E+T D_{0 j}-M\left(1-x_{0 j}^{v}\right) \leq s_{j v}, \forall j \in C, \forall v \in V$

$s_{i v}+T A_{i}+T D_{i 0}-M\left(1-x_{i 0}^{v}\right) \leq F E, \forall i \in C, \forall v \in V$

$z_{0 h}^{v} \geq\left(\sum_{i=1}^{N} \sum_{j=1}^{N+1} R_{i} x_{i j}^{v}\right)-M\left(1-x_{0 h}^{v}\right), \forall h \in C, \forall v \in V$ 
$z_{h i}^{v} \leq z_{0 h}^{v}-R_{h}+M\left(1-x_{0 h}^{v}\right), \forall i, h \in C, i \neq h, \forall v \in V$

$z_{i j}^{v} \leq z_{h i}^{v}-R_{i}+M\left(1-x_{h i}^{v}\right), \forall i, j, h \in C, i \neq j$ e $h \neq i, \forall v \in V$

$s_{i v} \in R_{+}, \forall i \in C, \forall v \in V$

$x_{i j}^{v} \in\{0,1\}, \forall i, j \in N, \forall v \in V$

$y_{v} \in\{0,1\}, \forall v \in V$

$z_{i j}^{v} \in \mathrm{Z}_{+}, \forall i, j \in N, \forall v \in V$

As restrições (3.2) a (3.7) são equações encontradas em Arenales et al. (2007, apud Araujo, 2008), as restrições (3.8) e (3.9) são equações tradicionais da roteirização de veículos com janelas de tempo, podendo ser encontradas, por exemplo em, Kohl et al.(1999), a restrição (3.10) pode ser encontrada em, Kallehauge (2008) e as restrições (3.11) e (3.12) são usadas por Fischer et al. (1997). As restrições (3.13), (3.14), (3.15) e a segunda parcela da função objetivo (3.1) são resultados do trabalho desenvolvido.

A Equação (3.1) representa a função objetivo, que compreende a minimização do custo total, sendo a soma do custo de deslocamento e o custo de possível perda da carga por roubo. A restrição (3.2) estabelece que cada cliente seja visitado uma única vez e por um só veículo. As restrições (3.3) e (3.4) garante que todo veículo deve sair e chegar ao depósito. A restrição (3.5) é uma equação de conservação de fluxo que assegura a continuidade de cada veículo na rota. A restrição (3.6) impõe que o tempo de ciclo do veículo não seja excedido. A restrição (3.7) atesta que a capacidade do veículo não seja excedida. As restrições (3.8) e (3.9) certificam que as janelas de tempo sejam respeitadas. A restrição (3.10) assegura a eliminação de sub-rotas, uma vez que define a relação entre horário de partida do veículo de um cliente, o tempo de deslocamento até o seu sucessor imediato e consequentemente a hora de chegada ao mesmo. Vale ressaltar que caso o veículo chegue muito cedo ao cliente, ele deverá esperar até que a janela esteja aberta. A restrição (3.11) e (3.12) garantem a compatibilidade entre o horário de início de funcionamento do $C D$, horários de chegada aos clientes, execução de serviço e o horário limite de retorno ao CD. A restrição (3.13) calcula o carregamento inicial do veículo quando o mesmo sai do depósito, é importante ressaltar que a carga de cada cliente não pode ser fracionada. As restrições (3.14) e (3.15) rastreiam a quantidade de carga que sai de cada cliente. Finalmente, a restrição (3.16) faz cumprir a não negatividade da variável, e as restrições (3.17), (3.18) e (3.19) certificam a integralidade das respectivas variáveis. 
Este novo modelo proposto difere dos existentes na literatura pela função objetivo utilizada (3.1) e pelas restrições (3.13), (3.14), (3.15).

\section{3 \\ Validação do Modelo}

Para validar o modelo proposto (VRPCTP) foram realizados 4 Testes com o intuito de comparar os resultados. O Teste 1 correu o modelo utilizando $\alpha=$ $0 \%$. No Teste 2 rodou-se o modelo VRPCTP considerando $\alpha=100 \%$ e vários veículos. No Teste 3 executou-se o modelo VRPCTP com $\alpha=100 \%$ e utilizando apenas um veículo. Finalmente foi realizado o Teste 4 utilizando o modelo VRPCTP com $\alpha=3 \%$, executado no AIMMS com alguns dados reais extraídos de um Centro de Distribuição (CD) de produtos farmacêuticos no Estado do Rio de Janeiro. Considerando-se o $\alpha=0 \%$ significa que em caso de roubo de carga a companhia de seguros pagará todos os custos de bens roubados, assim o CD realiza uma roteirização básica sem considerar a questão do roubo de carga. No caso em que $\alpha=100 \%$ significa que o CD não tem contrato com empresa de seguros e assim será responsável por todos os custos em caso de roubo de carga.

Para ressaltar as consequências da aplicação dos modelos a comparação foi feita utilizando um exemplo de estudo com 5 clientes e 5 veículos.

Cada cliente requer um determinado tempo de atendimento médio calculado a partir do histórico de atendimento da empresa que é igual a 404 seg.. Com relação à restrição de janela de tempo, a mesma foi criada de maneira a eliminar sub-rotas devido à sua fácil aplicação no software utilizado e também de maneira a deixar o problema mais geral, portanto o horário da janela de tempo de cada cliente é o próprio horário de funcionamento dos mesmos, $8 \mathrm{hr}$ até $18 \mathrm{hr}$, é importante ressaltar que o horário de funcionamento do CD é de $8 \mathrm{hr}$ até $17 \mathrm{hr}$, com $1 \mathrm{hr}$ de parada, portanto tem-se um tempo de trabalho de $8 \mathrm{hr}$.

$\mathrm{Na}$ Tabela 6 e 7 são apresentadas, respectivamente, a demanda de cada cliente (em SKU) e a matriz origem-destino (matriz O/D).

Tabela 6: Demanda por cliente

\begin{tabular}{llllll}
\hline Cliente & 1 & 2 & 3 & 4 & 5 \\
Demanda & 24 & 3 & 2 & 12 & 30 \\
\hline
\end{tabular}

Fonte: Autor, 2015. 
Tabela 7: Matriz O/D assimétrica utilizada para testes

\begin{tabular}{lllllll}
\hline De(i)/Para(j) & 0 & 1 & 2 & 3 & 4 & 5 \\
\hline 0 & 0 & 9,9 & 0,12 & 10,9 & 49,8 & 17,1 \\
1 & 9,8 & 0 & 9,9 & 19,6 & 47 & 7,6 \\
2 & 0,16 & 10 & 0 & 11 & 49,9 & 17,2 \\
3 & 11,8 & 19,4 & 11,9 & 0 & 49,8 & 27 \\
4 & 46,3 & 45,7 & 46,4 & 51,7 & 0 & 50,4 \\
5 & 15,6 & 7,3 & 15,8 & 25,2 & 52,1 & 0 \\
\hline
\end{tabular}

Fonte: Autor, 2015.

A matriz de tempos foi desenvolvida com base na matriz O/D, adotando uma velocidade média de $38 \mathrm{~km} / \mathrm{h}$, considerando dados do CD.

Os veículos de 1 a 5 utilizados nos testes têm capacidades distintas, mensuradas em SKUs, sendo as seguintes, respectivamente, 140, 180, 300, 450 e 600. Os mesmos têm um tempo de ciclo condicionado à carga horária máxima diária da tripulação equivalente às $8 \mathrm{hr}$. Ainda, segundo dados do CD, cada tipo de veículo possui um custo por $\mathrm{km}(\mathrm{R} \$ / \mathrm{km})$, referentes aos custos fixos associados e aos custos variáveis, esses custos são, respectivamente, 0,62, $0,647,0,734,0,76$ e 0,81 , sendo que o veículo com menor capacidade possui o menor custo associado e assim sucessivamente.

Para todos os testes aqui realizados, de maneira exata, utilizou-se o software AIMMS e o solver CPLEX 12.4, e um computador Intel Core i5 2,67 Ghz e 4GB de memória RAM.

No Teste 1 correu o modelo VRPCTP com $\alpha=0 \%$, i.e, a segunda parcela da função objetivo, que correspondem ao roubo de carga, é anulada. Este modelo de Programação Linear Inteira Mista (linear Mixed Integer Programming MIP) gerou para este primeiro Teste 776 restrições, 306 variáveis, sendo 155 interias. A solução ótima encontrada tem o valor de custo de transporte igual a $\mathrm{R} \$ 79,62$. E o tempo de execução de $0,20 \mathrm{seg}$. A Tabela 8 apresenta o resultado obtido nesse Teste 1. 
Tabela 8: Resultado - Teste 1

\begin{tabular}{|c|c|c|c|c|c|}
\hline $\begin{array}{l}\text { Veículo } \\
\text { (SKU) }\end{array}$ & Rota & $\begin{array}{l}\text { Horário de } \\
\text { Saída/Chegada } \\
\text { ao Depósito }(\mathrm{Hr})\end{array}$ & $s_{i v}(\mathrm{Hr})$ & $z_{i j}^{v}(\mathrm{SKU})$ & $\begin{array}{l}\text { Custo de } \\
\text { Transporte } \\
\text { (R\$) }\end{array}$ \\
\hline \multirow{7}{*}{$1(140)$} & 0 & 8,00 & & 71 & \\
\hline & 2 & & 8,003 & 68 & 0,07 \\
\hline & 3 & & 8,40 & 66 & 6,82 \\
\hline & 4 & & 9,83 & 54 & 30,88 \\
\hline & 5 & & 11,27 & 24 & 31,25 \\
\hline & 1 & & 15,63 & 0 & 4,53 \\
\hline & 0 & 16,00 & & & 6,08 \\
\hline \multicolumn{2}{|c|}{ Tempo de Ciclo } & 8,00 & & Custo Total & 79,62 \\
\hline
\end{tabular}

Fonte: Autor, 2015.

Como pode ser observado nos resultados, o veículo 1 foi selecionado para distribuir os produtos para os 5 clientes. Trata-se do veículo com menor capacidade (140 SKUs), e menor custo por $\mathrm{km}, \mathrm{R} \$ 0,62 / \mathrm{km}$, já que a soma das demandas dos clientes é menor que a capacidade de cada tipo de veículo. Sendo a função objetivo de minimização do custo, então foi selecionado o veículo com menor custo por $\mathrm{km}$. Pode-se ver a coerência da rota, onde a mesma não forma sub-rotas, e cada cliente é atendido por um único veículo e uma única vez, assim como o veículo 1 chega e sai de um cliente e o mesmo sai e chega ao depósito, além de obedecer à restrição de tempo de ciclo e capacidade do veículo. Analisando, percebe-se o horário de partida do depósito, assim como o horário de chegada em cada cliente e no depósito. Ainda, é possível visualizar a quantidade de SKUs que sai de cada nó. E por fim, o custo de transporte total mínimo. Vale ressaltar que o custo de transporte nó a nó e o horário de saída/chegada ao depósito é calculado a partir dos resultados gerados pelas variáveis do problema.

Após isso, foi realizado o Teste 2 no qual foi considerado $\alpha=100 \%$, desta maneira adotou-se apenas para análises valores arbitrários para a probabilidade de roubo de carga e valor da carga por SKU.

Para o Teste 2 adotou-se o valor médio de carga por SKU igual a $R \$$ 200,00 e a probabilidade de roubo de carga apresentadas na Tabela 9. Estes dados de probabilidade significam a chance de o veículo ser roubado no momento da visita ao cliente. Desta maneira, estes dados mostram o quanto cada região é mais perigosa que a outra, por exemplo, se na região do cliente 1 a probabilidade de roubo é de $10 \%$ e na região do cliente 2 é de $20 \%$ então pode-se inferir que, se a distância compensar, vale mais a pena visitar o cliente 
que está situado na região 1 , i.e, se a região 1 for visitada 100 vezes então haverá a chance de 10 roubos, mas caso haja 100 visitas à região 2, então haverá a probabilidade de ser roubado 20 vezes. Assim, o custo expresso pela segunda parcela da função objetivo visa minimizar esse possível prejuízo por perda de carga, devido ao roubo, caso venha ocorrer, ponderando com a distância e verificando se vale a pena fazer um percurso maior e correr um risco menor de perda de carga consolidada. Vale ressaltar que atualmente empresas do setor realizam roteiros maiores fugindo de regiões perigosas e deixando-as por último.

Tabela 9: Probabilidade de roubo de carga - Teste 2

\begin{tabular}{lccccc}
\hline Cliente & 1 & 2 & 3 & 4 & 5 \\
Probabilidade & 0,05 & 0,8 & 0,3 & 0,1 & 0,5 \\
\hline
\end{tabular}

Fonte: Autor, 2015.

Para este Teste 2, foram geradas 776 restrições, 306 variáveis, sendo 155 inteiras. A solução encontrada é a ótima, com o valor de $R \$ 4.192,60$. O tempo de execução foi de $155 \mathrm{seg}$. A Tabela 10 apresenta o resultado do Teste 2.

Tabela 10: Resultado - Teste 2

\begin{tabular}{|c|c|c|c|c|c|c|c|}
\hline $\begin{array}{l}\text { Veículo } \\
\text { (SKU) }\end{array}$ & Rota & $\begin{array}{l}\text { Horário de } \\
\text { Saída/Chegada } \\
\text { ao Depósito } \\
\text { (Hr) }\end{array}$ & $s_{i v}(\mathrm{Hr})$ & $z_{i j}^{v}(\mathrm{SKU})$ & $\begin{array}{l}\text { Custo de } \\
\text { Transporte } \\
\text { (R\$) (1) }\end{array}$ & $\begin{array}{l}\text { Custo de } \\
\text { Roubo Carga } \\
\text { (R\$) (2) }\end{array}$ & FO $[(1)+(2)]$ \\
\hline & 0 & 8,00 & & 12 & & & \\
\hline \multirow[t]{2}{*}{$1(140)$} & 4 & & 9,31 & & 30,88 & 240,00 & \\
\hline & 0 & 10,64 & & & 28,71 & & \\
\hline \multirow[t]{2}{*}{ Tempo de Ciclo } & & 2,64 & & Custo/Rota & 59,58 & 240,00 & 299,58 \\
\hline & 0 & 8,00 & & 30 & & & \\
\hline \multirow[t]{2}{*}{$2(180)$} & 5 & & 8,45 & & 11,06 & $3.000,00$ & \\
\hline & 0 & 8,97 & & & 10,09 & & \\
\hline \multirow[t]{2}{*}{ Tempo de Ciclo } & & 0,97 & & Custo/Rota & 21,16 & $3.000,00$ & $3.021,16$ \\
\hline & 0 & 8,00 & & 2 & & & \\
\hline \multirow[t]{2}{*}{$3(300)$} & 3 & & 8,29 & & 8,00 & 120,00 & \\
\hline & 0 & 8,71 & & & 8,66 & & \\
\hline \multirow[t]{2}{*}{ Tempo de Ciclo } & & 0,71 & & Custo/Rota & 16,66 & 120,00 & 136,66 \\
\hline & 0 & 8,00 & & 24 & & & \\
\hline \multirow[t]{2}{*}{$4(450)$} & 1 & & 8,26 & & 7,52 & 240,00 & \\
\hline & 0 & 8,63 & & & 7,45 & & \\
\hline \multirow[t]{2}{*}{ Tempo de Ciclo } & & 0,63 & & Custo/Rota & 14,97 & 240,00 & 254,97 \\
\hline & 0 & 8,00 & & 3 & & & \\
\hline \multirow[t]{2}{*}{$5(600)$} & 2 & & 8,00 & & 0,10 & 480,00 & \\
\hline & 0 & 8,12 & & & 0,13 & & \\
\hline \multirow[t]{2}{*}{ Tempo de Ciclo } & & 0,12 & & Custo/Rota & 0,23 & 480,00 & 480,23 \\
\hline & & & & Custo Total & 112,60 & $4.080,00$ & $4.192,60$ \\
\hline
\end{tabular}


Neste caso observa-se que o modelo criou um roteiro para cada veículo e isso é devido ao fato do custo de perda de carga ser muito superior ao custo de transporte, visto que a empresa é responsável por todo o custo em caso de roubo de carga. Nesse sentido é preferível carregar cada veículo com a carga de um único cliente, pois em caso de roubo apenas se perde a carga de um cliente. Pode-se ver a coerência da rota com relação às outras restrições do modelo que também são atendidas. Além disso, consegue-se visualizar a quantidade de carga que sai de cada nó. Assim como no Teste 1, o custo de transporte nó a nó e o horário de saída/chegada ao depósito é calculado a partir dos resultados gerados pelas variáveis do problema, para melhor visualização.

O roteiro realizado pelo veículo 1 inicia no depósito com a carga do cliente, que nesse caso é o cliente 4 com demanda igual a 12 SKUs, realizando um roteiro com um custo de transporte de $\mathrm{R} \$ 59,58$, além disso o modelo calcula o custo de uma possível perda de carga, que é a probabilidade de roubo no local onde o cliente encontra-se localizado, multiplicado pela quantidade de carga que sai do nó anterior, e o valor da mesma e $\alpha=100 \%$, neste caso o depósito, portanto esse custo de uma possível perda é de $\mathrm{R} \$ 240,00$ para esse roteiro. Percebe-se que o valor real, caso aconteça o roubo de carga, seria o próprio valor da carga de $\mathrm{R} \$ 2.400,00$, mas devido à multiplicação pelo dado de probabilidade esse valor reduz, assim conclui-se que a segunda parcela da Função Objetivo é uma ponderação para escolher o roteiro a ser utilizado.

Comparando os dois Testes já realizados, percebe-se um aumento no custo de transporte de $41 \%$, e por ser um aumento muito relevante é interessante analisar como o roteiro se comportaria limitando a quantidade de veículos a apenas um, partindo do princípio que com a realização do Teste 1 , sabe-se que é possível atender a demanda com apenas um veículo.

Desta maneira, para melhor análise e compreensão do modelo, com $\alpha=$ $100 \%$, será realizado o Teste 3 , a fim de verificar o comportamento do modelo VRPCTP com apenas um veículo, e comparar com o Teste 1.

Para o Teste 3, foram geradas 160 restrições, 62 variáveis, sendo 31 inteiras. A solução encontrada é a ótima, com o valor de $R \$ 6.019,63$. O tempo de execução foi de 0,11 seg. Verificar o resultado na Tabela 11. 
Tabela 11: Resultado - Teste 3

\begin{tabular}{|c|c|c|c|c|c|c|c|}
\hline $\begin{array}{l}\text { Veículo } \\
\text { (SKU) }\end{array}$ & Rota & $\begin{array}{l}\text { Horário de } \\
\text { Saída/Chegada } \\
\text { ao Depósito } \\
\text { (Hr) }\end{array}$ & $s_{i v}(\mathrm{Hr})$ & $z_{i j}^{v}(\mathrm{SKU})$ & $\begin{array}{l}\text { Custo de } \\
\text { Transporte } \\
(\mathrm{R} \$)(1)\end{array}$ & $\begin{array}{l}\text { Custo de } \\
\text { Roubo Carga } \\
\text { (RS) (2) }\end{array}$ & $\mathrm{FO}[(1)+(2)]$ \\
\hline \multirow{7}{*}{$1(140)$} & 0 & 8,00 & & 71,00 & & & \\
\hline & 1 & & 8,26 & 47,00 & 6,14 & 710,00 & \\
\hline & 4 & & 9,61 & 35,00 & 29,14 & 940,00 & \\
\hline & 5 & & 11,05 & 5,00 & 31,25 & 3500,00 & \\
\hline & 3 & & 15,46 & 3,00 & 15,62 & 300,00 & \\
\hline & 2 & & 15,88 & 0,00 & 7,38 & 480,00 & \\
\hline & 0 & 16,00 & & & 0,10 & & \\
\hline Tempo de Ciclo & & 8,00 & & Custo/Rota & 89,63 & 5930,00 & 6019,63 \\
\hline
\end{tabular}

Com o seguinte resultado percebe-se que o modelo resulta em um custo de transporte de $R \$ 89,63,12,6 \%$ maior do que o Teste 1 , isso é devido a preferência em alguns casos de locais com menor chance de roubo de carga em detrimento da menor distância, ou seja, considerando o possível roubo de carga é preferível roteiros mais longos e com menos riscos de perda de maiores volumes de carga. Por exemplo, no roteiro do Teste 1 o primeiro cliente da rota é o cliente 2, devido a menor distância em relação ao depósito, contudo no Teste 3 a probabilidade de roubo de carga neste cliente é de $80 \%$, em virtude disso, o cliente 2 foi designado para ser o último a ser atendido, já o cliente 1, apesar da distância ser maior, a probabilidade de roubo é muito baixo, assim sendo alocado como o primeiro na rota, no Teste 3 .

Sabendo que existe a probabilidade de roubo nas regiões onde se encontram os clientes, então, caso o tomador de decisão preferir realizar o roteiro do Teste 1 o mesmo terá um custo de roubo de carga igual a $R \$$ 22.400,00, aproximadamente quatro vezes maior do que o Teste 3 , desta maneira vale a pena ter um custo maior de $12,6 \%$ de custo de transporte e reduzir o risco de perda de carga.

A seguir será realizado o Teste 4, utilizando o modelo VRPCTP com $\alpha=$ $3 \%$ (dados da empresa), ou seja, a empresa paga $3 \%$ do valor da mercadoria em caso de roubo.

No Teste 4, foram geradas 776 restrições, 306 variáveis, sendo 155 inteiras. A solução encontrada é a ótima, com o valor de $R \$ 223,81$. O tempo de execução foi de $99 \mathrm{seg}$. Visualizar a Tabela 12. 
Tabela 12: Resultado - Teste 4

\begin{tabular}{|c|c|c|c|c|c|c|c|}
\hline $\begin{array}{l}\text { Veículo } \\
\text { (SKU) }\end{array}$ & Rota & $\begin{array}{l}\text { Horário de } \\
\text { Saída/Chegada } \\
\text { ao Depósito } \\
(\mathrm{Hr})\end{array}$ & $s_{i v}(\mathrm{Hr})$ & $z_{i j}^{v}(\mathrm{SKU})$ & $\begin{array}{l}\text { Custo de } \\
\text { Transporte } \\
\text { (R\$) (1) }\end{array}$ & $\begin{array}{l}\text { Custo de Roubo } \\
\text { Carga (R\$) (2) }\end{array}$ & $\mathrm{FO}[(1)+(2)]$ \\
\hline \multirow{5}{*}{$1(140)$} & 0 & 8,00 & & 38 & & & \\
\hline & 1 & & 8,26 & 14 & 6,14 & 11,40 & \\
\hline & 4 & & 14,10 & 2 & 29,14 & 8,40 & \\
\hline & 3 & & 15,58 & 0 & 32,05 & 3,60 & \\
\hline & 0 & 16,00 & & & 7,32 & & \\
\hline \multirow{2}{*}{ Tempo de Ciclo } & & 8,00 & & Custo/Rota & 74,65 & 23,40 & 98,05 \\
\hline & 0 & 8,00 & & 30 & & & \\
\hline \multirow[t]{2}{*}{$2(180)$} & 5 & & 8,45 & 0 & 11,06 & 90,00 & \\
\hline & 0 & 8,97 & & & 10,09 & & \\
\hline \multirow[t]{2}{*}{ Tempo de Ciclo } & & 0,97 & & Custo/Rota & 21,16 & 90,00 & 111,16 \\
\hline & 0 & 8,00 & & 3 & & & \\
\hline \multirow[t]{2}{*}{$3(300)$} & 2 & & 8,003 & 0 & 0,09 & 14,40 & \\
\hline & 0 & 8,12 & & & 0,12 & & \\
\hline \multirow[t]{2}{*}{ Tempo de Ciclo } & & 0,12 & & Custo/Rota & 0,21 & 14,40 & 14,61 \\
\hline & & & & Custo Total & 96,01 & 127,80 & 223,81 \\
\hline
\end{tabular}

Fonte: Autor, 2015.

Com base nos resultados obtidos, pode-se inferir que o modelo proposto opta pela utilização de 3 veículos, resultando em um custo de transporte de $R \$$ $96,01,20,6 \%$ mais custoso em comparação ao Teste 1 e $7,11 \%$ maior que o custo do Teste 3. Mas apesar do elevado custo de transporte o mesmo tem uma redução no possível custo de roubo de carga, isso é devido à redução dos custos por parte da empresa, devido ao a. Portanto com o modelo consegue-se encontrar o melhor roteiro ponderando a distância e o custo de roubo de carga.

Para efetuar a comparação dos custos de roubo de carga do Teste $4 \mathrm{com}$ os outros deve-se multiplicar os resultados dos testes anteriores por $3 \%$, portanto em caso de roubo de carga o valor pago pela empresa à seguradora é de apenas $3 \%$ do valor da carga roubada, assim pode-se comparar com o mesmo grau de grandeza. Conclui-se que apesar de um aumento do custo de transporte de $20,6 \%$ em comparação ao Teste 1 , tem-se uma redução de $R \$$ 672,00 para $R \$ 127,00$, e em comparação ao Teste 3 tem-se uma redução de $R \$ 177,9$ para $R \$ 127,00$. Após a apresentação destes resultados fica a critério do tomador de decisão conforme a suas necessidades e realizar o trade-off e decidir se prefere ter um custo um pouco maior de deslocamento, mas reduzindo as chances de roubo de carga consolidada. 


\section{4}

\section{Análise do Modelo}

Este tópico visa demonstrar o funcionamento do modelo proposto de maneira gráfica comparando os resultados após variações no parâmetro de probabilidade e verificando a influência no aumento do valor da carga na escolha do número de veículos.

Foi realizado o Teste 5 considerando $\alpha=3 \%$ e apenas um veículo. A Figura 7 (a) mostra o roteiro realizado pelo Teste 5, e a Figura 7 (b) mostra o roteiro com o dado de probabilidade de roubo de carga do cliente 4 alterada para $25 \%$. Ambos mostram as distâncias $(\mathrm{km})$ percorridas.

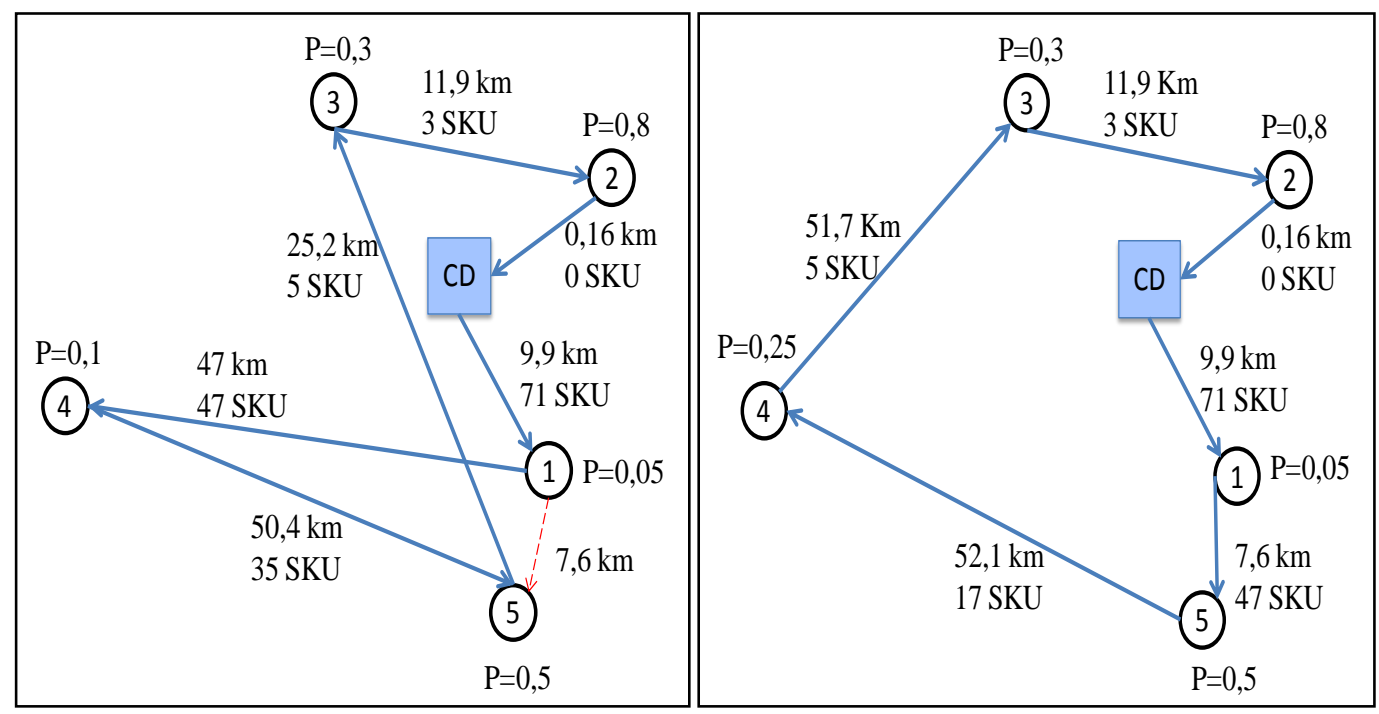

Figura 7: (a) Roteiro Teste 5 e (b) com mudança do dado de probabilidade.

Fonte: Autor, 2015.

No roteiro da Figura 7 (a) pode-se perceber que apesar da distância do cliente 1 para o cliente 5 ser consideravelmente menor que a distância para o cliente 4 , a rota prioriza o cliente 4 devido a baixa chance de roubo comparada ao 5. Porém, ao aumentar o probabilidade de roubo de carga de $10 \%$ para $25 \%$ no cliente 4, já se torna viável correr um maior risco e visitar primeiro o cliente 5 , minimizando o problema de maneira global. Para efeito de comparação manteve-se o roteiro da Figura 7 (a) alterando a porcentagem do cliente 4, para $25 \%$, de maneira a verificar o custo por roubo de carga e também os custos de deslocamento, caso o tomador de decisão mantivesse o roteiro (a). Podendo ser verificado na Tabela 13. 
Tabela 13: Comparação com probabilidade de $25 \%$ no cliente 4

\begin{tabular}{|c|c|c|c|c|c|c|c|}
\hline $\begin{array}{l}\text { Rota } \\
\text { (a) }\end{array}$ & $z_{i j}^{v}(\mathrm{SKU})$ & $\begin{array}{l}\text { Custo de } \\
\text { Transporte } \\
\text { (R\$) (1) }\end{array}$ & $\begin{array}{l}\text { Custo de } \\
\text { Roubo Carga } \\
\text { (R\$) (2) }\end{array}$ & $\begin{array}{l}\text { Rota } \\
\text { (b) }\end{array}$ & $z_{i j}^{v}(\mathrm{SKU})$ & $\begin{array}{l}\text { Custo de } \\
\text { Transporte } \\
\text { (R\$) (1) }\end{array}$ & $\begin{array}{l}\text { Custo de } \\
\text { Roubo Carga } \\
\text { (R\$) (2) }\end{array}$ \\
\hline 0 & 71 & & & 0 & 71 & & \\
\hline 1 & 47 & 6,14 & 21,30 & 1 & 47 & 6,14 & 21,30 \\
\hline 4 & 35 & 29,14 & 70,50 & 5 & 17 & 4,71 & 141,00 \\
\hline 5 & 5 & 31,25 & 105,00 & 4 & 5 & 32,30 & 25,50 \\
\hline 3 & 3 & 15,62 & 9,00 & 3 & 3 & 32,05 & 9,00 \\
\hline 2 & 0 & 7,38 & 14,40 & 2 & 0 & 7,38 & 14,40 \\
\hline \multirow[t]{3}{*}{0} & & 0,10 & & 0 & & 0,10 & \\
\hline & Custo/Rota & 89,63 & 220,20 & & Custo/Rota & 82,68 & 211,20 \\
\hline & Total Rota & 309,83 & & & Total Rota & 293,88 & \\
\hline
\end{tabular}

Fonte: Autor, 2015.

Manteve-se a rota da Figura 7 (a) e mudando apenas o dado de probabilidade do cliente 4 percebe-se um maior custo tanto de transporte quanto de risco de roubo, já otimizando o problema com a nova probabilidade, rota (b), gerou-se uma nova rota onde é minimizado tanto o custo de transporte quanto o custo total de risco de perda de carga, vale ressaltar que ao analisar o problema nó a nó aparentemente o risco de perda aumentaria visto que o possível valor do cliente 1 para o 5 seria de $R \$ 141,00$ enquanto na rota da Figura 7 (a) o custo de 1 para 4 seria de $R \$ 70,50$, mas apesar do aumento local o solução global é melhor, devido ao sucessor do nó 5 ter um custo de perda muito menor e a quantidade de carga que fica após o nó 5 ser pouca, devido a alta demanda do cliente 5 que foi entregue, então caso haja o roubo de carga a partir desse ponto, será roubado uma quantidade menor.

$\mathrm{Na}$ Tabela 14 faz-se uma análise similar, mas considerando a probabilidade de roubo de carga do cliente 4 igual a $20 \%$.

Tabela 14: Comparação com probabilidade de $20 \%$ no cliente 4

\begin{tabular}{|c|c|c|c|c|c|c|c|}
\hline $\begin{array}{l}\text { Rota } \\
\text { (a) }\end{array}$ & $z_{i j}^{v} \quad(\mathrm{SKU})$ & $\begin{array}{l}\text { Custo de } \\
\text { Transporte } \\
\text { (R\$) (1) }\end{array}$ & $\begin{array}{l}\text { Custo de } \\
\text { Roubo Carga } \\
(\mathrm{R} \$)(2)\end{array}$ & $\begin{array}{l}\text { Rota } \\
\text { (b) }\end{array}$ & $z_{i j}^{v} \quad(\mathrm{SKU})$ & $\begin{array}{l}\text { Custo de } \\
\text { Transporte } \\
\text { (R\$) (1) }\end{array}$ & $\begin{array}{l}\text { Custo de } \\
\text { Roubo Carga } \\
\text { (R\$) (2) }\end{array}$ \\
\hline 0 & 71 & & & 0 & 71 & & \\
\hline 1 & 47 & 6,14 & 21,30 & 1 & 47 & 6,14 & 21,30 \\
\hline 4 & 35 & 29,14 & 56,40 & 5 & 17 & 4,71 & 141,00 \\
\hline 5 & 5 & 31,25 & 105,00 & 4 & 5 & 32,30 & 20,40 \\
\hline 3 & 3 & 15,62 & 9,00 & 3 & 3 & 32,05 & 9,00 \\
\hline 2 & 0 & 7,38 & 14,40 & 2 & 0 & 7,38 & 14,40 \\
\hline \multirow[t]{3}{*}{0} & & 0,10 & & 0 & & 0,10 & \\
\hline & Custo/Rota & 89,63 & 206,10 & & Custo/Rota & 82,68 & 206,10 \\
\hline & Total Rota & 295,73 & & & Total Rota & 288,78 & \\
\hline
\end{tabular}

Fonte: Autor, 2015. 
Para este caso é interessante perceber que os custos de roubo de carga são iguais, portanto o modelo atualizou o roteiro otimizando pelo custo de transporte.

Após realizar a análise alterando os valores de probabilidade de roubo de carga, agora será analisado a influência do valor da carga no comportamento do roteiro, considerando diferentes valores de carga, utilizando os dados de probabilidade de roubo de carga mostradas na Seção 3.3 e a utilização dos 5 veículos. A Figura 8 mostra a quantidade de veículos utilizados pela variação do valor da carga, onde cada veículo realiza um único roteiro.

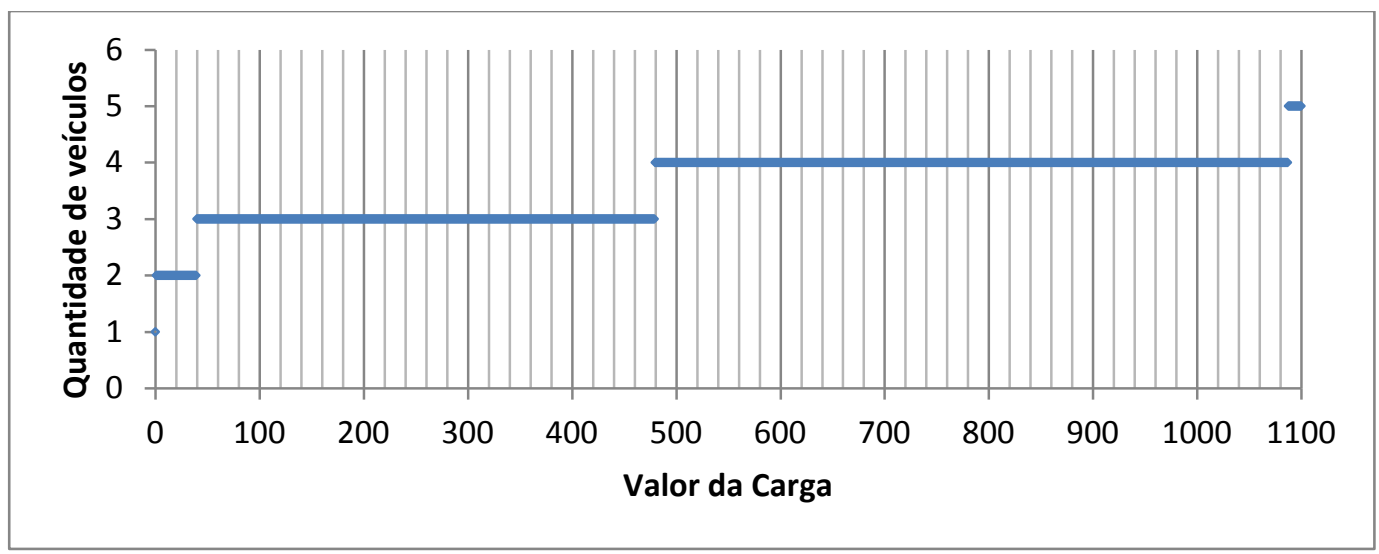

Figura 8: Quantidade de veículos por valor de carga.

Fonte: Autor, 2015.

Ao visualizar a figura acima pode ser perceber que à medida que o valor da carga aumenta é preferível fracionar a carga em mais veículos para minimizar o risco da perda. Ao valor de carga igual a zero utiliza-se apenas um veículo, quando o valor fica entre $R \$ 1,00$ e $R \$ 39,00$ é preferível utilizar 2 veículos, já com o valor entre $R \$ 40,00$ e $R \$ 479,00$ o modelo otimiza utilizando apenas 3 veículos, passa-se a utilizar 4 veículos quando a faixa do valor de carga se encontra entre $R \$ 479,00$ e $R \$ 1.087,00$ e a partir de $R \$ 1.088,00$, para este exemplo, é escolhido utilizar 5 veículos.

\section{5}

\section{Estratégia de Solução}

Como descrito no item 2.8, os problemas de roteirização de veículos são NP-hard, e o problema tratado nesta dissertação também se encaixa nessa classe de problemas combinatórios de difícil resolução, o que justifica o uso de heurísticas e Metaheurísticas para a sua resolução. 
Deve-se ressaltar que o solver CPLEX 12.4, utilizado nas Seções de validação e análise do modelo, é uma referência para resolver problemas de otimização, mas não é capaz de resolver esse modelo na sua forma exata para instâncias elevadas, acima de 15 nós. Portanto escolheu-se o Simulated Annealing, pois apesar da sua simplicidade, existem diversos trabalhos com resultados excelentes obtidos para diversos tipos de problema de otimização.

Dessa forma, é implementada a heurística de distribuição e a Metaheurística Simulated Annealing - SA, para resolução do problema estudado. A solução inicial é gerada pela heurística de distribuição. A seguir será apresentado o SA segundo Metropolis et al. (1953), Kirkpatrick et al. (1983) e Mauri (2006) e Pereira \& Azevedo (2013).

\subsection{1}

\section{Simulated Annealing}

A metaheurística Simulated Annealing - SA foi desenvolvida por Kirkpatrick et al. (1983) para utilização na resolução de problemas de otimização combinatória. O SA se baseia em um processo de mecânica estática modelado inicialmente por Metropolis et al. (1953), que simula um conjunto de átomos em equilíbrio em uma certa temperatura utilizando o método de Monte Carlo para integração numérica multidimensional.

A inspiração da Metaheurística advém do processo de tempero de sólidos. Neste processo, um sólido é aquecido até atingir altas temperaturas, permitindo grande movimentação de átomos, e a partir deste ponto é resfriado de maneira gradual e lentamente, de forma que os átomos se estruturem de forma organizada e a substância cristalize ao final do resfriamento, o que a permite obter propriedades diferentes do estado anterior (como maior dureza e resistência). Alterando-se a analogia para problemas de otimização combinatória, os diferentes estados de energia correspondem aos diferentes calores da solução objetivo e o estado de energia mínima corresponde à solução ótima.

O algoritmo então permite que movimentos de piora sejam feitos na função objetivo, de maneira a não se prender em ótimos locais. Para tal, o SA baseia-se no seguinte: o procedimento principal consiste em um loop que gera aleatoriamente o valor de uma solução vizinha $S$ ', em cada iteração, considerando a energia $S$ do sistema como o valor da função objetivo da solução atual. E então a cada geração de um vizinho $S^{\prime}$ de $S$, é testado à variação do 
valor da função objetivo, isto é, $\Delta=f\left(S^{\prime}\right)-f(S)$. Para um problema de minimização, se $\Delta \leq 0$, ou seja caso a solução vizinha permita melhorias na função objetivo ou mantenha a mesma, a solução é imediatamente aceita. Porém para os casos em que $\Delta>0$, a solução vizinha candidata também poderá ser aceita, segundo a probabilidade de aceitação $P(\Delta)=e^{-\Delta / T}$, onde $T$ é a temperatura total do sistema, que regula a probabilidade de aceitação de soluções de pior custo. $O$ valor de $T$ diminui gradualmente a cada iteração conforme uma taxa de resfriamento $\beta(0<\beta<1)$.

A temperatura $T$ assume, no inicio, um valor $T_{0}$ elevado. SAmax é um parâmetro do método, que representa o número fixo de iterações necessárias para atingir o equilíbrio térmico em uma dada temperatura. Com esse procedimento, no início, existe uma probabilidade maior de escapar de mínimos locais e, à medida que $T$ se aproxima do zero, o algoritmo comporta-se como método de descida, visto que reduz as chances de se aceitar movimentos de piora $\left(T \rightarrow 0 \Rightarrow e^{-\Delta / T} \rightarrow 0\right)$.

O processo termina quando a temperatura alcança um valor próximo de zero, que é conhecido como temperatura de congelamento, $T_{c}$, e nenhuma solução que piore o valor da atual solução é aceita, ou seja, quando o sistema está estável. A solução resultante evidencia o encontro de um mínimo local, que em alguns casos pode ser um mínimo global. Os parâmetros de controle do procedimento são a taxa de resfriamento $\beta$, o número de iterações para cada temperatura $S A \max$, a temperatura inicial $T_{0}$ e a temperatura de congelamento $T_{c}$.

Ao aplicar o SA, é necessário definir um método para geração de uma solução inicial $S$, um método de geração de soluções vizinhas $S^{\prime}$ (estrutura de vizinhança), e uma função objetivo $f(S)$ a ser otimizada.

\subsubsection{1}

\section{Geração de solução inicial}

Para a presente dissertação, a geração da solução inicial é a partir da heurística de distribuição, a qual é responsável pela roteirização dos veículos, isto é, pela organização dos agrupamentos dos locais nas rotas e da sequência de atendimento destes.

$\mathrm{Na}$ heurística apresentada na Figura 9, são geradas inicialmente $m$ rotas vazias, sendo alocado, a cada uma delas, um veículo específico. Em seguida, todas as demandas de transporte dos clientes são atribuídas aleatoriamente, 
porém de forma uniforme, a essas rotas, isto é, as $n$ requisições são divididas igualmente entre os $m-1$ veículos. Obviamente em alguns casos a divisão de $n$ por $m$ não será inteira, e nesses casos a última rota deverá atender as requisições restantes. A seleção das requisições e das rotas que as atenderão também é aleatória.

Devido ao fato de toda rota começar e terminar no depósito, então se deve considerar que estes locais sempre serão alocados como primeiro e último ponto em cada rota criada.

1. CRIAR ( $m$ rotas vazias, e atribuir aos $v$ veículos);

2. CRIAR (uma lista $L$ com todos os $n$ clientes);

3. PARA (cada rota $k, k=1,2, \ldots, m-1$ ) FACA

4. SELECIONAR $(\lfloor n / m\rfloor$ clientes de $L)$;

5. INSERIR $(\lfloor n / m\rfloor$ clientes na rota $k)$;

6. RETIRAR (os $\lfloor n / m\rfloor$ clientes da lista $L$ );

7. FIM-PARA;

8. INSERIR os clientes restantes da lista $L$ na rota $m$;

9. FIM

Figura 9: Heurística de distribuição.

Fonte: Mauri (2006).

\subsubsection{2}

\section{Estrutura de vizinhança}

Uma solução pode apresentar diversas estruturas de vizinhança. A estrutura de vizinhança está essencialmente associada ao conceito de movimento. Uma solução $S$ 'é considerada vizinha da solução atual $S$ se esta está a um movimento de distância de $S$. O conjunto de todos os vizinhos de $S$ é a vizinhança desta solução.

Um movimento é uma forma de alterar uma solução, transformando-a em outra. Considerando um problema de roteirização de veículos - VRP, a permuta de um cliente de um roteiro com um cliente de outra rota é um tipo de movimento, outro tipo de movimento é a remoção de um cliente de uma rota e pôr em outra (sem que esta última perca clientes). Estes dois movimentos criam duas estruturas de vizinhança distintas. Os movimentos geralmente são incrementais, o que possibilita que sejam realizados milhares destes por iteração. 
No caso do VRP, diferenciam-se dois tipos de movimento: intra-rotas e inter-rotas. São considerados movimentos intra-rotas os que são executados dentro de uma mesma rota, como a troca de dois clientes de posição. Os interrotas são efetuados entre duas ou mais rotas.

Os movimentos podem ser configurados para diferenciar entre soluções factíveis e infactíveis. Podendo existir movimentos que transformam uma solução factível em uma infactível e vice-versa.

Para esta dissertação, como estrutura de vizinhança, utilizaram-se três movimentos de troca, Reordenar rota, Realocar ponto e Trocar pontos.

Vale ressaltar que os movimentos citados acima não são válidos para os depósitos, visto que os mesmos são fixos em todas as rotas, por conseguinte não podem ser alterados.

O primeiro movimento citado, Reordenar rota, compreende em selecionar uma rota qualquer já pertencente à solução, selecionar um ponto qualquer nessa rota, selecionar uma nova posição para esse ponto e trocar sua posição para a nova (movimento intra-rotas). Verificar Figura 10.

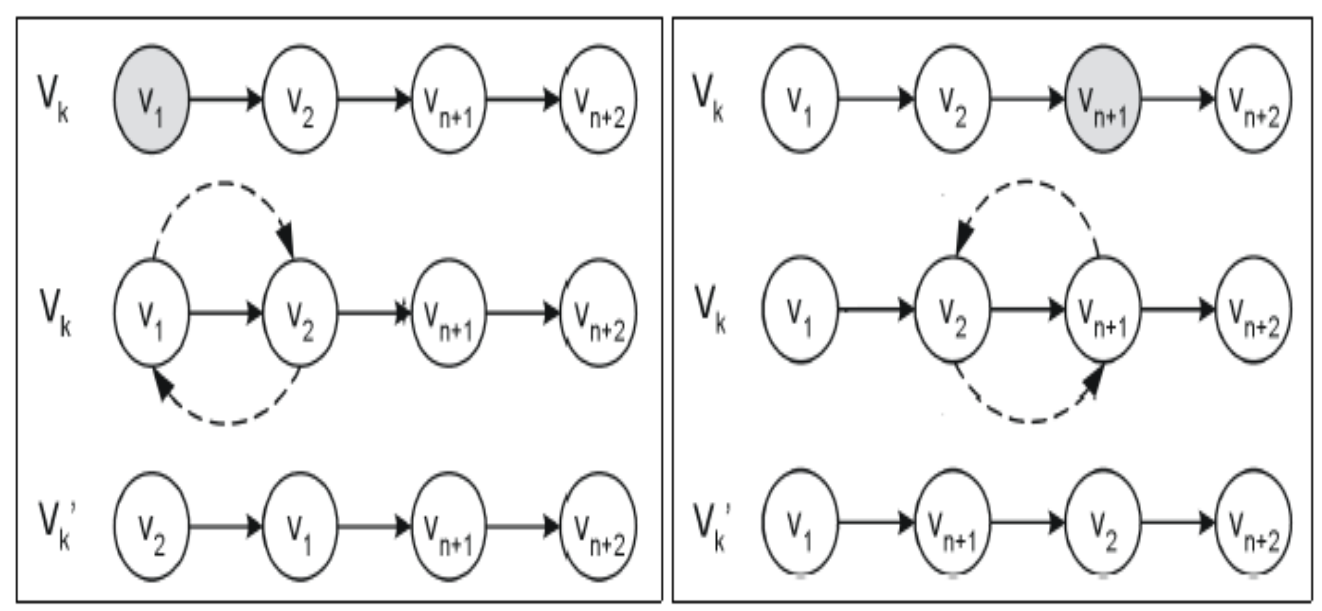

Figura 10: Movimento Reordenar rota.

Fonte: Mauri (2006).

O movimento Realocar pontos consiste em selecionar duas rotas, aleatoriamente, pertencentes à atual solução, selecionar um ponto qualquer em apenas uma das duas rotas, retirá-la de sua rota original e adicionar em outra, em uma posição aleatória (movimento inter-rotas). Pode ser visualizado na Figura 11. 


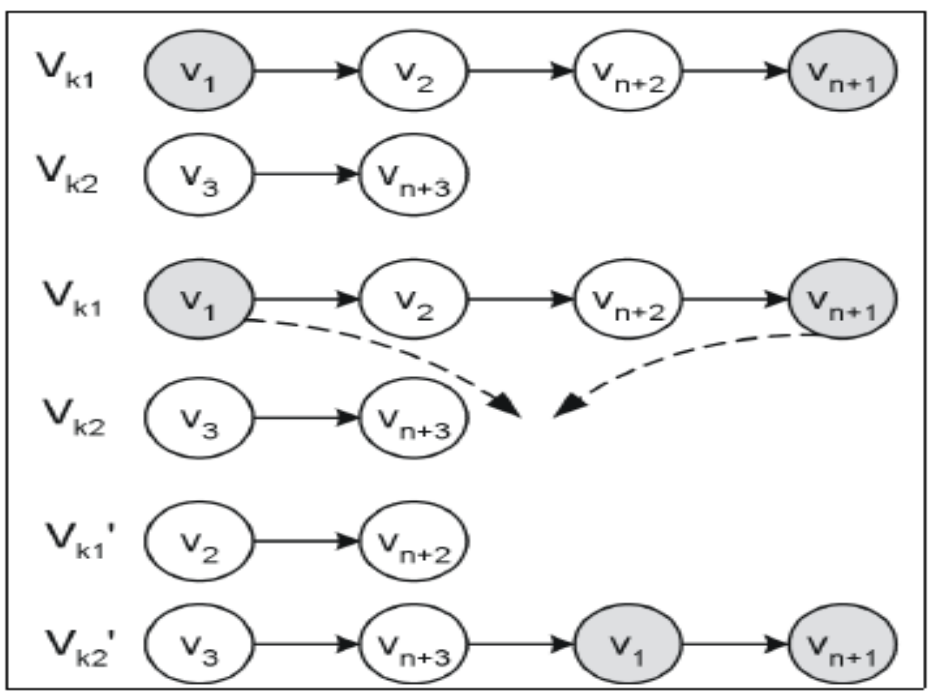

Figura 11: Movimento Realocar ponto.

Fonte: Mauri (2006).

O movimento Trocar ponto seleciona duas rotas aleatórias pertencentes à solução atual, selecionar um ponto qualquer em cada uma das duas rotas selecionadas, e trocá-las (movimento inter-rotas). Ilustrado na Figura 12.

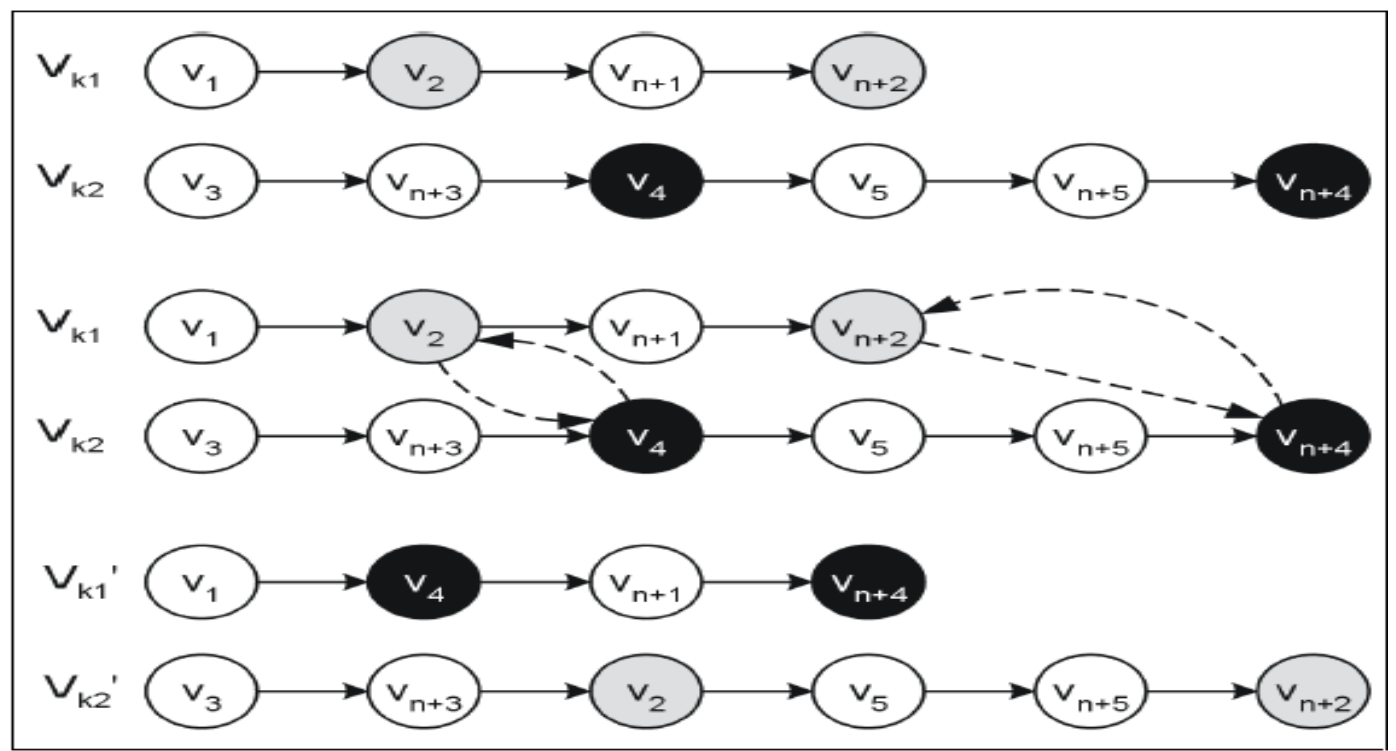

Figura 12: Movimento Trocar ponto.

Fonte: Mauri (2006).

O SA implementado considera que cada solução vizinha é gerada por apenas um desses movimentos, sendo a sua escolha realizada de maneira aleatória, contudo uniformemente distribuída, viabilizando assim uma ótima diversidade entre as soluções intermediárias encontradas, e, por conseguinte uma boa exploração do espaço de solução. 
A função objetivo $f(S)$ usada para a resolução do problema é descrita pela equação (3.1) e as restrições mostradas no modelo proposto (3.2 a 3.19), ambas na Seção 3.2, são atendidas na heurística de distribuição e nos movimentos de troca aqui descritos. Um pseudocódigo do Simulated Annealing implementado, adaptado, pode ser visualizado na Figura 13. A diferença do pseudocódigo do Mauri (2006) foi o acréscimo da linha 21, que visa ordenar no final do processo as menores cargas nos veículos de menores custos.

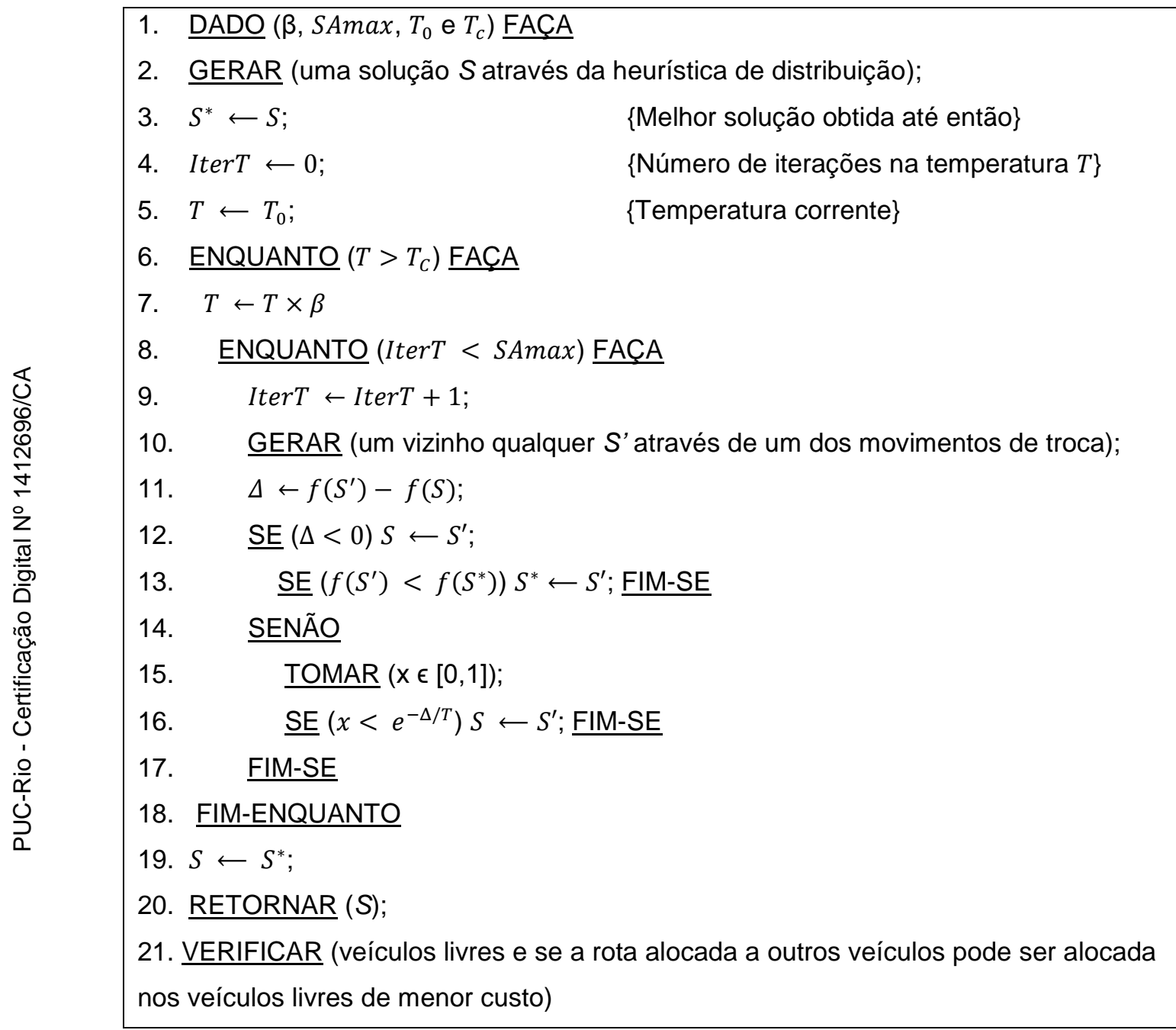

Figura 13: Pseudocódigo do Simulated Annealing implementado. Fonte: Adaptado de Mauri (2006). 


\section{4}

\section{Estudo de Caso}

O modelo proposto (VRPCTP) foi implementado para resolver o problema de distribuição de uma empresa de produtos farmacêuticos. A Seção 4.1 apresenta a empresa utilizada como estudo de caso. A Seção 4.2 apresenta os dados utilizados. Ressaltar que foram utilizadas 2 instâncias. As instâncias variam em número de clientes a atender e pretendem demonstrar a aplicabilidade do modelo e método de resolução desenvolvido. A Seção 4.3 apresenta os resultados obtidos para a primeira e segunda instância, respectivamente com 151 e 465 pontos de entrega.

\section{1} Apresentação da Empresa

O presente estudo de caso foi realizado em uma empresa de distribuição de produtos farmacêuticos, fundada em 1961 no Estado do Rio de Janeiro. Em 1996 abriu sua primeira filial, em Minas Gerais. Em 1998 abriu outra filial no Espírito Santo. Em 2001 abriram filiais no Paraná e no Distrito Federal. Em 2004 abriu filial na Bahia. Em 2007 abriram filiais em Pernambuco e Ceará, adquiriu um Centro de Distribuição (CD) no Rio Grande do Sul, e outra filial em Goiás. Em 2013 entrou para o mercado de varejo farmacêutico adquirindo redes de farmácias. Em 2014 criou-se uma Joint Venture. Neste momento a empresa é responsável por abastecer o varejo das farmácias dos Estados em que se encontra.

O tipo de serviço realizado pelo CD tem elevada frequência de entregas, baixos volumes, dispersão geográfica dos clientes e relevante incidência de roubo de carga. Desta maneira, visando melhorar o nível de serviço, foi realizado esse estudo para aprimorar o processo de roteirização minimizando os custos de transporte da empresa e as possíveis perdas por roubo de carga. O CD que foi utilizado como base para a realização dessa dissertação é localizado no Estado do Rio de Janeiro. 


\section{2 \\ Coleta e Tratamento dos Dados}

O estudo de caso é implementado a partir de um Centro de Distribuição (CD). O mesmo utiliza de uma frota própria para a realização de todas as entregas de mercadorias, sendo composta por 60 veículos. Os modelos de veículos do CD utilizados nas operações da empresa podem ser visualizados na Tabela 15, com as respectivas quantidades de cada modelo, capacidades e custos de transporte por $\mathrm{km}$.

Tabela 15: Caracterização dos veículos

\begin{tabular}{llll}
\hline Tipo de veículos & Quantidade & Capacidade (SKU) & $\begin{array}{l}\text { Custo de Transporte } \\
(\mathrm{R} \$ / \mathrm{km})\end{array}$ \\
\hline Fiorino & 36 & 140 & 0,620 \\
Kombi & 12 & 180 & 0,647 \\
Ducato & 6 & 300 & 0,734 \\
Iveco & 3 & 450 & 0,760 \\
Sprinter & 3 & 600 & 0,810 \\
\hline
\end{tabular}

Fonte: Autor, 2015.

Para se representar a rede das farmácias, de tal forma que se possam avaliar as distâncias a serem percorridas nas rotas propostas, assim como calcular o tempo necessário para percorrê-las, é necessário conhecer a localização de cada ponto. Portanto, foi realizado um levantamento dos dados sobre a localização dos clientes e assim construído uma matriz Origem/Destino (O/D) assimétrica. Esta matriz O/D foi desenvolvida a partir das coordenadas (latitude e longitude), fornecidas pela empresa e por fim com a obtenção das distâncias por meio do Google Directions API, o qual é um serviço que calcula rotas entre locais usando uma solicitação HTTP, permitindo a obtenção das distâncias reais e atualizadas usando uma série de pontos de referências. $\mathrm{O}$ código fonte foi desenvolvido em Visual Basic for Applications (VBA) por Bernades (2015).

Para a Seção 4.3, a qual se configura em uma aplicação do Simulated Annealing em um contexto real, para isto utilizou-se duas instâncias, uma para melhor analisar os resultados do algoritmo e outra com o intuito gerar o melhor roteiro para a demanda de um dia de entregas pelo Centro de Distribuição (CD). Desta maneira, tem-se uma instância de 151 pontos, sendo 150 farmácias e 1 CD e outra com 465 nós, sendo 464 farmácias e 1 CD. 
A empresa tem um horário de funcionamento de $8 \mathrm{hr}$ a $17 \mathrm{hr}$, com parada para almoço de $1 \mathrm{hr}$, portanto veículos tem um tempo de ciclo de $8 \mathrm{hr}$. As farmácias podem receber as mercadorias entre $8 \mathrm{hr}$ e $18 \mathrm{hr}$.

Vale reforçar que os clientes não apresentam janelas de tempo específicas, portanto o modelo apesar de ter restrições para tal problema, a restrição de janela de tempo foi definida de maneira a tornar o problema mais geral.

A matriz de tempo de deslocamento tem como base a matriz O/D e a velocidade média de $38 \mathrm{~km} / \mathrm{h}$, a partir de dados históricos da empresa. O tempo de atendimento nos clientes, ou tempo de descarga, é uma média do histórico da empresa igual 404 seg..

Para o problema utilizado na Seção 4.3 têm-se as seguintes demandas. É importante ressaltar que para a instância de 151 pontos, foram utilizadas as 150 primeiras farmácias. Visualizadas na Tabela 16.

Tabela 16: Demanda 464 farmácias - Problema Real

\begin{tabular}{llllllllllllllll}
\hline Farmácia & 1 & 2 & 3 & 4 & 5 & 6 & 7 & 8 & 9 & 10 & 11 & 12 & 13 & 14 & 15 \\
Demanda & 117 & 2 & 1 & 1 & 60 & 2 & 1 & 5 & 1 & 2 & 1 & 7 & 24 & 2 & 1 \\
\hline Farmácia & 16 & 17 & 18 & 19 & 20 & 21 & 22 & 23 & 24 & 25 & 26 & 27 & 28 & 29 & 30 \\
Demanda & 2 & 1 & 12 & 13 & 3 & 15 & 2 & 1 & 1 & 2 & 1 & 1 & 2 & 3 & 3 \\
\hline Farmácia & 31 & 32 & 33 & 34 & 35 & 36 & 37 & 38 & 39 & 40 & 41 & 42 & 43 & 44 & 45 \\
Demanda & 2 & 1 & 1 & 1 & 1 & 1 & 1 & 2 & 3 & 1 & 1 & 1 & 1 & 1 & 2 \\
\hline Farmácia & 46 & 47 & 48 & 49 & 50 & 51 & 52 & 53 & 54 & 55 & 56 & 57 & 58 & 59 & 60 \\
Demanda & 1 & 17 & 13 & 3 & 4 & 5 & 2 & 1 & 2 & 8 & 2 & 1 & 20 & 10 & 2 \\
\hline Farmácia & 61 & 62 & 63 & 64 & 65 & 66 & 67 & 68 & 69 & 70 & 71 & 72 & 73 & 74 & 75 \\
Demanda & 1 & 10 & 2 & 1 & 1 & 1 & 1 & 6 & 2 & 3 & 15 & 1 & 1 & 3 & 2 \\
\hline Farmácia & 76 & 77 & 78 & 79 & 80 & 81 & 82 & 83 & 84 & 85 & 86 & 87 & 88 & 89 & 90 \\
Demanda & 3 & 1 & 1 & 1 & 4 & 10 & 1 & 4 & 7 & 2 & 2 & 1 & 1 & 2 & 3 \\
\hline Farmácia & 91 & 92 & 93 & 94 & 95 & 96 & 97 & 98 & 99 & 100 & 101 & 102 & 103 & 104 & 105 \\
Demanda & 3 & 1 & 4 & 1 & 2 & 1 & 7 & 3 & 1 & 2 & 1 & 3 & 5 & 1 & 4 \\
\hline Farmácia & 106 & 107 & 108 & 109 & 110 & 111 & 112 & 113 & 114 & 115 & 116 & 117 & 118 & 119 & 120 \\
Demanda & 22 & 3 & 5 & 1 & 3 & 1 & 3 & 3 & 1 & 2 & 3 & 1 & 3 & 4 & 1 \\
\hline Farmácia & 121 & 122 & 123 & 124 & 125 & 126 & 127 & 128 & 129 & 130 & 131 & 132 & 133 & 134 & 135 \\
Demanda & 1 & 3 & 13 & 8 & 1 & 2 & 2 & 5 & 1 & 1 & 3 & 3 & 4 & 1 & 19 \\
\hline Farmácia & 136 & 137 & 138 & 139 & 140 & 141 & 142 & 143 & 144 & 145 & 146 & 147 & 148 & 149 & 150 \\
Demanda & 1 & 1 & 10 & 1 & 4 & 1 & 1 & 4 & 3 & 4 & 1 & 1 & 1 & 8 & 1 \\
\hline Farmácia & 151 & 152 & 153 & 154 & 155 & 156 & 157 & 158 & 159 & 160 & 161 & 162 & 163 & 164 & 165 \\
Demanda & 4 & 1 & 1 & 1 & 3 & 1 & 1 & 2 & 2 & 3 & 2 & 2 & 3 & 9 & 2 \\
\hline Farmácia & 166 & 167 & 168 & 169 & 170 & 171 & 172 & 173 & 174 & 175 & 176 & 177 & 178 & 179 & 180 \\
Demanda & 1 & 2 & 2 & 3 & 2 & 2 & 3 & 2 & 2 & 2 & 2 & 2 & 12 & 4 & 17 \\
\hline Farmácia & 181 & 182 & 183 & 184 & 185 & 186 & 187 & 188 & 189 & 190 & 191 & 192 & 193 & 194 & 195 \\
Demanda & 1 & 6 & 1 & 2 & 8 & 3 & 7 & 2 & 2 & 2 & 3 & 2 & 3 & 1 & 1 \\
\hline
\end{tabular}


Farmácia 196197198199200201202203204205206207208209210 $\begin{array}{llllllllllllllll}\text { Demanda } & 17 & 3 & 10 & 4 & 32 & 1 & 1 & 7 & 1 & 3 & 3 & 1 & 1 & 1 & 2\end{array}$

Farmácia $2112212213214215216217218219220221222 \quad 223224225$

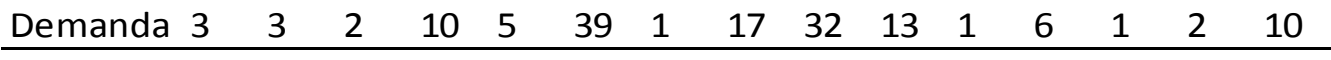

Farmácia $2226227228229230231232233234235236 \quad 237238239240$

\begin{tabular}{llllllllllllllll} 
Demanda & 1 & 3 & 26 & 2 & 2 & 1 & 4 & 4 & 1 & 1 & 9 & 2 & 8 & 2 & 19 \\
\hline
\end{tabular}

Farmácia $241242243244245246247 \quad 248249250251252 \quad 253254255$

\begin{tabular}{|c|}
\hline emanda 3 \\
\hline
\end{tabular}

Farmácia 256257258259260261262263264265266267268269270

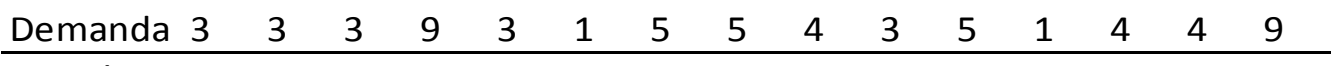

Farmácia 271272273274275276277278279280281282283284285

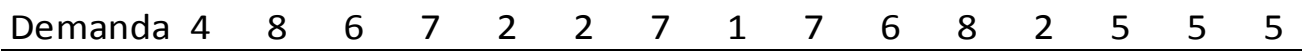

Farmácia 286287288289290291292293294295296297298299300

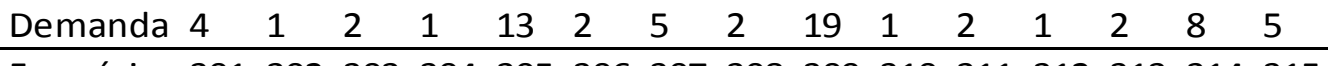

Farmácia $301302303 \quad 304305306307308309310311312313314315$

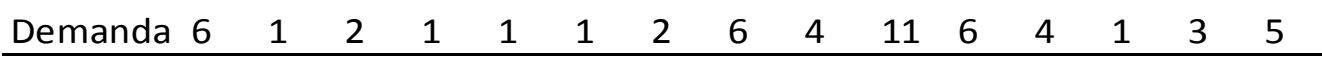

Farmácia 316317318319320321322323324325326327328329330 $\begin{array}{llllllllllllllll}\text { Demanda } & 1 & 7 & 2 & 1 & 4 & 2 & 11 & 6 & 4 & 2 & 6 & 3 & 8 & 8 & 5\end{array}$

Farmácia $331332333334335336337338339340341342343 \quad 344345$

$\begin{array}{llllllllllllllll}\text { Demanda } & 18 & 24 & 6 & 10 & 6 & 2 & 3 & 10 & 26 & 6 & 1 & 2 & 14 & 4 & 1\end{array}$

Farmácia 346347348349350351352353354355356357358359360

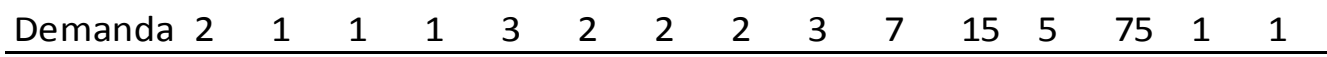

Farmácia 361362363364365366367368369370371372373374375

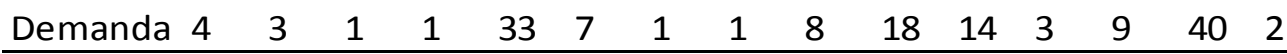

Farmácia 376377378379380381382383384385386387388389390

\begin{tabular}{llllllllllllllll} 
Demanda & 1 & 2 & 2 & 3 & 1 & 1 & 9 & 22 & 10 & 1 & 1 & 1 & 2 & 17 & 8 \\
\hline
\end{tabular}

Farmácia 391392393394395396397398399400401402403404405 $\begin{array}{llllllllllllllll}\text { Demanda } & 1 & 7 & 2 & 4 & 11 & 3 & 10 & 7 & 2 & 2 & 3 & 1 & 3 & 5 & 3\end{array}$

Farmácia 406407408409410411412413414415416417418419420

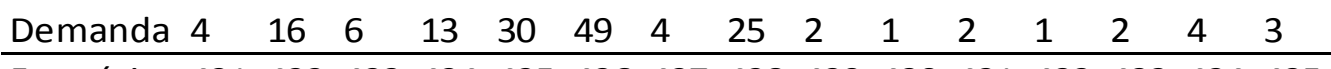

Farmácia $421422 \quad 423 \quad 424425426427428429430431432433434435$

\begin{tabular}{llllllllllllllll} 
Demanda & 3 & 8 & 1 & 1 & 19 & 17 & 4 & 3 & 1 & 1 & 18 & 1 & 2 & 2 & 2 \\
\hline
\end{tabular}

Farmácia $436437438439440441442443444445446 \quad 447448449450$

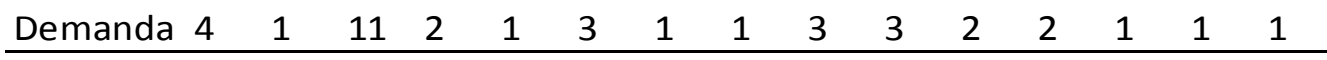

Farmácia 451452453454455456457458459460461462463464

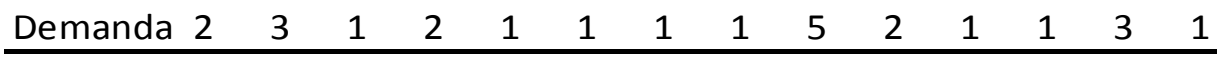

Fonte: Autor, 2015.

Com base no histórico apresentado pela empresa, utilizou-se uma média do valor de carga por SKU, sendo igual a $R \$ 387,00$. O parâmetro correspondente à porcentagem paga às seguradoras em caso de roubo de carga é de $3 \%(\alpha)$, dados da empresa, i.e., em caso de roubo o CD tem que pagar $3 \%$ do valor da carga que foi roubado.

Para saber a probabilidade de roubo de carga das regiões onde estão situadas as farmácias e com isso fazer uma roteirização, foram calculadas a 
partir de dados de roubos de carga registrados pela empresa nas regiões atendidas. A empresa detém de um histórico de visitas realizadas e os registros de roubo de carga por meio de boletins de ocorrência registrados em delegacias das regiões do Estado do Rio de Janeiro. Desta maneira, podem-se verificar quantas visitas ocorreram nas regiões e o número de roubos registrados pela empresa obtendo assim a probabilidade de roubo. Para identificar as regiões em que os clientes estão associados foi verificado os Departamentos de Polícia (DP) associados a essas regiões, visto que os registros de roubo que aconteceram na empresa foram registrados nos DPs da região onde se localizam os clientes. As probabilidades de roubo de carga dos 464 farmácias podem ser verificadas na Tabela 17. Os DP's relacionados aos clientes representam as regiões onde se situam, portando clientes que estão em uma mesma região tem o mesmo DP e consequentemente a mesma probabilidade de roubo, vale ressaltar que existem casos onde se tem mais de um DP atendendo uma mesma região.

Tabela 17: Probabilidade de roubo de carga

\begin{tabular}{lll}
\hline DP & Clientes & Prob. (\%) \\
\hline 9 & $183,185,188,191,192,196,199,200,202,203,205,210$ & 0,06 \\
10 & $190,193,194,198,207,208,211,216,218,219,220,227$ & 0,03 \\
11 & 282 & 0,01 \\
14 & $225,228,234,235,248$ & 0,04 \\
15 & $206,214,289,291$ & 0,03 \\
16 & $306,311,321,322,327,329,331,332,341,345,347,355$, & 0,10 \\
17 & $360,365,372$ & 0,45 \\
20 & 129 & 0,17 \\
21 & $130,174,178,181$ & 0,71 \\
22 & $74,75,85,92,94,113,114,116,117$ & 0,72 \\
23 & $58,63,64,73$ & 0,27 \\
24 & $87,144,160,167,179,180,182,186$ & 0,38 \\
26 & 18,80 & 0,23 \\
27 & $15,24,26,32,37,38,41,42$ & 0,53 \\
28 & $82,83,84,86$ & 0,16 \\
29 & 56,78 & 0,29 \\
30 & 53 & 0,35 \\
31 & $20,66,76,79$ & 0,50 \\
32 & $106,118,119,266,288,300,302,344$ & 0,17 \\
33 & $89,109,115$ & 0,54 \\
34 & $96,97,102,104,110,111,122,123,127,128,135,137$, & 1,28 \\
& 155,201 & \\
35 & $148,153,168,177,187,189,209,212,213,215,217,224$, & \\
& $230,232,241,246,249,250,251,252,253,255,257,258$, & 0,90 \\
36 & $265,269,271,287,293,294,305$ & 0,22 \\
& $336,352,354,358,363,377,390$ & \\
& & \\
& & \\
& &
\end{tabular}




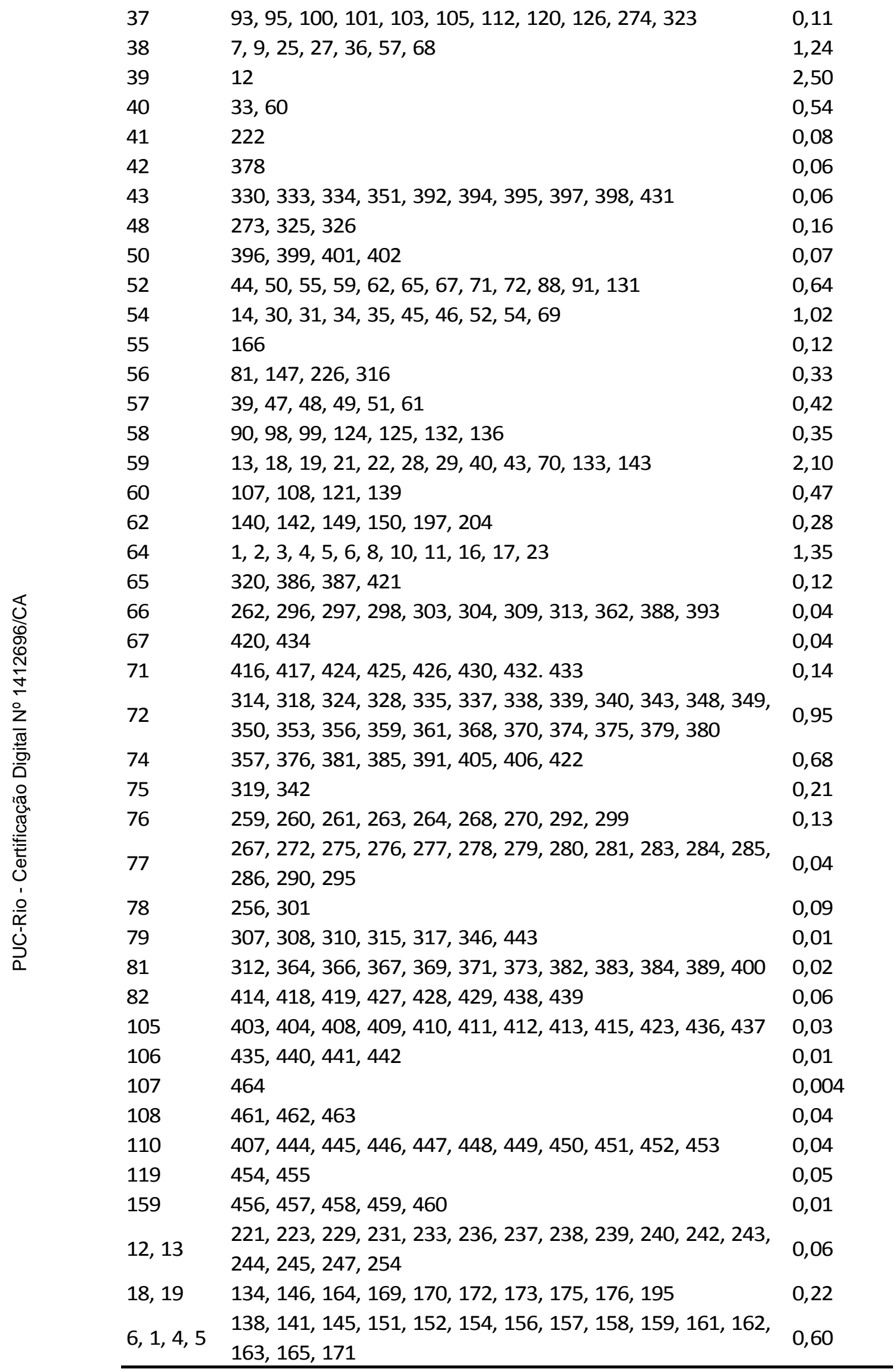

Fonte: Autor, 2015. 


\section{3 Apresentação e Análise dos Resultados Obtidos}

Nesta Seção o modelo VRPCTP será testado em duas instâncias, sendo uma com 151 nós e outra com 465 nós.

A fim de analisar a relevância dos custos de roubo de carga sobre a geração de rotas, foram realizadas análises sobre o parâmetro $\alpha$. Considerou-se no estudo de caso os dados da empresa, onde $\alpha=3 \%$ (agora designado de Teste 1) e foram realizados dois testes adicionais, o primeiro com $\alpha=0 \%$ (agora chamado de Teste 2) e o segundo com $\alpha=100 \%$ (agora nomeado de Teste 3 ).

Vale ressaltar que $\alpha=0$ corresponde a um cenário livre de custos roubo para a empresa, ou seja, a companhia de seguros pagaria as perdas totais em relação aos SKUs roubados. Se este fosse o caso, a empresa iria realizar uma roteirização tradicional sem considerar a questão do roubo de carga (é equivalente a eliminar o item de custo roubo da função objetivo). Já com o $\alpha=$ $100 \%$ corresponde a um cenário em que a empresa não está protegido por um seguro e, portanto, deve arcar com todos os prejuízos em relação roubado SKUs. E por fim, a utilização do $\alpha=3 \%$ é devido à empresa do estudo de caso arcar com 3\% do valor da carga roubada.

Além disso, é realizada outra análise somente para a instância de 151 nós (Seção 4.3.1), com o intuito de verificar a influência que ocorre ao adicionar uma restrição que limite a quantidade mínima de carga por veículo ao sair do depósito (agora conhecida como Teste 4).

Para todos as instâncias resolvidas nesta Seção, utilizou-se o Simulated Annealing (SA) implementado no VS Express 2013 for Desktop, o computador utilizado detém um processador Intel Core i5 2,67 Ghz e 4GB de memória RAM.

O SA foi aplicado considerando os seguintes parâmetros: $T_{0}=20.000$, $\beta=0,975, T_{c}=0,01$ e $S A_{\max }=1.000$.

Para a aplicação do SA utilizou-se a metodologia de Mauri (2006), tal metodologia visa validar o algoritmo realizando 5 testes para a instância utilizada. Portanto serão apresentadas tabelas com resumos dos resultados obtidos nesses testes $(f(S)$ é o valor da função objetivo obtido). A coluna "Melhor $f(S)$ " indica o valor da função objetivo da melhor solução encontrada nos 5 testes realizados. A coluna " $f(S)$ média" apresenta a média aritmética das 5 funções objetivo encontradas, e a coluna "Desvio" apresenta a variância obtida entre esses testes, o cálculo do Desvio é definido por Mauri (2006) (ver equação $(4.1))$. 
Desvio $=\left(\frac{f(S) \text { média }- \text { Melhor } f(S)}{\text { Melhor } f(S)}\right) \times 100$

\subsection{1 \\ Instância de 151 nós}

Considerando o modelo proposto, utilizando $\alpha=3 \%$ (Teste 1 ), a melhor solução obtida utiliza 19 veículos e representa um custo total de $R \$ 741,12$, dos quais $R \$ 550,51$ estão relacionados com o transporte e $R \$ 190,61$ são relativos a custos de roubo de carga. O desvio entre as cinco gerações de soluções é de $4,25 \%$. A Tabela 18 demonstra o resumo e a Tabela 19 mostra os resultados completos. O tempo de execução foi de $1524 \mathrm{seg}$.

Tabela 18: Resumo da solução obtida pelo Simulated Annealing - $\alpha=3 \%-151$ nós

\begin{tabular}{|c|c|c|c|c|c|}
\hline Instância & $\begin{array}{l}\text { No de veículos } \\
\text { alocados }\end{array}$ & $\begin{array}{l}\text { No de requisições } \\
\text { (SKU) }\end{array}$ & $\begin{array}{l}f(S) \text { média } \\
(R S)\end{array}$ & $\begin{array}{l}\text { Melhor } f(S) \\
(R S)\end{array}$ & Desvio (\%) \\
\hline 151 & 19 & 697 & 772,59 & 741,12 & 4,25 \\
\hline
\end{tabular}

Tabela 19: Melhor solução obtida pelo Simulated Annealing $-\alpha=3 \%-151$ nós

\begin{tabular}{|c|c|c|c|c|c|c|c|}
\hline Rota & Veículo & Roteiro & $z_{i j}^{v}(\mathrm{SKU})$ & $\begin{array}{l}\text { Taxa de Utilização } \\
\text { da Capacidade }\end{array}$ & $\begin{array}{l}\text { Tempo } \\
\text { de Ciclo } \\
(\mathrm{Hr})\end{array}$ & $\begin{array}{l}\text { Custo de } \\
\text { Transporte } \\
\text { (RS) }\end{array}$ & $\begin{array}{l}\text { Custo de } \\
\text { Roubo } \\
\text { (RS) }\end{array}$ \\
\hline 1 & Fiorino & 061120 & 5320 & $4 \%$ & 0,58 & 5,83 & 1,57 \\
\hline 2 & Fiorino & 019970 & 15210 & $11 \%$ & 0,86 & 12,45 & 4,08 \\
\hline 3 & Fiorino & 013314213914014312143100 & 1814131284320 & $13 \%$ & 2,50 & 37,63 & 9,15 \\
\hline 4 & Fiorino & 0266368747594736457250 & 201917118654320 & $14 \%$ & 2,15 & 24,12 & 8,80 \\
\hline 5 & Fiorino & 076971021111151092040 & 211811875410 & $15 \%$ & 2,05 & 27,26 & 7,86 \\
\hline 6 & Fiorino & 07015014910854524546350 & 25222113864210 & $18 \%$ & 2,78 & 41,69 & 10,70 \\
\hline 7 & Fiorino & 013220 & 2620 & $19 \%$ & 0,69 & 10,93 & 6,82 \\
\hline 8 & Fiorino & 095105120126112103934028290 & 272521201815106530 & $19 \%$ & 2,60 & 34,94 & 5,14 \\
\hline 9 & Fiorino & 021180 & 27120 & $19 \%$ & 0,67 & 10,44 & 9,50 \\
\hline 10 & Fiorino & 05062596567441617230 & 3127177654210 & $22 \%$ & 1,82 & 19,14 & 8,01 \\
\hline 11 & Fiorino & 07913114812312711082833724150 & 313027261311873210 & $22 \%$ & 3,00 & 41,70 & 14,92 \\
\hline 12 & Fiorino & 012413213612581909834310 & 322421201996320 & $23 \%$ & 2,55 & 36,27 & 5,89 \\
\hline 13 & Fiorino & $\begin{array}{l}092145134851001011141161178777 \\
8086788453330\end{array}$ & $\begin{array}{l}34332928262423221918 \\
171612109210\end{array}$ & $24 \%$ & 4,55 & 62,36 & 16,91 \\
\hline 14 & Fiorino & 05571911477288996910730140 & 40321714131211108520 & $29 \%$ & 3,39 & 50,80 & 11,92 \\
\hline 15 & Fiorino & $\begin{array}{l}058113129138141146130144384142 \\
3236270\end{array}$ & $\begin{array}{l}472724231312111075432 \\
10\end{array}$ & $34 \%$ & 3,25 & 39,52 & 12,37 \\
\hline 16 & Fiorino & 0394713513712812210496896630 & 54513415149654210 & $39 \%$ & 2,87 & 38,53 & 17,91 \\
\hline
\end{tabular}




\begin{tabular}{llllllll}
17 & Fiorino & 0106119118485161496056120 & 6240363320151411970 & $44 \%$ & 3,25 & 50,23 & 9,73 \\
18 & Fiorino & 0580 & 6550 & $46 \%$ & 0,49 & 6,32 & 10,98 \\
19 & Fiorino & 010 & 1170 & $84 \%$ & 0,13 & 0,34 & 18,35 \\
\hline \multicolumn{3}{r}{} & Média & $26 \%$ & SubTotal & 550,51 & 190,61 \\
\hline
\end{tabular}

Fonte: Autor, 2015.

A melhor solução encontrada apenas usa o veículo de menor capacidade (Fiorinos), e mesmo assim, todos os veículos percorrem os roteiros abaixo da sua capacidade plena, onde a taxa de utilização da capacidade mínima, média e máxima são, respectivamente, 4\%, 26\% e $84 \%$. Este fator é devido à pequena instância e a dispersão geográfica das farmácias, podendo ser verificadas na Figura 14. Outro fator que contribui, em alguns casos, é a probabilidade alta de roubo. A rota 19 detém o valor máximo em virtude de um único clientes solicitar um pedido de 117 SKUs, já na Rota 1 se tem o valor mínimo, que apesar de atender 3 farmácias a soma de suas demandas são de apenas 5 SKUs, vale dizer que estas farmácias da Rota 1 estão localizadas na terceira região mais perigosa, com probabilidade de roubo de carga de 1,35\%. Outro exemplo é a Rota 18 que só serve a farmácia número 5 e 8 . Isso é justificado pela segunda maior demanda que é do cliente 5 (60 SKUs) e as farmácias estão localizadas, também, em uma área com a terceira maior probabilidade de roubo de carga $(1,35 \%)$. Apesar de incluir pouca entrega o custo roubo da rota 18 é a sétima maior entre as 19 rotas.

A Rota 4 é um resultado típico deste modelo e inclui dez farmácias. A primeira farmácia a ser visitada é a farmácia 26 , que tem a menor probabilidade de roubo da rota $(P=0,53 \%)$, seguido da farmácia 63 com $P=0,72 \%$ e farmácia 68 com $P=1,24 \%$. Em seguida, ele visita farmácias 74, 75 e 94 em que estão localizados na mesma região com $P=0,71 \%$, as farmácias 73 e 64, também em uma mesma região, com $\mathrm{P}=0,72 \%$. Finalmente, ele deixa por último as duas farmácias com maiores probabilidades, farmácias 57 e 25 de $P=1,24 \%$.

A Figura 14 mostra a localização das farmácias no Estado do Rio de Janeiro. 


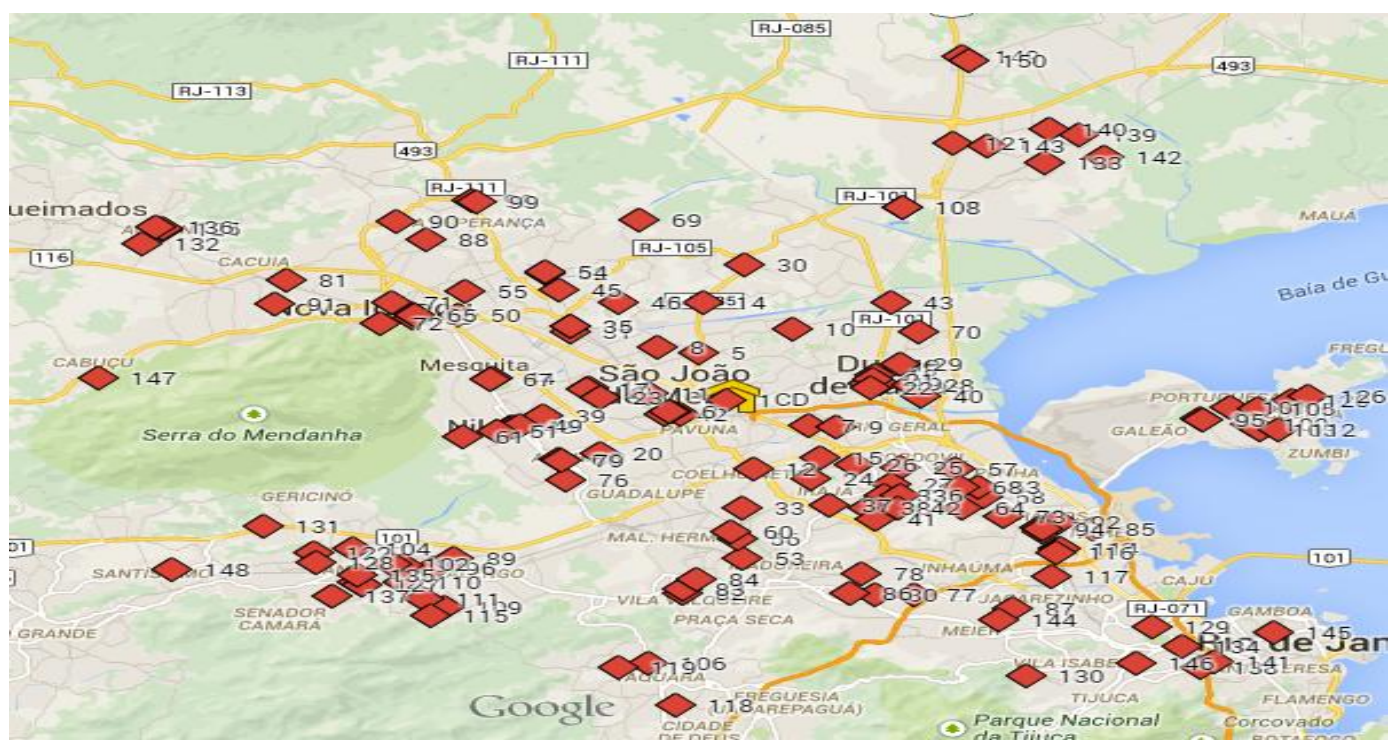

Figura 14: Localização das farmácias - 151 nós.

Fonte: Autor (2015).

A Tabela 20 mostra o resumo dos resultados do Teste 2 ( $\alpha=0 \%$ ), obtendo um baixo desvio nas soluções encontradas (1,85\%). O algoritmo SA resolveu em 936 seg.. Na Tabela 21 podem ser visualizadas as rotas realizadas pela melhor solução obtida, vale ressaltar que a coluna com custo de roubo de carga adicionada é calculada apenas para efeito de comparação (adotando para cálculo $\alpha=3 \%)$.

Tabela 20: Resumo da solução obtida pelo Simulated Annealing - $\alpha=0 \%-151$ nós

\begin{tabular}{llllll}
\hline Instância & $\begin{array}{l}\text { No de veículos } \\
\text { alocados }\end{array}$ & $\begin{array}{l}\text { № de requisições } \\
\text { (SKU) }\end{array}$ & $\begin{array}{l}f(S) \text { média } \\
(R S)\end{array}$ & $\begin{array}{l}\text { Melhor } f(S) \\
(R S)\end{array}$ & Desvio (\%) \\
\hline 151 & 11 & 697 & 521,95 & 512,47 & 1,85 \\
\hline \multicolumn{5}{c}{ Fonte: Autor, 2015. }
\end{tabular}

Tabela 21: Melhor solução obtida pelo Simulated Annealing $-\alpha=0 \%-151$ nós

\begin{tabular}{|c|c|c|c|c|c|c|c|}
\hline Rota & Veículo & Roteiro & $z_{i j}^{v}(\mathrm{SKU})$ & $\begin{array}{l}\text { Taxa de Utilização } \\
\text { da Capacidade }\end{array}$ & $\begin{array}{l}\text { Tempo } \\
\text { de Ciclo } \\
\text { (Hr) } \\
\end{array}$ & $\begin{array}{l}\text { Custo de } \\
\text { Transporte } \\
\text { (RȘ) } \\
\end{array}$ & $\begin{array}{l}\text { Custo de } \\
\text { Roubo } \\
(R S) \\
\end{array}$ \\
\hline 1 & Fiorino & $\begin{array}{l}01411451341291169214213927 \\
32366863424138970\end{array}$ & $\begin{array}{l}30292524232019181716 \\
15148654210\end{array}$ & $21 \%$ & 5,10 & 72,61 & 20,74 \\
\hline 2 & Fiorino & $\begin{array}{l}0751178595101126120105102 \\
979667445034353120\end{array}$ & $\begin{array}{l}38363533313028272320 \\
1312111065420\end{array}$ & $27 \%$ & 4,87 & 67,14 & 23,74 \\
\hline 3 & Fiorino & $\begin{array}{l}0941461381301448773582526 \\
24150\end{array}$ & $\begin{array}{l}4342413130272625532 \\
10\end{array}$ & $31 \%$ & 3,02 & 39,42 & 15,24 \\
\hline
\end{tabular}




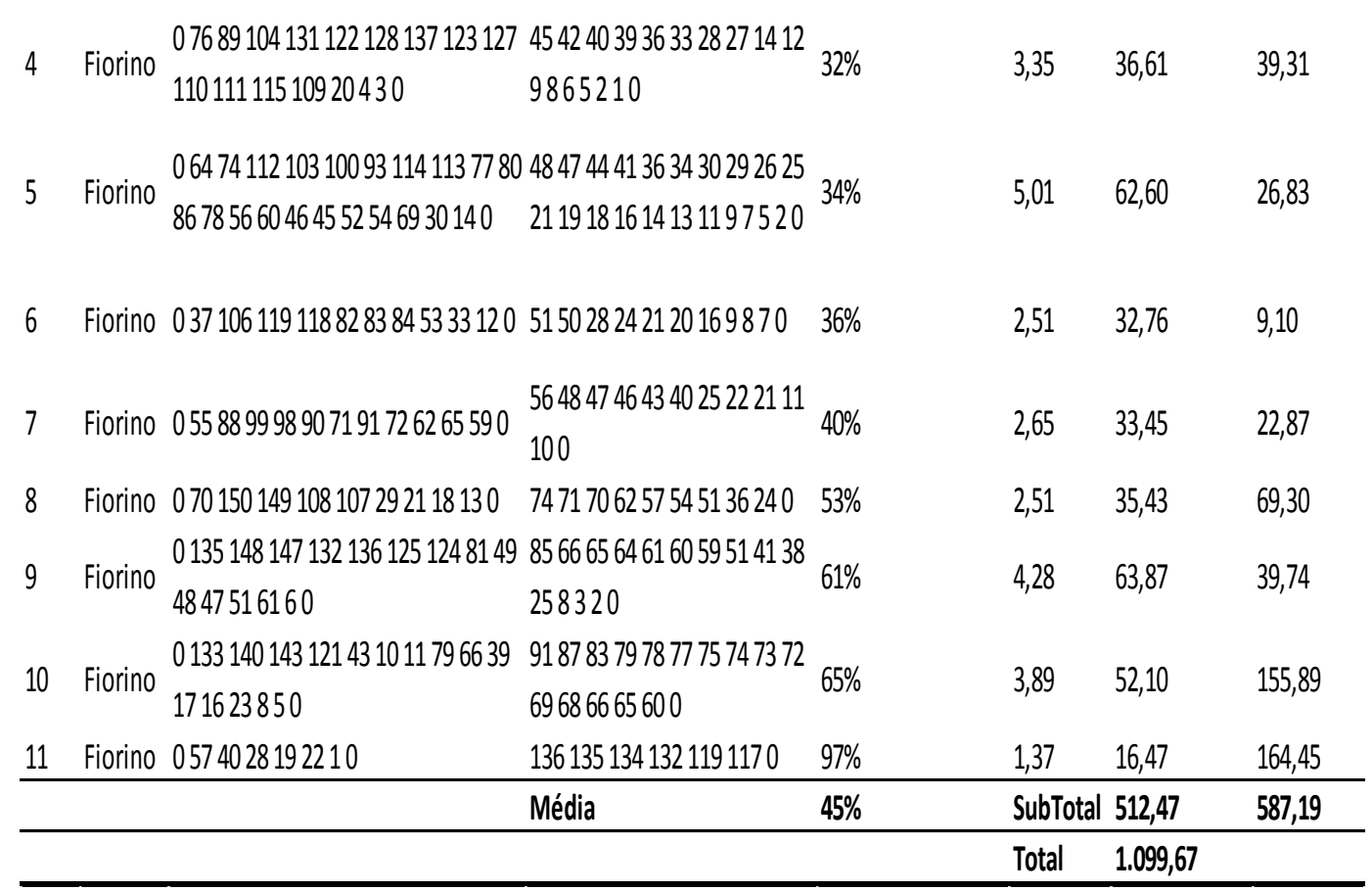

Fonte: Autor, 2015.

A solução encontrada mostra um custo de transporte de $R \$ 512,47$, sobre o uso de 11 veículos, o que significa menos 8 veículos (42\%) e menos de $R \$$ $38,04(6,9 \%)$ nos custos de transporte do que no Teste 1 . Dada a dispersão das farmácias de varejo, a restrição limitante para a rota 11 foi a capacidade, cujo veículo ficou perto de sua capacidade total (140 SKUs). Os custos de roubo resumiriam $R \$ 587,19$, ou seja, $R \$ 396,58$ maior que os do Teste 1.

Pode ser percebido na solução desse Teste 2 que a taxa de utilização já se torna um pouco maior. Obtendo uma taxa mínima, média e máxima, respectivamente, $21 \%$, $45 \%$ e $97 \%$. As baixas taxas de utilização aparecem devido à dispersão das farmácias.

Devido ao efeito de subutilização da capacidade do veículo pode-se analisar os resultados após adicionar uma restrição extra, apenas para análise, que corresponde a um limite mínimo de carregamento. Assim realizou-se o Teste 4, o qual foi considerado que o veículo deve sair com no mínimo $20 \%$ de sua capacidade e $\alpha=3 \%$. A seguir é apresentada a Restrição 4.1, adicionada. Tal restrição é mais uma opção de solução para o tomador de decisão verificar qual conjunto de roteiros mais atende a suas necessidades. Foi testado apenas com a porcentagem de $20 \%$, pois quando testado com valores maiores não se encontrou solução viável, devido à grande dispersão geográfica das farmácias e consequentemente não conseguindo roteiros viáveis que atendessem, também, a restrição de tempo de ciclo (3.6) de 8 horas. 
$\sum_{i=1}^{N} \sum_{j=1}^{N+1} R_{i} x_{i j}^{v} \geq 0,2 * Q_{v} y_{v}, \forall v \in V$

A Tabela 22 demonstra o resumo dos resultados na realização do Teste 4, apresentando um desvio de 4,90\%. A Tabela 23 mostra as rotas realizadas utilizando a restrição (4.1). O tempo de execução foi de 1295 seg.

Tabela 22: Resumo da solução obtida pelo Simulated Annealing $-\alpha=3 \% \mathrm{e}$ restrição (4.1) - 151 nós

\begin{tabular}{llllll}
\hline Instância & $\begin{array}{l}\text { No de veículos } \\
\text { alocados }\end{array}$ & $\begin{array}{l}\text { № de requisições } \\
\text { (SKU) }\end{array}$ & $\begin{array}{c}f(S) \text { média } \\
(R S)\end{array}$ & $\begin{array}{l}\text { Melhor } f(S) \\
(R S)\end{array}$ & Desvio (\%) \\
\hline 151 & 16 & 697 & 796,92 & 759,69 & 4,90 \\
\hline \multicolumn{5}{c}{ Fonte: Autor, 2015. }
\end{tabular}

Tabela 23: Melhor solução obtida pelo Simulated Annealing $-\alpha=3 \%$ e restrição

(4.1) - 151 nós

\begin{tabular}{|c|c|c|c|c|c|c|c|}
\hline Rota & Veículo & Roteiro & $z_{i j}^{v}(S K U)$ & $\begin{array}{l}\text { Taxa de Utilização } \\
\text { da Capacidade }\end{array}$ & $\begin{array}{l}\text { Tempo } \\
\text { de Ciclo } \\
\text { (Hr) }\end{array}$ & $\begin{array}{l}\text { Custo de } \\
\text { Transporte } \\
\text { (RS) }\end{array}$ & $\begin{array}{l}\text { Custo de } \\
\text { Roubo } \\
\text { (RS) } \\
\end{array}$ \\
\hline 1 & Fiorino & 06259653180 & 28188750 & $20 \%$ & 1,36 & 18,73 & 5,63 \\
\hline 2 & Fiorino & 02118220 & 291420 & $21 \%$ & 0,83 & 11,64 & 10,96 \\
\hline 3 & Fiorino & 014513413814114613014437120 & 29252414131211870 & $21 \%$ & 2,84 & 43,12 & 8,71 \\
\hline 4 & Fiorino & 055717216620 & 302276420 & $21 \%$ & 1,59 & 21,66 & 6,27 \\
\hline 5 & Fiorino & 010512012611210393857574272570 & 30262523201511974310 & $21 \%$ & 3,04 & 39,94 & 5,14 \\
\hline 6 & Fiorino & $\begin{array}{l}079848311895100101114116383236 \\
26150\end{array}$ & $\begin{array}{l}302922181513111096432 \\
10\end{array}$ & $21 \%$ & 4,02 & 57,78 & 6,34 \\
\hline 7 & Fiorino & 01329284090 & 3174210 & $22 \%$ & 1,24 & 15,95 & 10,86 \\
\hline 8 & Fiorino & $\begin{array}{l}0761151099710212812210413114813 \\
8253330\end{array}$ & $\begin{array}{l}33302827201712985432 \\
10\end{array}$ & $24 \%$ & 3,58 & 47,43 & 20,07 \\
\hline 9 & Fiorino & 050811241251361321479134351140 & 3531211312118743210 & $25 \%$ & 3,05 & 40,21 & 8,24 \\
\hline 10 & Fiorino & 01501493039485161172330 & 3736282522943210 & $26 \%$ & 3,14 & 47,44 & 9,56 \\
\hline 11 & Fiorino & 0664749197043100 & 403922196320 & $29 \%$ & 2,12 & 31,47 & 12,43 \\
\hline 12 & Fiorino & $\begin{array}{l}058647311311712987778086785660 \\
240\end{array}$ & $\begin{array}{l}412120191615141312865 \\
310\end{array}$ & $29 \%$ & 3,21 & 38,62 & 12,86 \\
\hline 13 & Fiorino & 01061198890989954524567440 & 42201615129864210 & $30 \%$ & 3,68 & 57,73 & 6,25 \\
\hline 14 & Fiorino & 02013512312711011196890 & 444122974320 & $31 \%$ & 2,14 & 29,15 & 15,45 \\
\hline 15 & Fiorino & $\begin{array}{l}051081071211431401391421336946 \\
140\end{array}$ & 882823201915111095320 & $063 \%$ & 3,30 & 45,94 & 27,11 \\
\hline \multirow[t]{3}{*}{16} & Fiorino & 01689492635742410 & 130137653210 & $93 \%$ & 1,86 & 22,62 & 24,36 \\
\hline & & & Média & $31 \%$ & SubTotal & 569,45 & 190,24 \\
\hline & & & & & Total & 759,69 & \\
\hline
\end{tabular}

Fonte: Autor, 2015. 
Percebe-se que em todas as análises realizadas os veículos selecionados foram sempre a Fiorino, isso é devido, também, à pequena quantidade de farmácias a serem atendidas, nesta instância. Neste caso selecionou-se 16 veículos, confrontando com os 19 veículos mostrados no Teste 1. Pode-se notar o aumento dos custos de transporte em $R \$ 18,94$, e uma ínfima redução do custo de roubo de carga de $R \$ 0,37$. Obteve-se um aumento no custo total de $\mathrm{R} \$ 18,57$. A restrição adotada foi atendida, onde a menor carga alocada foi 28 SKU, na Rota 1 , representando $20 \%$ de utilização da capacidade da Fiorino. A utilização média da capacidade é de $31 \%$, sendo maior do que o exigido pela restrição.

Por fim, foi realizado o Teste $3(\alpha=100 \%)$, com o intuito de verificar o que ocorrer com o roteiro quando o CD não dispõe de seguro. A Tabela 24 resume os resultados obtidos nas cinco soluções geradas. A melhor solução foi de $R \$$ $4.294,53$ e apresentou um desvio baixo $(0,61 \%)$. O tempo de execução foi de 1805 seg.

Tabela 24: Resumo da solução obtida pelo Simulated Annealing - $\alpha=100 \%$ 151 nós

\begin{tabular}{llllll}
\hline Instância & $\begin{array}{l}\text { № de veículos } \\
\text { alocados }\end{array}$ & $\begin{array}{l}\text { № de requisições } \\
\text { (SKU) }\end{array}$ & $(S)$ média & $\begin{array}{l}\text { Melhor } f(S) \\
(R S)\end{array}$ & Desvio (\%) \\
\hline 151 & 54 & 697 & $4.320,67$ & $4.294,53$ & 0,61 \\
\hline \multicolumn{5}{c}{ Fonte: Autor, 2015. }
\end{tabular}

Tabela 25: Melhor solução obtida pelo Simulated Annealing $-\alpha=100 \%-151$ nós

\begin{tabular}{|c|c|c|c|c|c|c|c|}
\hline Rota & Veículo & Roteiro & $z_{i j}^{v}(\mathrm{SKU})$ & $\begin{array}{l}\text { Taxa de } \\
\text { Utilização } \\
\text { da } \\
\text { Capacidade }\end{array}$ & $\begin{array}{l}\text { Tempo } \\
\text { de Ciclo } \\
(\mathrm{Hr})\end{array}$ & $\begin{array}{l}\text { Custo de } \\
\text { Transporte } \\
\text { (R\$) }\end{array}$ & $\begin{array}{l}\text { Custo de } \\
\text { Roubo } \\
\text { (R\$) }\end{array}$ \\
\hline 1 & Fiorino & 0220 & 20 & $1 \%$ & 0,56 & 10,52 & 16,23 \\
\hline 2 & Fiorino & 0700 & 30 & $2 \%$ & 0,71 & 14,01 & 24,35 \\
\hline 3 & Fiorino & 0290 & 30 & $2 \%$ & 0,50 & 9,24 & 24,35 \\
\hline 4 & Fiorino & 010743 & 410 & $3 \%$ & 1,12 & 21,15 & 15,40 \\
\hline 5 & Fiorino & 0764 & 410 & $3 \%$ & 0,71 & 11,37 & 13,04 \\
\hline 6 & Fiorino & 05452 & 420 & $3 \%$ & 0,82 & 14,08 & 23,77 \\
\hline 7 & Fiorino & 02016 & 520 & $4 \%$ & 0,68 & 10,84 & 20,22 \\
\hline 8 & Fiorino & 07475 & 631 & $4 \%$ & 1,15 & 19,14 & 29,52 \\
\hline 9 & Fiorino & 05161 & 721 & $5 \%$ & 1,01 & 15,98 & 19,75 \\
\hline 10 & Fiorino & 010828 & 720 & $5 \%$ & 1,16 & 21,94 & 28,99 \\
\hline
\end{tabular}




\begin{tabular}{|c|c|c|c|c|c|c|c|}
\hline 11 & Fiorino & 06832 & 710 & $5 \%$ & 0,89 & 15,58 & 35,50 \\
\hline 12 & Fiorino & 0131122 & 741 & $5 \%$ & 1,66 & 31,14 & 42,06 \\
\hline 13 & Fiorino & 083115 & 842 & $6 \%$ & 1,83 & 32,61 & 22,33 \\
\hline 14 & Fiorino & 09098 & 963 & $6 \%$ & 1,65 & 28,20 & 36,23 \\
\hline 15 & Fiorino & 0140139 & 1065 & $7 \%$ & 1,99 & 36,32 & 59,73 \\
\hline 16 & Fiorino & 05545 & 1020 & $7 \%$ & 0,90 & 15,81 & 32,71 \\
\hline 17 & Fiorino & 097102 & 1030 & $7 \%$ & 1,32 & 25,88 & 64,24 \\
\hline 18 & Fiorino & 06235 & 1221 & $9 \%$ & 1,06 & 17,04 & 41,63 \\
\hline 19 & Fiorino & 0144130 & 1298 & $9 \%$ & 2,81 & 47,59 & 49,25 \\
\hline 20 & Fiorino & 0105126 & 1286 & $9 \%$ & 2,57 & 42,07 & 36,58 \\
\hline 21 & Fiorino & 0180 & 120 & $9 \%$ & 0,56 & 10,45 & 97,38 \\
\hline 22 & Fiorino & 0190 & 130 & $9 \%$ & 0,57 & 10,86 & 105,50 \\
\hline 23 & Fiorino & 0112100 & 13108 & $9 \%$ & 2,14 & 37,29 & 28,94 \\
\hline 24 & Fiorino & 0138141 & 1332 & $9 \%$ & 2,02 & 37,07 & 50,55 \\
\hline 25 & Fiorino & 0103101 & 1387 & $9 \%$ & 2,27 & 37,73 & 33,93 \\
\hline 26 & Fiorino & 0149150 & 1465 & $10 \%$ & 2,16 & 40,23 & 64,17 \\
\hline 27 & Fiorino & 0124132 & 1463 & $10 \%$ & 1,86 & 30,61 & 36,46 \\
\hline 28 & Fiorino & 0123137 & 1521 & $11 \%$ & 1,96 & 38,19 & 87,48 \\
\hline 29 & Fiorino & 0210 & 150 & $11 \%$ & 0,56 & 10,44 & 121,73 \\
\hline 30 & Fiorino & 08191 & 1663 & $11 \%$ & 2,42 & 43,85 & 44,28 \\
\hline 31 & Fiorino & 07167 & 1721 & $12 \%$ & 1,16 & 19,50 & 49,57 \\
\hline 32 & Fiorino & 04849 & 1852 & $13 \%$ & 1,32 & 20,49 & 42,98 \\
\hline 33 & Fiorino & 0135127 & 2120 & $15 \%$ & 1,46 & 29,02 & 113,66 \\
\hline 34 & Fiorino & 04739 & 2141 & $15 \%$ & 1,08 & 17,50 & 45,57 \\
\hline 35 & Fiorino & 0130 & 240 & $17 \%$ & 0,52 & 9,63 & 194,77 \\
\hline 36 & Fiorino & 0106119 & 35139 & $25 \%$ & 2,51 & 43,22 & 66,76 \\
\hline 37 & Kombi & 0100 & 20 & $1 \%$ & 0,39 & 6,83 & 10,46 \\
\hline 38 & Kombi & 02615 & 321 & $2 \%$ & 0,77 & 10,65 & 15,01 \\
\hline 39 & Kombi & 02425 & 320 & $2 \%$ & 0,72 & 12,25 & 15,70 \\
\hline 40 & Kombi & 03014 & 520 & $3 \%$ & 0,66 & 10,70 & 27,73 \\
\hline 41 & Kombi & 03863 & 531 & $3 \%$ & 1,01 & 16,50 & 23,42 \\
\hline 42 & Kombi & 05031 & 620 & $3 \%$ & 0,84 & 15,05 & 22,79 \\
\hline 43 & Kombi & 05660 & 642 & $3 \%$ & 1,21 & 18,83 & 19,68 \\
\hline 44 & Kombi & 0120 & 70 & $4 \%$ & 0,42 & 7,60 & 67,73 \\
\hline 45 & Kombi & 08680 & 973 & $5 \%$ & 1,60 & 25,63 & 27,83 \\
\hline 46 & Kombi & 05965 & 1221 & $7 \%$ & 1,09 & 18,58 & 39,93 \\
\hline 47 & Kombi & 084128 & 1361 & $1 \%$ & 1,85 & 37,27 & 42,52 \\
\hline 48 & Kombi & 05892 & 2332 & $13 \%$ & 1,36 & 22,32 & 78,85 \\
\hline 49 & Ducato & 030 & 10 & $0,3 \%$ & 0,26 & 4,02 & 5,23 \\
\hline 50 & Ducato & 020 & 20 & $0,7 \%$ & 0,24 & 3,61 & 10,46 \\
\hline 51 & Ducato & 060 & 20 & $0,7 \%$ & 0,32 & 5,91 & 10,46 \\
\hline 52 & Ducato & 080 & 50 & $1,7 \%$ & 0,39 & 7,64 & 26,14 \\
\hline 53 & Ducato & 050 & 600 & $20 \%$ & 0,30 & 5,34 & 313,66 \\
\hline 54 & Ducato & 010 & 1170 & $39 \%$ & 0,13 & 0,40 & 611,63 \\
\hline & & & Média & $8 \%$ & SubTotal & $1.105,71$ & $3.188,82$ \\
\hline & & & & & Total & $4.294,53$ & \\
\hline
\end{tabular}

Fonte: Autor, 2015. 
Neste caso, foram observados que o modelo utiliza mais rotas, distribuindo as cargas entre os 54 veículos selecionados, utilizando outros veículos de maiores custos, além da Fiorino que foi utilizada nos testes anteriores. Isso é devido ao fator de roubo de carga ter um peso maior no momento de decidir junto a distância, assim sendo muito mais relevante do que o custo de transporte. Isso acaba afetando a questão da taxa de utilização da capacidade, que passa a ter uma média de apenas $8 \%$, sendo inviável no dia-a-dia operacional do CD. É interessante perceber que as três únicas rotas a terem uma taxa de utilização que se destacam das demais são as 36, 53 e a 54, sendo estes dois últimos em virtude do pedido solicitado por um único cliente que é grande e não pode ser fracionado em outros veículos.

Neste teste foi verificado um custo de transporte de $R \$ 1.105,71$, um custo roubo de carga de $\mathrm{R} \$ 3.188,82$ e um custo total (transporte mais roubo de carga) de $R \$ 4.294,53$, foram utilizados 54 veículos. Vale ressaltar que o custo de roubo de carga para este teste é alto devido à responsabilidade do CD por todos os custos em caso de roubo de carga.

Comparando os resultados deste último teste (com $\alpha=100 \%$ ) com os anteriores, podem-se fazer as comparações abaixo.

Pode-se ver um aumento de $100 \%$ no custo de transporte em relação ao Teste 1, um aumento de $115 \%$ no custo de transporte em comparado ao Teste 2 e em relação ao Teste 4 verificou-se um aumento no custo de transporte de 94\%. Portanto, logicamente, o melhor dos cenários é quando o a assumir o menor valor possível, i.e., o tomador de decisão poderá realizar uma roteirização básica e minimizar apenas o custo de deslocamento, evitando rotas mais longas para fugir de possíveis roubos.

Ao comparar o custo de roubo de carga percebe-se um aumento em aproximadamente 17 vezes em relação ao Teste 1 e ao Teste 4 e um aumento em 5 vezes em relação ao Teste 2. Estes valores relevantes são explicados pelo fato de este último teste considerar o $\alpha=100 \%$, i.e., o CD não possui contrato com empresa de seguro e assim faz-se necessário arcar com todos os custos de roubo de carga e elevando esse valor. Apenas para efeito de comparação, se aplicar $\alpha=3 \%$ par este último teste. Então teria um custo roubo de carga igual $R \$ 95,66, R \$ 94,94$ menor em relação ao Teste $1, R \$ 491,53$ menor na comparação com o Teste 2 e $\mathrm{R} \$ 94,58$ menor em relação ao Teste 4. Isto é devido ao grande distribuição de carga nos veículos que foi influenciada no momento da roteirização pelo $\alpha=100 \%$. 
Portanto após analisar esta Seção pode-se afirmar que o modelo realiza o Trade-off entre o custo de transporte e o custo de roubo de carga e assim selecionando o melhor roteiro e número de rotas de maneira a minimizar a função objetivo. Além de mostrar que nem sempre sair do Centro de Distribuição (CD) com o veículo cheio é viável, dependendo, é claro, da demanda total a ser atendida no dia. Além dessa análise pode se afirmar que com o veículo mais cheio há a chance de perder um valor de carga, em caso de roubo, muito maior. Esse fator de quantidade de carga dentro de um veículo é um dos fatores determinantes em cláusulas contratuais de seguro, onde há empresas de seguro que só "cobrem" o roubo de carga se o veículo sair do CD carregado com uma quantidade de mercadoria limitada pelo valor total da carga.

\subsection{2 \\ Instância de 465 nós}

Considerando o modelo proposto, utilizando $\alpha=3 \%$ (Teste 1 ), a melhor solução obtida utiliza 48 veículos e representa um custo total de $R \$ 4.374,32$, dos quais $R \$ 4.049,07$ estão relacionados com o transporte e $R \$ 325,25$ são relativos a custos de roubo de carga. $O$ desvio entre as cinco gerações de soluções é baixa (1,19\%), que dá crédito à solução encontrada. A Tabela 26 demonstra o resumo e a Tabela 27 mostra os resultados completos. O tempo de execução foi de $3368 \mathrm{seg}$.

Tabela 26: Resumo da solução obtida pelo Simulated Annealing $-\alpha=3 \%-465$ nós

\begin{tabular}{llllll}
\hline Instância & $\begin{array}{l}\text { No de veículos } \\
\text { alocados }\end{array}$ & $\begin{array}{l}\text { № de requisições } \\
\text { (SKU) }\end{array}$ & $\begin{array}{l}f(S) \text { média } \\
(R S)\end{array}$ & $\begin{array}{l}\text { Melhor } f(S) \\
(R S S)\end{array}$ & Desvio (\%) \\
\hline 465 & 48 & 2.495 & $4.426,41$ & $4.374,32$ & 1,19 \\
\hline \multicolumn{5}{c}{ Fonte: Autor, 2015. }
\end{tabular}

Tabela 27: Melhor solução obtida pelo Simulated Annealing - $\alpha=3 \%-465$ nós

\begin{tabular}{|c|c|c|c|c|c|c|c|}
\hline & & & & Taxade & Tempo & Custo de & Custo de \\
\hline Rota & Veículo & Roteiro & $z_{i j}^{v}(\mathrm{SKU})$ & $\begin{array}{l}\text { Utilização da } \\
\text { Capacidade }\end{array}$ & $\begin{array}{l}\text { de Ciclo } \\
(\mathrm{Hr})\end{array}$ & $\begin{array}{l}\text { Transporte } \\
(R S)\end{array}$ & $\begin{array}{l}\text { Roubo } \\
\text { (RSS) }\end{array}$ \\
\hline 1 & Fiorino & 086347300410 & 97610 & $6 \%$ & 2,53 & 49,12 & 0,43 \\
\hline 2 & Fiorino & 05715415917316937240 & 1110975210 & $8 \%$ & 2,39 & 37,89 & 3,38 \\
\hline 3 & Fiorino & 0704464534424404354231210 & 1297654210 & $9 \%$ & 6,20 & 124,88 & 3,07 \\
\hline
\end{tabular}




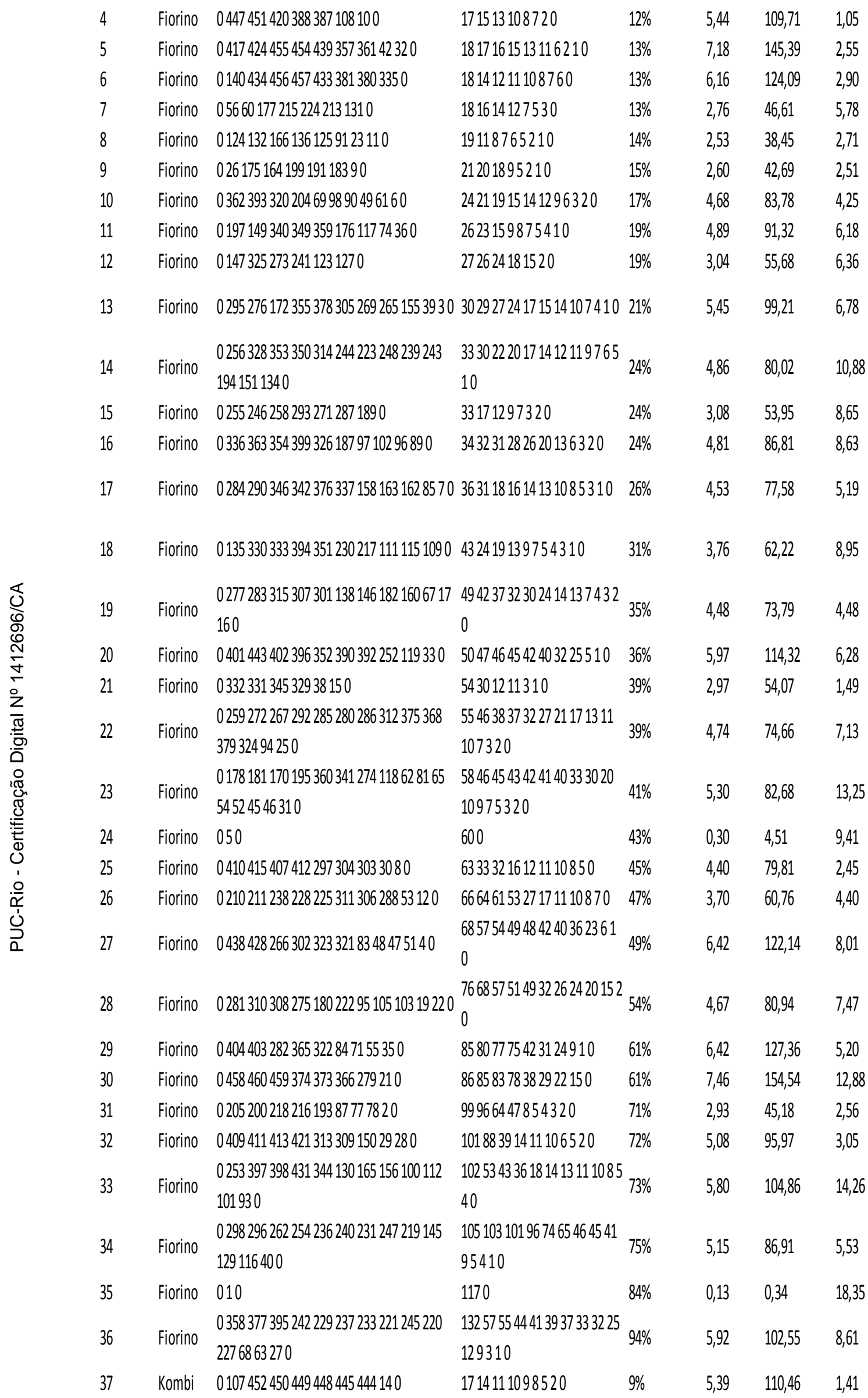




\begin{tabular}{|c|c|c|c|c|c|c|c|}
\hline 38 & Kombi & 0270264299278143139142133430 & 332420121176510 & $18 \%$ & 4,11 & 76,28 & 5,91 \\
\hline 39 & Kombi & 0582631881521922021711571611410 & 371712109764310 & $21 \%$ & 3,86 & 67,29 & 5,23 \\
\hline 40 & Kombi & 0250249316226598899340 & 37181514133210 & $21 \%$ & 3,46 & 62,97 & 8,23 \\
\hline 41 & Kombi & 0464463461462441436437408130 & 4443403938353130240 & $24 \%$ & 8,00 & 172,19 & 6,78 \\
\hline 42 & Kombi & $\begin{array}{l}0185203207291289294232201153122 \\
1040\end{array}$ & 4840333230291065410 & $27 \%$ & 4,60 & 82,70 & 7,20 \\
\hline 43 & Kombi & 010632737233425725111079200 & 5432292616137430 & $30 \%$ & 4,00 & 73,58 & 6,45 \\
\hline 44 & Kombi & $\begin{array}{l}033933840540639182128168212209 \\
1481370\end{array}$ & 58322219151413863210 & $32 \%$ & 5,98 & 114,01 & 18,59 \\
\hline 45 & Kombi & 021423523420619820819019675180 & 594948474434333114120 & $33 \%$ & 3,26 & 52,53 & 5,55 \\
\hline 46 & Kombi & $\begin{array}{l}0386432430425426416422385268260 \\
1741841671791141139273640\end{array}$ & $\begin{array}{l}74737271523533252420 \\
17151311763210\end{array}$ & $41 \%$ & 7,16 & 123,52 & 14,22 \\
\hline 47 & Kombi & $\begin{array}{l}0429427389367369371364317343356 \\
3483182611261200\end{array}$ & $\begin{array}{l}898884676658444336227 \\
64310\end{array}$ & $49 \%$ & 6,68 & 122,74 & 9,83 \\
\hline \multirow[t]{3}{*}{48} & Kombi & $\begin{array}{l}0384419418414383382400370319144 \\
1868076664472500\end{array}$ & $\begin{array}{l}90807674725041392120 \\
17141076540\end{array}$ & $50 \%$ & 6,63 & 116,00 & 10,76 \\
\hline & & & Média & $35 \%$ & SubTotal & $4.049,07$ & 325,25 \\
\hline & & & & & Total & $4.374,32$ & \\
\hline
\end{tabular}

Fonte: Autor, 2015.

A melhor solução encontrada usa apenas os veículos de menor capacidade (Fiorinos e Kombis), e mesmo assim, todos os veículos percorrem os roteiros abaixo da sua capacidade plena, onde a taxa de utilização da capacidade mínima, média e máxima são, respectivamente, 6\%, 35\% e $94 \%$. A Figura 15 é mostra as rotas 41 e 37 , onde tem uma utilização da capacidade baixa, $24 \%$ e $9 \%$, devido à baixa demanda dos clientes e um considerável tempo de ciclo, 8h e 5,39h. Estes resultados são justificados, principalmente, pela alta dispersão geográfica das farmácias. Ainda, em alguns casos, a causa é a probabilidade alta de roubo. Por exemplo, Rote 35 só serve a farmácia número 1. Isso é justificado pela sua demanda que é a mais alta (117 SKUs) e a farmácia está localizada em uma área com a terceira maior probabilidade de roubo de carga (1,35\%). Apesar de incluir uma única entrega, o custo de roubo da rota 35 é a segunda maior entre as 48 rotas $(R \$ 18,35$ contra $R \$ 18,59$ da rota 44$)$.

A Rota 7 é um resultado típico deste modelo e inclui sete farmácias. A primeira farmácia a ser visitada é a farmácia 56 , que tem a menor probabilidade de roubo da rota $(P=0,29 \%)$, seguido da farmácia 60 com $P=0,54 \%$. Em seguida, ele visita farmácias 177, 215, 224 e 213 em que estão localizados na mesma região com $\mathrm{P}=0,90 \%$. Finalmente, e apesar de ter uma probabilidade 
roubo menor $(P=0,64 \%)$ do que as farmácias anteriores, ele visita farmácia 131 localizada mais longe.

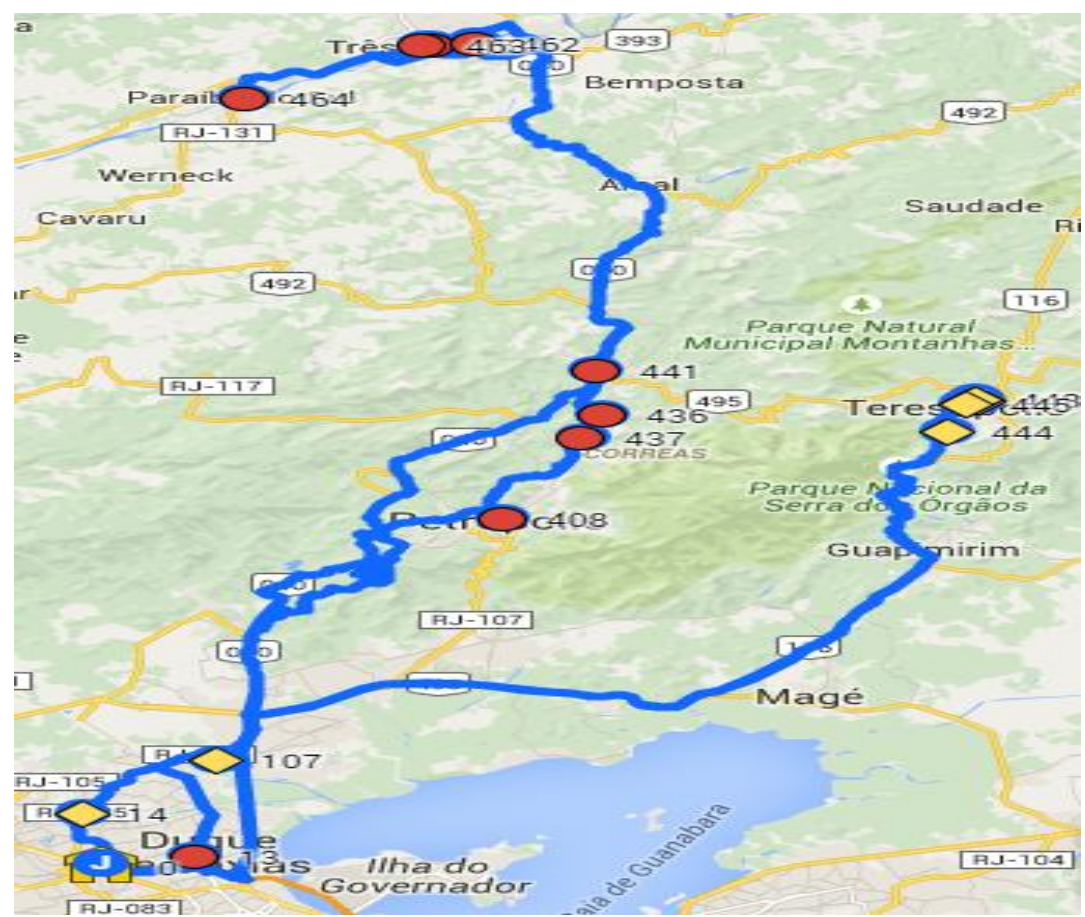

Figura 15: Rotas 41 e 37 - 465 nós.

Fonte: Autor (2015).

Na Figura 16, pode ser visualizada a localização das farmácias no Estado do Rio de Janeiro para estes 465 pontos. Podem ser notadas a dimensão da quantidade de farmácias e a grande dispersão destas no Estado e devido a essa dispersão, ou seja, devido o atendimento de todo o Estado do Rio de Janeiro, há situações de o veículo ser obrigado a sair do depósito com pouca carga, para atender essas regiões mais distantes.

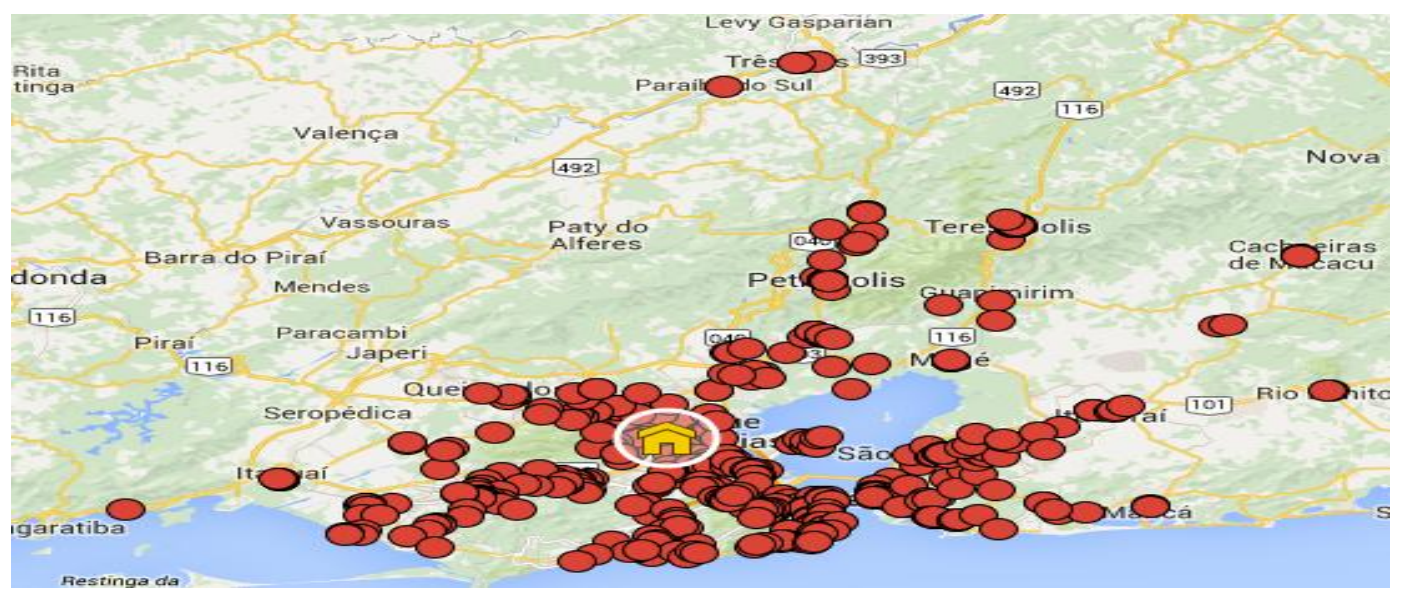

Figura 16: Localização das farmácias - 465 nós.

Fonte: Autor (2015). 
A Tabela 28 mostra os resultados gerais obtidos no Teste $2(\alpha=0 \%)$. O algoritmo SA correu em 2075 seg.. Na Tabela 29 podem ser visualizadas as rotas realizadas pela melhor solução obtida, vale ressaltar que a coluna com roubo de carga adicionada é calculada apenas para efeito de comparação (adotando para cálculo $\alpha=3 \%$ ).

Tabela 28: Resumo da solução obtida pelo Simulated Annealing $-\alpha=0 \%-465$ nós

\begin{tabular}{|c|c|c|c|c|c|}
\hline Instância & $\begin{array}{l}\text { № de veículos } \\
\text { alocados }\end{array}$ & $\begin{array}{l}\text { № de requisições } \\
\text { (SKU) }\end{array}$ & $\begin{array}{l}f(S) \text { média } \\
(R S)^{\prime}\end{array}$ & $\begin{array}{l}\text { Melhorf(S) } \\
(R S)\end{array}$ & Desvio (\%) \\
\hline 465 & 42 & 2.495 & $3.779,86$ & $3.609,45$ & 4,72 \\
\hline
\end{tabular}

Tabela 29: Melhor solução obtida pelo Simulated Annealing - $\alpha=0 \%-465$ nós

\begin{tabular}{|c|c|c|c|c|c|c|c|}
\hline Rota & Veículo & Roteiro & $z_{i j}^{v}(\mathrm{SKU})$ & $\begin{array}{l}\text { Taxa de Utilização } \\
\text { de Capacidade }\end{array}$ & $\begin{array}{l}\text { Tempo } \\
\text { de Ciclo } \\
\text { (Hr) }\end{array}$ & $\begin{array}{l}\text { Custo de } \\
\text { Transporte } \\
\text { (RSS) }\end{array}$ & $\begin{array}{l}\text { Custo de } \\
\text { Roubo (R\$S) }\end{array}$ \\
\hline 1 & Fiorino & 09411411311663320 & 111096310 & $8 \%$ & 1,59 & 21,52 & 3,28 \\
\hline 2 & Fiorino & 0304303309446451450300 & 15141286430 & $11 \%$ & 5,47 & 110,45 & 0,64 \\
\hline 3 & Fiorino & 042771608078120 & 17161512870 & $12 \%$ & 1,88 & 28,50 & 5,03 \\
\hline 4 & Fiorino & 0320444420421313297204121100 & 1915129654320 & $14 \%$ & 5,71 & 110,75 & 1,17 \\
\hline 5 & Fiorino & 095101126120105112103100930 & 24222119181411640 & $17 \%$ & 2,42 & 33,19 & 1,77 \\
\hline 6 & Fiorino & 0273884264174063497370 & 282725873210 & $20 \%$ & 3,81 & 68,60 & 5,88 \\
\hline 7 & Fiorino & 08630228883796781125124720 & 3129282622212010910 & $22 \%$ & 3,74 & 61,71 & 6,64 \\
\hline 8 & Fiorino & $\begin{array}{l}0226316187137127306311266274 \\
53330\end{array}$ & $\begin{array}{l}3332312423212014921 \\
0\end{array}$ & $24 \%$ & 4,28 & 71,79 & 13,69 \\
\hline 9 & Fiorino & $\begin{array}{l}043422385357346283281295276 \\
2780\end{array}$ & 343325241917124310 & $24 \%$ & 4,81 & 86,81 & 14,88 \\
\hline 10 & Fiorino & 01352172302462321280 & 36171614950 & $26 \%$ & 2,54 & 44,05 & 11,92 \\
\hline 11 & Fiorino & $\begin{array}{l}0347345294189168177148115109 \\
3920\end{array}$ & 363534151311986520 & $26 \%$ & 4,56 & 78,41 & 10,80 \\
\hline 12 & Fiorino & $\begin{array}{l}0434447445452449448453436423 \\
41226214957250\end{array}$ & $\begin{array}{l}38363431282726252120 \\
1611320\end{array}$ & $27 \%$ & 7,03 & 128,68 & 2,33 \\
\hline 13 & Fiorino & 0362393140139142702919180 & 4239373332312825120 & $30 \%$ & 3,93 & 68,69 & 27,84 \\
\hline 14 & Fiorino & 0761312522512132092011226660 & 4239361610876320 & $30 \%$ & 3,11 & 46,88 & 15,07 \\
\hline 15 & Fiorino & 02232392542482352911188284600 & 4342401816151310920 & $31 \%$ & 3,58 & 57,87 & 1,85 \\
\hline 16 & Fiorino & 0438439424425405361851330 & 463533321310640 & $33 \%$ & 6,37 & 128,91 & 5,17 \\
\hline 17 & Fiorino & $\begin{array}{l}091325401399443396352336273 \\
271287153123200\end{array}$ & $\begin{array}{l}46434138363532302822 \\
18171630\end{array}$ & $33 \%$ & 6,24 & 110,02 & 15,77 \\
\hline 18 & Fiorino & 01721761781812221061190 & 50474533322640 & $36 \%$ & 2,74 & 46,01 & 4,89 \\
\hline 19 & Fiorino & 0212269265390395431144117410 & 5249454234235210 & $37 \%$ & 4,51 & 82,55 & 17,09 \\
\hline
\end{tabular}




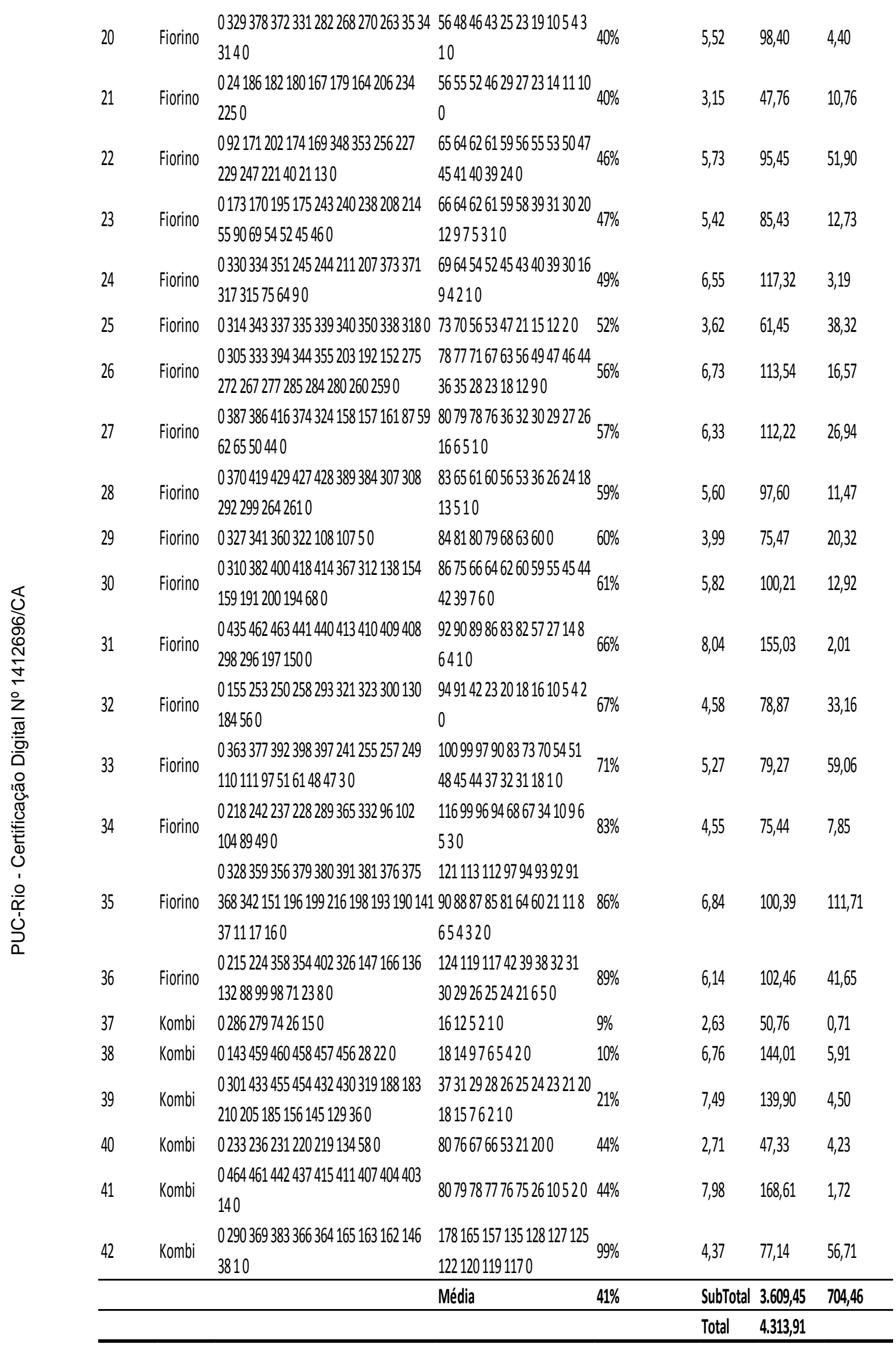

Fonte: Autor, 2015. 
A solução encontrado mostra um custo de transporte de $R \$ 3.779,86$, sobre o uso de 42 veículos, o que significa menos 6 veículos (12,5\%) e menos de $R \$ 439,62(10,9 \%)$ nos custos de transporte do que no Teste 1 . Dada a dispersão das farmácias de varejo, a restrição limitante é o tempo de ciclo, exceto, talvez, para rotas 35,36 e 42, cujos veículos são perto de sua capacidade total (respectivamente 140, 140 e 180 SKUs). Por exemplo, a rota 41 serve 10 farmácias que saem do depósito com uma carga de 80 SKU (apenas $44 \%$ da capacidade do veículo) e um tempo de ciclo de 7,98 horas (8 horas é o máximo). Os custos de roubo resumiriam $R \$ 704,46$, ou seja, $R \$ 379,21$ maior que os do Teste 1. Estes resultados e análises são indicadores importantes a serem levados em conta pelo tomador de decisão ao planejar as rotas.

Pode ser percebido na solução desse Teste 2 que a taxa de utilização já se torna um pouco maior. Obtendo uma taxa mínima, média e máxima, respectivamente, $8 \%, 41 \%$ e $99 \%$. Mas mesmo assim ainda existem rotas com ociosidade em suas capacidades, em virtude da dispersão geográfica dos clientes, não sendo possível em alguns casos a alocação de mais clientes nas rotas.

A Tabela 30 resume os resultados gerais obtidos pelo Teste $3(\alpha=100 \%)$. O tempo de execução foi de $3061 \mathrm{seg}$. Os resultados completos podem ser vistos na Tabela 31.

Tabela 30: Resumo da solução obtida pelo Simulated Annealing $-\alpha=100 \%$ 465 nós

\begin{tabular}{|c|c|c|c|c|c|}
\hline Instância & $\begin{array}{l}\text { № de veículos } \\
\text { alocados }\end{array}$ & $\begin{array}{l}\text { № de requisições } \\
\text { (SKU) }\end{array}$ & $\begin{array}{l}f(S) \text { média } \\
(R S)\end{array}$ & $\begin{array}{l}\text { Melhorf(S) } \\
(R \$)\end{array}$ & Desvio (\%) \\
\hline 465 & 60 & 2.495 & $12.529,28$ & $12.423,60$ & 0,85 \\
\hline
\end{tabular}

Tabela 31: Melhor solução obtida pelo Simulated Annealing - $\alpha=100 \%-465$ nós

\begin{tabular}{|c|c|c|c|c|c|c|c|}
\hline Rota & Veículo & Roteiro & $z_{i j}^{v}(\mathrm{SKU})$ & $\begin{array}{l}\text { Taxa de } \\
\text { Utilização da } \\
\text { Capacidade }\end{array}$ & $\begin{array}{l}\text { Tempo } \\
\text { de Cidlo } \\
\text { (Hr) }\end{array}$ & $\begin{array}{l}\text { Custo de } \\
\text { Transporte } \\
(\mathrm{R} \$) \\
\end{array}$ & $\begin{array}{l}\text { Custo de } \\
\text { Roubo } \\
(\mathrm{R} \$) \\
\end{array}$ \\
\hline 1 & Fiorino & 0444446388901472262131480 & 151210854310 & $11 \%$ & 7,47 & 154,79 & 41,69 \\
\hline 2 & Fiorino & 0831181321661366544170 & 15118543210 & $11 \%$ & 3,75 & 67,30 & 52,73 \\
\hline 3 & Fiorino & 0593163523631020 & 1776430 & $12 \%$ & 3,24 & 63,21 & 74,24 \\
\hline 4 & Fiorino & $\begin{array}{l}0462464463461441440442415 \\
70280\end{array}$ & 1716151211876520 & $12 \%$ & 8,00 & 162,82 & 65,14 \\
\hline
\end{tabular}




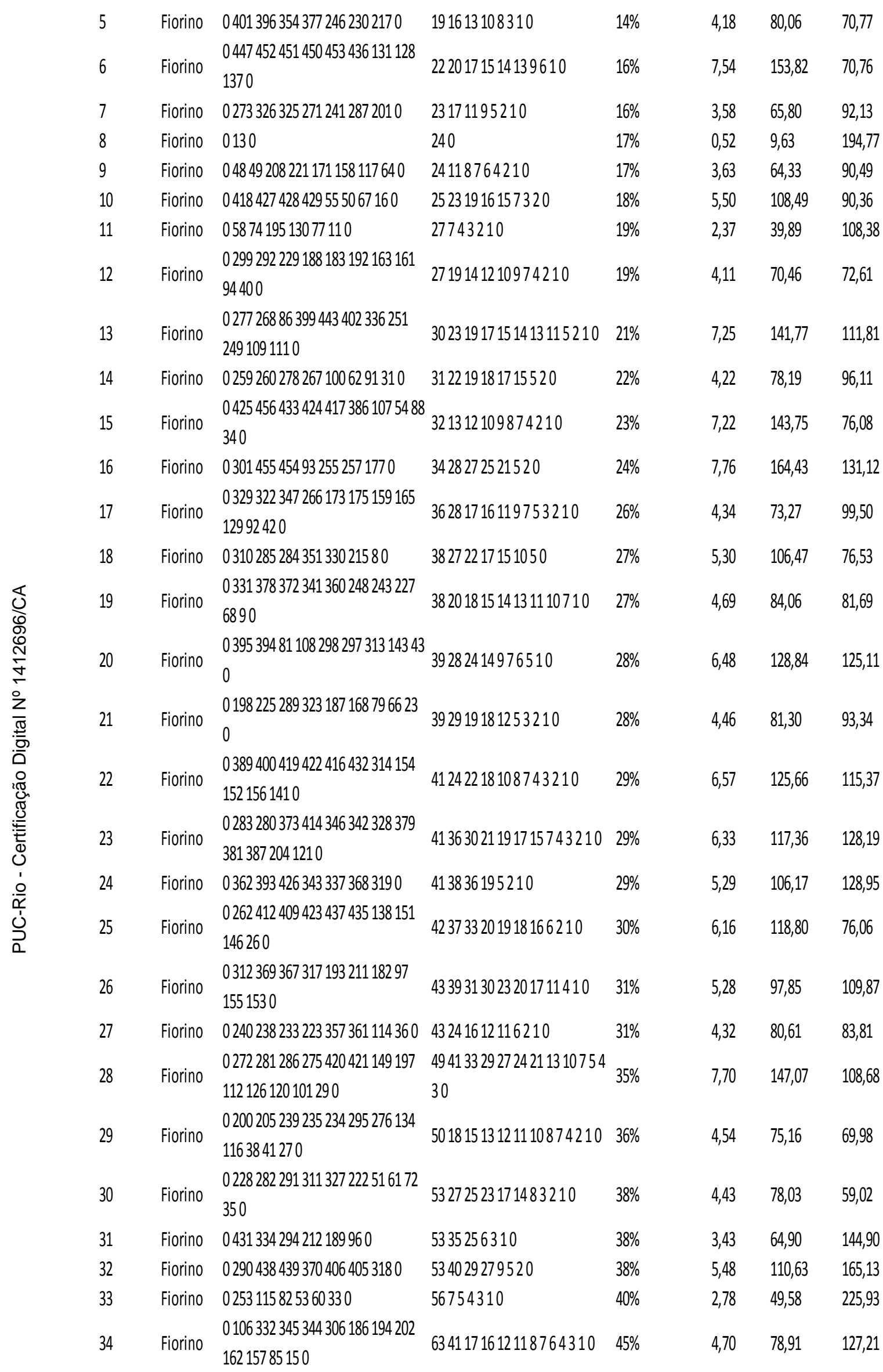




\begin{tabular}{|c|c|c|c|c|c|c|c|}
\hline 35 & Fiorino & $\begin{array}{l}0216206164172174340353348 \\
3590\end{array}$ & 6627241512104210 & $47 \%$ & 4,42 & 80,33 & 114,19 \\
\hline 36 & Fiorino & 04114132962501221040 & 99502523410 & $71 \%$ & 5,33 & 109,77 & 127,35 \\
\hline 37 & Kombi & 021220 & 1720 & $9 \%$ & 0,72 & 12,15 & 154,19 \\
\hline 38 & Kombi & 03093033201241252582933050 & 2521191576310 & $14 \%$ & 6,06 & 126,83 & 81,29 \\
\hline 39 & Kombi & 02522321270 & 26620 & $14 \%$ & 2,17 & 45,00 & 121,09 \\
\hline 40 & Kombi & 02563563353853910 & 26238210 & $14 \%$ & 3,53 & 73,04 & 130,60 \\
\hline 41 & Kombi & $\begin{array}{l}0245244247242237145113784 \\
0\end{array}$ & 272018141195210 & $15 \%$ & 3,22 & 54,29 & 63,56 \\
\hline 42 & Kombi & 027933932470 & 3831510 & $21 \%$ & 3,01 & 62,91 & 141,87 \\
\hline 43 & Kombi & 03083713663641351100 & 504430232230 & $28 \%$ & 4,18 & 86,14 & 132,22 \\
\hline 44 & Kombi & $\begin{array}{l}0218207254236231210140304 \\
1501391421330\end{array}$ & 64474624151412876540 & $36 \%$ & 5,32 & 97,59 & 107,50 \\
\hline 45 & Kombi & 0307315383382384263180 & 656358362717120 & $36 \%$ & 3,67 & 70,88 & 118,14 \\
\hline 46 & Kombi & 0530140 & 65520 & $36 \%$ & 0,79 & 11,21 & 367,58 \\
\hline 47 & Kombi & $\begin{array}{l}02192201782743021791448737 \\
240\end{array}$ & 75433018111063210 & $42 \%$ & 3,82 & 66,44 & 74,49 \\
\hline 48 & Kombi & 041040740840440311912360 & 7949332722191520 & $44 \%$ & 5,43 & 111,55 & 124,00 \\
\hline 49 & Ducato & $\begin{array}{l}0459460458457430184160167 \\
32250\end{array}$ & 20151312111085320 & $7 \%$ & 7,33 & 173,17 & 47,33 \\
\hline 50 & Ducato & 0203191190 & 2316130 & $8 \%$ & 2,04 & 47,56 & 114,86 \\
\hline 51 & Ducato & 0333398397392338350261730 & 45393222155210 & $15 \%$ & 6,27 & 149,78 & 111,19 \\
\hline$\frac{21}{\pi}$ & Ducato & $\begin{array}{l}0445449448434374375376380 \\
3490\end{array}$ & 524948474553210 & $17 \%$ & 6,56 & 154,93 & 229,55 \\
\hline $\begin{array}{l}\overline{0} \\
\stackrel{0}{\circ}\end{array}$ & Ducato & $\begin{array}{l}019619918510510395805676 \\
2030\end{array}$ & 5336322420151397410 & $18 \%$ & 3,95 & 75,70 & 109,67 \\
\hline 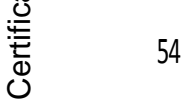 & Ducato & $\begin{array}{l}0190214365355321300288892 \\
0\end{array}$ & 6563532013116420 & $22 \%$ & 3,92 & 81,14 & 78,75 \\
\hline 55 & Iveco & 071989969460 & 2274310 & $5 \%$ & 1,83 & 36,78 & 85,28 \\
\hline 56 & Iveco & 084473952450 & 31247420 & $7 \%$ & 2,07 & 43,71 & 92,76 \\
\hline 57 & Iveco & 03583902692652242090 & 9318106310 & $21 \%$ & 3,46 & 80,39 & 162,72 \\
\hline 58 & Sprinter & 0270264120 & 201170 & $3 \%$ & 2,36 & 62,21 & 83,08 \\
\hline 59 & Sprinter & 01801691701761817563570 & 301310865310 & $5 \%$ & 2,68 & 54,74 & 88,61 \\
\hline 60 & Sprinter & 01100 & 11920 & $20 \%$ & 0,52 & 9,00 & 632,63 \\
\hline & & & Média & $24 \%$ & SubTotal & $5.270,67$ & $7.152,98$ \\
\hline & & & & & Total & $12.423,64$ & \\
\hline
\end{tabular}

Fonte: Autor, 2015.

A melhor solução encontrada no Teste 3 tem um custo total de $R \$$ 12.423,60, $R \$ 5.270,67$ dos quais diz respeito aos custos de transporte e $R \$$ 7.152,98 para as despesas de roubo de carga. Os custos de transporte são de $\mathrm{R} \$ 1.221,6(30,2 \%)$ maiores do que os encontrados no Teste 1 e são usados todos os veículos disponíveis, 60 no total. Este resultado é expectável porque quando todos os custos de roubo são suportados pela empresa eles ultrapassam 
por muito os custos de transporte, gerando uma taxa média de utilização da capacidade dos veículos de $24 \%$, sendo a mínima 3\% e a máxima $71 \%$. Assim, - modelo aloca todos os veículos de tal modo que os roubos de cargas consolidadas são minimizados. Para efeito de comparação, se aplicarmos $\alpha=$ $3 \%$ para Teste 3 os custos de roubo resumiriam em $R \$ 214,59$, ou seja, $R \$$ $110,66(34,0 \%)$ menos do que os do Teste 1. 


\section{5 \\ Considerações Finais}

Neste capítulo são ilustradas as considerações sobre os resultados alcançados e elencadas as propostas de estudos futuros.

\section{1}

\section{Considerações Sobre os Resultados Alcançados}

A presente dissertação debruçou-se sobre o problema de roteirização de veículo com probabilidade de roubo de carga. Este tópico é, tanto quanto o autor tem conhecimento, inédito na literatura de roteirização. O problema de roubo de carga é especialmente relevante nos países da América do Sul, onde o número de roubos de carga é altamente expressivo. Nesse sentido, este trabalho propôs uma nova abordagem para o problema de roteirização de veículos, onde o risco de roubo de carga é levado em conta. Assim foi desenvolvido um modelo para otimizar as rotas de distribuição de mercadorias farmacêuticas considerando que as regiões onde estão localizados os clientes têm associadas uma determinada probabilidade de roubo pré-definida. O modelo foi aplicado a um estudo de caso real envolvendo uma empresa de distribuição de produtos farmacêuticos do Rio de Janeiro, Brasil.

Os resultados obtidos para a empresa de distribuição farmacêutica evidenciam que há um trade-off importante a considerar ao planejar rotas de distribuição em áreas afetadas por roubos de carga. Quando os custos de roubo de carga são considerados, não apenas a sequência pela qual os clientes são servidos é alterada, mas também o número de rotas (ou veículos) atribuído. À medida que os custos de roubo aumentam, mais difícil é justificar o transporte de carga consolidada para áreas perigosas. Estas conclusões foram também extraídas pela empresa que num passado recente procurou minimizar os danos alterando os esquemas de roteirização com base no saber empírico do setor responsável. O modelo proposto é, portanto, uma ferramenta importante a ter em conta ao proporcionar soluções mais eficientes que as empíricas.

O modelo VRPCTP minimiza os custos de transporte e os custos de roubo de carga. As soluções propostas são aparentemente menos óbvias se 
analisadas do ponto de vista geográfico, mas permitem a redução de circulação de carga em áreas mais perigosas.

A formulação matemática, objetivo proposto, apresentou certo grau de dificuldade devido à existência de restrições que exigiam um cauteloso refinamento. Vale ressaltar que o modelo proposto apresenta elevado grau de dificuldade de computação por ser um NP-Hard. Daí a necessidade de utilizar um método heurístico. O desenvolvimento da heurística não era, no entanto, o principal objetivo desta dissertação.

Para a implementação do modelo, foi utilizada uma heurística comum, a Metaheurística Simulated Annealing, cujos resultados demonstram que o modelo é relevante. Para problemas de médio porte, em torno de 400 pontos, o algoritmo apresentou desvios padrão baixos. Os tempos de computação para as instâncias maiores, apesar de aceitáveis, foram consideráveis. Valeria num estudo futuro aprofundar a escolha da heurística mais eficiente para resolver o modelo.

\section{2}

\section{Proposta de Estudos Futuros}

Por se tratar de um estudo novo os campos para aplicações futuras são vastos. Entre elas destacam-se a inclusão de restrições novas. Neste sentido sugerem-se como oportunidades de desenvolvimento os seguintes trabalhos futuros:

- Melhorar alguns aspectos de maneira a reduzir o número de iterações e ganhar em tempo de processamento, viabilizando a utilização em problemas ainda maiores.

- Analisar o impacto da implantação das Unidades de Polícia Pacificadora (UPP) no Estado do Rio de Janeiro com o intuito de verificar a correlação entre o número de UPP's, a probabilidade de roubo de carga e o custo de distribuição.

- Realizar uma nova abordagem que trate de probabilidade de roubo no arco.

- Considerar a variação da probabilidade de roubo em diferentes turnos.

- Aplicar em setores com alto risco, como empresas que distribuem dinheiro para bancos. 
- Inverter a lógica do modelo para problemas de coleta de mercadorias.

- Modelar a aplicação nas diversas variações do VRP.

- Considerar um valor de carga indexado por produto requerido por cliente.

- Comparar os Resultados obtidos pelo Simulated Annealing com outros métodos de resolução.

- Resolver utilizando simulação, para analisar os custos quando acontece o roubo e o roteiro é interrompido.

- Como as seguradoras restringem o limite de carga pelo valor transportado, então se propõe uma restrição que limite a utilização do veículo pelo valor e não pelo volume. 


\section{Referências}

ABTC - Associação Brasileira de Logística e Transporte de Carga. Reportagem especial: roubo de cargas. Brasília, 2010. Disponível em: < http://www.abtc.org.br/paginas/noticia.aspx? $n=3>$. Acesso em: 23 set. 2014.

ARAUJO, Victor K. W. S. Avaliação de custos para a produção de biodiesel a partir de óleos residuais fritura. 2008. 97 p. Dissertação (Mestrado em Engenharia de Produção) - Programa de Pós-Graduação em Engenharia de Produção, PUC - RIO, Rio de Janeiro.

ARENALES, M.; ARMENTANO, V.; MORABITO, R.; YANASSE, $H$. Pesquisa Operacional para Cursos de Engenharia. Rio de Janeiro: Campus, 2007.

ASSAD, A. A. Modeling and implementation issues in vehicle routing. In: Vehicle Routing: Methods and studies, GOLDEN, B.L.; ASSAD, A.A. (Eds), Elsevier Sciences Publishers, North-Holland, Amsterdam, p.7-45, 1988.

BAKER, E. K. Vehicle routing with time widows constraints. Logistic and Transportation Review, v.18, n.4, p.385-401, 1982.

BALAKRISHNAN, N. Simple heuristics for the vehicle routing problem with soft time windows. The Journal of the Operational Research Society, v.44, n.3, p.279-287, 1993.

BALDACCI, R.; CHRISTOFIDES, N.; MINGOZZI, A. An exact algorithm for the vehicle routing problem based on the set partitioning formulation with additional cuts. Mathematical Programming Ser. A, v.115, n.2, p.351-385, 2008.

BALLOU, R. H. Gerenciamento da cadeia de suprimentos: planejamento, organização e logística empresarial. 4aㅡ ed. Porto Alegre: Bookmann, 2001.

BALLOU, R. H. Gerenciamento da Cadeia de Suprimentos/Logística Empresarial. 5a ed. Porto Alegre: Bookman, 2006.

BALSEIRO, S. R.; LOISEAU, I.; RAMONET, J. An Ant Colony algorithm hybridized with insertion heuristics for the Time Dependent Vehicle Routing Problem with Time Windows. Computers and Operations Research, v.38, n.6, p.954-966, 2011. 
BATISTUS, D. R. O Problema de Roteirização de Veículos com Restrições de Janelas de Tempo: Uma Proposta de Solução por meio da Metaheurística Scatter Search. 2009. 234 p. Tese (Doutorado em Engenharia de Produção) - Programa de Pós-Graduação em Engenharia de Produção, UFSC, Florianópolis.

BELFIORE, P. P. Scatter search para Problemas de Roteirização de Veículos com Frota Heterogênea, Janelas de Tempo e Entregas Fracionadas. 2006. 203 p. Tese (Doutorado em Engenharia de Produção) - Programa de Pós-Graduação em Engenharia de Produção, USP, São Paulo.

BELFIORE, P. P.; FÁVERO, L. P. L.; ALVAREZ, R. A. G. Problema de Roteirização de Veículos com Frota Heterogênea: Revisão da Literatura. In: Simpósio Brasileiro de Pesquisa Operacional - SBPO, 2006, Goiás, Anais do XXXVIII SBPO, 2006.

BERNADES, A. L. VBA Excel - Usando a API do Google Maps para retornar a distância em Km entre dois lugares - Google Maps distance function. Disponível em: < http://inanyplace.blogspot.com.br/2012/12/vbaexcel-usando-api-do-google-maps.html >. Acesso em: 13 mar. 2015.

BEZERRA, M. S. S. Uma contribuição à análise de elementos básicos do gerenciamento do risco de ocorrência do roubo de carga no transporte rodoviário. 2006. 117 p. Dissertação (Mestrado em Engenharia de Transportes) - Programa de Pós-Graduação em Engenharia, COPPE/UFRJ, Rio de Janeiro.

BODIN, L. A taxonomic structure for vehicle routing and scheduling problems. Compuers. \& Urban Society, v.1, n.1, p.11-29, 1975.

BODIN, L. D.; GOLDEN, B. Classification in Vehicle Routing and Scheduling. Networks, v.11, n.2, p.97-108, 1981.

BODIN, L. D.; GOLDEN, D.; ASSAD, A.; BALL, M. Routing and scheduling of vehicles and crews: The state of the art. Computers and Operations Research, v.10, n.2, p.63-201, 1983.

BORDIN, E. Análise das Empresas Transportadoras de Carga com Énfase na Tecnologia de Rastreamento. 2008. 117 p. Dissertação (Mestrado em Transportes) - Programa de Pós-Graduação em Engenharia, COPPE/UFRJ, Rio de Janeiro.

BOWERSOX, D. J.; CLOSS, D. J. Logística Empresarial: o processo de integração da cadeia de suprimento. São Paulo: Atlas, 2001.

BOWERSOX, D. J.; CLOSS, D. J.; COOPER, M. B. Gestão da cadeia de suprimentos e logística. $2^{\mathrm{a}}$ ed. Rio de Janeiro: Elsevier, 2007. 
BREJON, S. R. C. Algoritmo para Resolução do Problema de Programação do Transporte de Suprimentos Para Unidades Marítimas de Exploração de Petróleo. 1998. 132 p. Dissertação (Mestrado em Engenharia Naval) - Programa de Pós-Graduação em Engenharia Naval, USP, São Paulo.

CAIXETA FILHO, J. V.; GAMEIRO, A. H. Administração de seguros no transporte de cargas. Revista de Administração de Empresas da Fundação Getúlio Vargas, v.1, n.1, p.1-12, 2002.

CATTARUZA, D.; ABSI, N.; FEILLET, D.; VIDAL, T. A memetic algorithm for the Multi Trip Vehicle Routing Problem. European Journal of Operational Research. v.236, n.3, p.833-848, 2014.

CHOI, E.; TCHA, D. W. A column generation approach to the heterogeneous fleet vehicle routing problem. Computers and Operations Research, v.34, n.7, p. 2080-2095, 2007.

CHRISTOFIDES, N.; MINGOZZI, A.; TOTH, P. Exact algorithms for the vehicle routing problem, based on spanning tree and shortest path relaxations. Mathematical Programming. v. 20, n.1, p.255-282, 1981.

CHRISTOFIDES, N. Vehicle Routing. In: The Traveling Salesman Problem: A Guided Tour of Combinatorial Optimization. LAWER, E.L.; LENSTRA, J.K.; KAN, A.H.G.R.; SHMOYS, D.B. (Eds), John Wiley \& Sons, 1985.

CLARKE, G.; WRIGHT, J. W. Scheduling of vehicles from a depot to a number of delivery points. Operations Research, v.12, n.4, p.568-581, 1964.

CMI, C. M. I. Millennium Prize Problems. 2000. Disponível em: <http://www.claymath.org/millennium/>. Acesso em: 30 jan. 2015.

COOK, S. The $P$ versus NP problem. 1992. Disponível em: < http://www.claymath.org/sites/default/files/pvsnp.pdf>. Acesso em: 30 jan. 2015.

CORDEAU, J. F.; GENDREAU, M.; LAPORTE, G. A Tabu Search Heuristic for Periodic and Multi-Depot Vehicle Routing Problems. Networks, v.30, n.2, p.105-119, 1997.

CORDEAU, J. F.; GENDREAU, M.; LAPORTE, G.; POTVIN, J. Y.; SEMET, F. A guide to vehicle routing heuristics. Journal of the Operational Research Society, v. 53, n.5, p.512-522, 2002.

CUNHA, C. B. Aspectos Práticos da Aplicação de Modelos de Roteirização de Veículos a Problemas Reais. Revista Transportes da ANPET - Associação Nacional de Pesquisa e Ensino em Transportes, v.8, n.2, p.51-74, 2000. 
DANTZIG, G.; FULKERSON, R.; JOHNSON, S. Solution of a large-scale travelling salesman problem. Journal of the Operations Research Society of America, v.2, n.4, p.393-410, 1954.

DESROCHERS, M.; DESROSIERS, J.; SOLOMON, M. A new optimization algorithm for the vehicle routing problem with time windows. Operations Research, v.40, n.2, p.342-354, 1992.

DROR, M.; LAPORTE, G.; TRUDEAU, P. Vehicle routing with split deliveries. Discrete Applied Mathematics, v.50, n.3, p.239-254, 1994.

DURÃO, M. Custos logísticos voltaram a crescer no País, diz pesquisa. Jornal O Estado de São Paulo online. São Paulo, 2013. Disponível em: <http://economia.estadao.com.br/noticias/geral,custos-logisticos-voltam-acrescer-no-pais-diz-pesquisa,166856e >. Acesso em: 16 set. 2014.

EISELT, H. A.; GENDREAU, M.; LAPORTE, G. Arc Routing Problems, Part I: The Chinese Postman Problem. Operations Research, v.43, n.2, p. 231-242, 1995.

EKSIOGLU, B.; VURAL, A. V.; REISMAN, A. The vehicle routing problem: a taxonomic review. Computers \& Industrial Engineering, v.57, n.4, p.1472 - 1483, 2009.

FISHER, M. L.; JAIKUMAR, R. A Generalized Assignment Heuristic for Vehicle Routing. Networks, v.11, n.2, p.109-124, 1979.

FISHER, M. L.; JÖRNSTEN, K. O; MADSEN, O. B. G. A. Vehicle routing with time windows: two optimization algorithms. Operations Research, v.45, n.3, p.488-492, 1997.

FI - FreightWatch International Supply Chain Intelligence Center. Global Cargo Theft Threat Assessment. USA, 2013. Disponível em: < https://www.naed.org/NAEDDocs/Research/Legal\%20lssues/FreightWatc h\%202013\%20Global\%20Cargo\%20Theft\%20Threat\%20Assesment\%20 Full_0.pdf >. Acesso em: 13 mai. 2015.

GAREY, M. R.; JOHNSON, D. S.; STOCKMEYER, L. Some simplified NPComplete graph problems. Theoretical Computer Science, v.1, n.3, p. 237267, 1976.

GENDREAU, M.; LAPORTE, G.; SÉGUIN, R. Stochastic vehicle routing. European Journal of Operational Research, v.88, n.1, p.3-12, 1996.

GOLDEN, B.; ASSAD, A.; LEVY, L.; GHEYSENS, F. The fleet size and mix vehicle routing problem. Computers \& Operations Research, v.11, n.1, p.49-66, 1984.

G1. Roubo de carga no RJ cresce 154\% diz ISP, Vigilante morreu nesta quinta. Rio de Janeiro, 2014. Disponível em: <http://g1.globo.com/rio-de- 
janeiro/noticia/2014/12/roubos-de-carga-no-rj-cresce-154-diz-isp-vigilantemorreu-nesta-quinta.html>. Acesso em: 16 jan. 2015.

HELD, M.; KARP, R. M. The traveling-salesman problem and minimum spanning trees: Part II. Mathematical Programming, v.1, n.1, p.6-25, 1971.

HEMMELMAYR, V. C.; DOERNER, K. F.; HARTL, R. F. A variable neighborhood search heuristic for periodic routing problems. European Journal of Operational Research, v.195, n.3, p.791-802, 2009.

ISP - Instituto de Segurança Pública. Comparativo das incidências publicadas no diário oficial do Estado. Rio de Janeiro, 2014. Disponível em:<http://arquivos.proderj.rj.gov.br/isp_imagens/Uploads/ResumoOut14. pdf >. Acesso em: 24 nov. 2014.

ISP - Instituto de Segurança Pública. Resumo Mensal por AISP Novembro 2014. Rio de Janeiro, 2014. Disponível em: < http://arquivos.proderj.rj.gov.br/isp_imagens/Uploads/201411arquivocompl eto.pdf >. Acesso em: 16 jan. 2015.

JIANG, J; NG, K. M.; POH, K. L.; TEO, K. M. Vehicle routing problem with a heterogeneous fleet and time windows. Expert Systems with Applications, v.41, n.8, p.3748-3760, 2014.

KALLEHAUGE, B. On the vehicle routing problem with time windows. Dinamarca, 2006. 115 p. Tese (Doutorado em Filosofia) - Centre for Traffic and Transport, Technical University of Denmark.

KALLEHAUGE, B. Formulations and exact algorithms for the vehicle routing problem with time windows. Computers \& Operations Research. v. 35, n.7, p.2307-2330, 2008.

KARP, R. Reducibility among combinatorial problems. Complexity of Computer Computations, Edited by R. Miller and J. Thatcher, p. 85-104, Plenum Press, New York, 1972.

KIM, B.; KIM, S.; SAHOO, S. Waste colletion vehicle routing problem with time windows. Computer \& Operations Research, v.33, n.12, p.3624-3642, 2006.

KIRKPATRICK, S.; GELLAT, D. C.; VECCHI, M. P. Optimization by Simulated Annealing. Science, v.220, n.4598, p.675-680, 1983.

KOÇ, Ç.; BEKTAS, T.; JABALI, O.; LAPORTE, G. A hybrid evolutionary algorithm for heterogeneous fleet vehicle routing problems with time windows. Interuniversity Research Centre on Enterprise Networks, Logistic and Transportation. 2014. 
KOHL, N.; DESROSIERS, J.; MADSEN, O. B. G.; SOLOMON, M. M.; SOUMIS, F. 2-path cuts for the vehicle routing problem with time windows. Transportation Science, v.33, n.1, p.101-116, 1999.

KOLEN, A. W. J.; RINNOOY, A. H. G.; TRIENEKENS, H. W. J. M. Vehicle routing with time windows. Operations Research, v.35, n.2, p.266-273, 1987.

LAMBERT, D. M.; STOCK, J. R.; VANTINE, J. G. Administração estratégica da logística. São Paulo: Vantine Consultoria, 1998.

LAPORTE, G.; NOBERT, Y. Exact algorithms for the vehicle routing problem. North-Holland Mathematics Studies, v.31, p. 147-184, 1987.

LAPORTE, G. The vehicle routing problem: An overview of exact and approximate algorithms. European Journal of Operational Research, v.59, n.3, p.345-358, 1992.

LAPORTE, G. What You Should Know about the Vehicle Routing Problem. Naval Research Logistics, v.54, n.8, p.811-819, 2007.

LEITÃO, L. Próxima parada: o crime de 1 bilhão. Revista Veja. 2014. Disponível em: <http://www.busvision.com.br/wpcontent/uploads/2014/10/veja_roubos_de_carga.pdf>. Acesso em: 15 jan. 2015.

LI, H.; LIM, A. Local search with annealing-like restarts to solve the VRPTW. European Journal of Operational Research, v.150, n.1, p.115127, 2003.

MARTINS, P. G.; LAUGENI, F. P. Administração da Produção. São Paulo: Saraiva, 1999.

MAURI, G. R. Uma nova abordagem para o problema de roteirização de veículos e programação de veículos. 2006. 39 p. Tese (Doutorado em Computação Aplicada) - Instituto Nacional de Pesquisas Espaciais, São José dos Campos.

METROPOLIS, N.; ROSENBLUTH, A. W.; ROSENBLUTH, M. N.; TELLER, A. H.; TELLER, E. Equation of state calculations by fast computing machines. The Journal of Chemical Physics, v.21, n.6, p.10871092, 1953.

MIURA, M. Modelagem heurística no problema de distribuição de cargas fracionadas de cimento. 2008. 84 p. Dissertação (Mestrado em Engenharia de Sistemas Logísticos) - Escola Politécnica, USP, São Paulo.

NOVAES, A. G. Logística e gerenciamento da cadeia de distribuição: estratégia, operação e avaliação. 2ª ed. Rio de Janeiro: Elsevier, 2004. 
NOVAES, A. G. Logística e Gerenciamento da Cadeia de Distribuição. $3^{\text {a }}$ ed. Rio de Janeiro: Editora Campus, 2007.

NTC \& Logística. Roubo de cargas no Rio cresce $30 \%$ no primeiro trimestre de 2012. Portal NTC. 2012. Disponível em: < http://www.portalntc.org.br/rodoviario/roubo-de-cargas-no-rio-cresce-30no-primeiro-trimestre-de-2012/46230>. Acesso em: 13 mai. 2015.

NTC \& Logística. Número de roubo de cargas bate recorde em 2012. Portal NTC. 2013. Disponível em: < http://www.portalntc.org.br/outros/numero-de-roubo-de-cargas-baterecorde-em-2012/48804>. Acesso em: 13 mai. 2015.

NTC \& Logística. Roubo de cargas cresce no País e preocupa empresários. Portal NTC. 2013. Disponível em: < http://www.portalntc.org.br/logistica/roubo-de-cargas-cresce-no-pais-epreocupa-empresarios/45197>. Acesso em: 13 mai. 2015.

NTC \& Logística. Aumenta o número de roubo de cargas em 2013, a região sudeste concentra os maiores números de casos registrados no país. Portal NTC. 2014. Disponível em: < http://www.portalntc.org.br/outros/aumenta-numero-de-roubo-de-cargasem-2013/55084>. Acesso em: 16 jan. 2015.

NTC \& Logística. Cresce o roubo de cargas nas rodovias. Portal NTC. 2014. Disponível em: < http://www.portalntc.org.br/rodoviario/cresce-oroubo-de-cargas-nas-rodovias/53621>. Acesso em: 15 mai. 2015.

PARASKEVOPOULOS, D. C.; REPOUSSIS, P. P.; TARANTILIS, C. D.; IOANNOU, G.; PRASTACOS, G. P. A reactive variable neighborhood tabu search for the heterogeneous fleet vehicle routing problem with time windows. Journal of Heuristics, v. 14, n. 5, p.425-455, 2007.

PEREIRA, T. J. G.; AZEVEDO, R. P. Um algoritmo híbrido Simulated Annealing - otimização por colônia de formigas para o problema de roteamento de veículos. 2013. 51 p. Trabalho de Conclusão de Curso (Graduação em Engenharia de Produção) - Centro de Ciências Naturais e Tecnologia, UEPA, Pará.

RONEN, D. Perspectives on practical aspects of truck routing and scheduling. European Journal of Operational Research, v. 35, n.2, p. 137145, 1988.

ROSA, A. Gestão do Transporte na Logística de Distribuição Física: uma análise da minimização do custo operacional. 2007. 90 p. Dissertação (Mestrado em Economia) - Universidade de Taubaté, São Paulo.

SAVELSBERGH, M. W. P. The General Pickup and Delivery Problem. Transportation Science, v.29, n.1, p.17-29, 1995. 
SILVA, E. L.; MENEZES, E. M. Metodologia da pesquisa e elaboração de dissertação. 3. ed. Florianópolis: Laboratório de Ensino a Distância da UFSC, 2001.

SILVA JÚNIOR, O. S. Algoritmos para os problemas de roteirização estática e dinâmica de veículos com janelas de tempo. 2013. 100 p. Tese (Doutorado em Engenharia de Produção) - Pontifícia Universidade Católica, Rio de Janeiro.

SOLOMON, M. M. Algorithms for the Vehicle Routing and Scheduling Problems with Time Window Constraints. Operations Research, v.35, n.2, p.254-265. 1987.

SOLOMON, M. M.; DESROSIERS, J. Time Window Constrained Routing and Scheduling Problem. Transportation Science, v.22, n.1, p.1-13, 1988.

SUBRAMANIAN, A.; UCHOA, E.; OCHI, L. S. A hybrid algorithm for a class of vehicle routing problems. Computers \& Industrial Engineering, v.40, n.10, p.2519 - 2531, 2013.

SUMMERFIELD, N. S.; DROR, M.; COHEN, M. A. City streets parking enforcement inspection decisions: The Chinese postman's perspective. European Journal of Operational Research, v.242, n.1, p.149-160, 2015.

TARANTILIS, C. D.; KIRANOUDES, C. T.; VASSILIADIS, V. S. A threshold accepting metaheuristic for the heterogeneous fixed fleet vehicle routing problem. European Journal of Operational Research, v.152, n.1, p.148-158, 2004.

TARANTILIS, C. D. Solving the vehicle routing problem with adaptive memory programming methodology. Computers \& Operations Research, v.32, n.9, p.2309-2327, 2005.

TAS, D.; JABALI, O.; WOENSEL, T. V. A Vehicle Routing Problem with Flexible Time Windows. Computers \& Operations Research. v.52, Part.A, p.39-54, 2014.

TORKI, A.; SOMHON, S.; ENKAWA, T. A competitive neural network algorithm for solving vehicle routing problem. Computers \& Industrial Engineering, v.33, n.3-4, p.473 - 476, 1997.

YIYO, K. Using simulated annealing to minimize fuel consumption for the time-dependent vehicle routing problem. Computer \& Industrial Engineering, v.59, n.1, p.157-165, 2010.

YU, B.; YANG, Z. Z.; YAO, B. Z. A hybrid algorithm for vehicle routing problem with time windows. Expert Systems with Applications, v.38, n.1, p.435-441, 2011. 